\title{
An empirical analysis of health implications and costs of obesity in Appalachia
}

\author{
Saman Janaranjana Herath Bandara
}

West Virginia University

Follow this and additional works at: https://researchrepository.wvu.edu/etd

\section{Recommended Citation}

Herath Bandara, Saman Janaranjana, "An empirical analysis of health implications and costs of obesity in Appalachia" (2012). Graduate Theses, Dissertations, and Problem Reports. 4865.

https://researchrepository.wvu.edu/etd/4865

This Dissertation is protected by copyright and/or related rights. It has been brought to you by the The Research Repository @ WVU with permission from the rights-holder(s). You are free to use this Dissertation in any way that is permitted by the copyright and related rights legislation that applies to your use. For other uses you must obtain permission from the rights-holder(s) directly, unless additional rights are indicated by a Creative Commons license in the record and/ or on the work itself. This Dissertation has been accepted for inclusion in WVU Graduate Theses, Dissertations, and Problem Reports collection by an authorized administrator of The Research Repository @ WVU.

For more information, please contact researchrepository@mail.wvu.edu. 


\title{
AN EMPIRICAL ANALYSIS OF HEALTH IMPLICATIONS AND COSTS OF OBESITY IN APPALACHIA
}

\author{
Saman Janaranjana Herath Bandara \\ Dissertation Submitted to the Davis College of Agriculture, Natural Resources, and Design \\ at West Virginia University \\ in Partial Fulfillment of the Requirements \\ for the Degree of \\ Doctor of Philosophy \\ in \\ Natural Resource Economics \\ Tesfa Gebremedhin, Ph.D., Co-Chair \\ Cheryl Brown, Ph.D., Co-Chair \\ Gerard D'Souza, Ph.D. \\ Michael Hendryx, Ph.D. \\ Blessing M. Maumbe, Ph.D. \\ Agricultural and Resource Economics Program \\ Division of Resource Management \\ West Virginia University \\ Morgantown, West Virginia \\ 2012
}

Keywords: Diseases; Health Implications; Cost; Obesity; Appalachian Region 


\title{
ABSTRACT An Empirical Analysis of Health Implications and Costs of Obesity in Appalachia
}

\author{
Saman Janaranjana Herath Bandara
}

Obesity is a major health problem in the United States (U.S.) and approximately 34 percent of the U.S. adult population is obese. Studies using the Behavioral Risk Factor Surveillance System (BRFSS), the National Health and Nutrition Examination Survey (NHANES), and many other research findings warn that if the current trend of obesity continues, 50 percent of the U.S. population will be obese in 2030. Unfortunately, several diseases, such as heart disease, diabetes (type II), hypertension, cancer, arthritis, asthma, and some psychological disorders are linked with obesity. Obesity increases the risk of premature mortality, and nearly 300,000 annual deaths are associated with obesity in the U.S. The economic burden associated with obesity is remarkably high. The magnitude of the health impacts of obesity depends on the levels of obesity-related diseases, socioeconomic factors, behavioral factors, environmental factors and geographical characteristics of a particular region. The main objective of this study is to examine health implications and costs of adult obesity in the Appalachian region. Appalachia is an economically less-developed region. It consists of 420 counties in 13 states and reports high rates of obesity compared to the rest of the U.S.

The theoretical models and arguments of the study are developed within the context of a consumer's utility maximization model based on a household production function. The empirical models and analyses are conducted at the county level as well as at an individual level, using a system of simultaneous equations and logit analyses. Three-stage least squares (3SLS) estimations were used for the simultaneous equations. The main source of data is the Center for Disease Control and Prevention's BRFSS. The statistical package of STATA is used to run the analyses.

The empirical results of the county level analyses reveal that obesity and obesity-related diseases are increasing in Appalachia, indicating that the healthcare sector has failed to control obesity even as incomes have been increasing. Importantly, results indicate potential reductions of obesity and obesity-related diseases with increasing employment opportunities.

Individual level analyses using logit estimations show a potential high risk of asthma, arthritis, cancer, diabetes, heart disease and hypertension with the occurrence of obesity. Almost all logit estimations highlight the potential benefits of increasing income and employment opportunities along with higher education to reduce obesity and obesity-related diseases.

The cost estimations for all diseases show a $\$ 14.7$ billion healthcare cost linked to adult obesity. This is nearly 1.4 percent of total GDP of the Appalachian region in 2009. Results further reveal the potential gains of reducing obesity compared to national and federal obesity rate targets.

An individual level analysis examining the potential use of reduced calorie intake and engaging in more physical activities indicates that these two behaviors could be used to significantly reduce obesity in Appalachia as long as there are adequate recreational facilities. 


\section{DEDICATION}

This doctoral dissertation is dedicated to my loving parents who inspired me in this long journey of education. 


\section{ACKNOWLEDGEMENTS}

I wish to express my greatest thanks and appreciation to Dr. Tesfa Gebremedhin and Dr. Cheryl Brown, major advisors, for their guidance, encouragement, and constructive comments throughout my studies. I am really grateful as well to my dissertation committee members, Dr. Michael Hendryx, Dr. Gerard D'Souza, and Dr. Blessing Maumbe for generously giving their time and expertise to better my work. My special thanks to Dr. Donald Lacombe for his valuable time spent on guiding me in my research analyses.

My gratitude extends to Dr. Jerry Fletcher, Director, Division of Resource Management who gave me an opportunity to enter the program and funding support throughout my studies. No doubt, I am really in debt to the moral support and advice given by Dr. Peter Schaeffer, graduate program coordinator and other faculty members to fulfill my studies. I really appreciate the administrative assistance, care, and help of Mrs. Lisa Lewis, Mrs. Melanie Jimmie, and Mrs. Ellen Hartley-Smith of the Division of Resource Management. My thanks must also go to my friends, especially Hari Vommi, who helped me in numerous ways.

And last but not least, my special thanks go to my wife Dayani and to my two loving sons Kaveen and Somesh who sacrificed their valuable time which they never can get back. If their patience, care, and support were not there, this dissertation would not have been easy to complete. 


\section{TABLE OF CONTENTS}

Abstract

Dedication

ii

Acknowledgements

iii

List of Tables

List of Figures

iv

vii

Viii

CHAPTER 1: INTRODUCTION

1.1 Problem Statement

1.2 Background Information

1.2.1 Defining Obesity

1.2.2 Study Area

1.3 Objectives of the Study

1.4 Organization of the Study

CHAPTER 2: LITERATURE REVIEW

2.1 Prevalence of Obesity

2.2 Health Impacts of Obesity

2.3 Factors Affecting Obesity

2.4 Economic and Social Burden of Obesity

2.5 Overcoming Obesity

CHAPTER 3: METHODOLOGY

3.1 Theoretical Framework

3.3 Empirical Models and Specifications of Variables

4.1 Determining the impacts of obesity on public health 41 4.1.1 Descriptive analysis $\quad 43$

4.1.2 Determining the impacts of obesity on asthma 45

4.1.3 Determining the impacts of obesity on arthritis $\quad 50$

4.1.4 Determining the impacts of obesity on diabetes $\quad 54$

4.1.5 Determining the impacts of obesity on heart disease 57

4.1.6 Determining the impacts of obesity on hypertension 61

4.2 Estimating the costs of major diseases linked to obesity 65 
4.2.1 Logit Analyses $\quad 65$

4.2.1.1 Logit Analysis for Asthma 66

4.2.1.2 Logit Analysis for Arthritis 68

4.2.1.3 Logit Analysis for Cancer $\quad 69$

4.2.1.4 Logit Analysis for Diabetes $\quad 70$

4.2.1.5 Logit Analysis for Heart Disease $\quad 71$

4.2.1.6 Logit Analysis for Hypertension $\quad 73$

4.2.2 Calculating total healthcare expenditures $\quad 74$

4.2.2.1 Calculating healthcare expenditures for asthma $\quad 74$

4.2.2.2 Calculating healthcare expenditures for arthritis $\quad 75$

4.2.2.3 Calculating healthcare expenditures for cancer 77

4.2.2.4 Calculating healthcare expenditures for diabetes 78

4.2.2.5 Calculating healthcare expenditures for heart disease $\quad 80$

4.2.2.6 Calculating healthcare expenditures for hypertension 81

4.2.3 Total economic cost of obesity-related diseases $\quad 82$

4.3 Measuring economic costs associated with reduction of obesity 83

4.4 Examining the use of reduced calorie intake and increased exercise for reducing $\quad 85$

obesity

4.5 Proposed health-related policies for the Appalachian region 90

CHAPTER 5: SUMMARY AND CONCLUSIONS 97

5.1 Summary and Conclusions $\quad 97$

5.2 Policy Recommendations $\quad 99$

5.3 Limitations of the Study 100

5.4 Suggestions for Future Work 101

$\begin{array}{lr}\text { REFERENCES } & 102\end{array}$ 


\section{LIST OF TABLES}

Page

Table 1.1: Classifications of Obesity

Table 1.2: Sub regional population in Appalachia

Table 1.3: Percent of Persons Age 21 to 64 with disabilities

Table 3.1: Definitions of variables used for county level analyses for objective 1

Table 3.2: Definitions of variables used in individual level analyses for objectives 2, 3 and 4

Table 4.1: County-level descriptive statistics of variables for all Appalachian counties, 2001

Table 4.2: County-level descriptive statistics of variables for all Appalachian counties, 2009

Table 4.3. County-level descriptive statistics for behavioral and environmental variables for all Appalachian counties, 2009

Table 4.1.2: Results for system of equations including change in asthma (ASMC)

Table 4.1.3: Results for system of equations including change in arthritis (ARTHC)

Table 4.1.4: Results for system of equations including change in diabetes (DIABC)

Table 4.1.5: Results for system of equations including change in heart disease (HRTC)

Table 4.1.6: Results for system of equations including change in hypertension (HYPC)

Table 4.2.1: Descriptive Statistics for obesity-related diseases, 2009

Table 4.2.1.1: Logit regression results: marginal effects of asthma

Table 4.2.1.2: Logit regression results: marginal effects of arthritis

Table 4.2.1.3: Logit regression results: marginal effects of cancer

Table 4.2.1.4: Logit regression results: marginal effects of diabetes

Table 4.2.1.5: Logit regression results: marginal effects of heart disease

Table 4.2.1.6: Logit regression results: marginal effects of hypertension

Table 4.2.2.1. Calculation of cost of arthritis for the Appalachian region (\$billion), 2009

Table 4.2.2.2. Calculation of cost of cancer for the Appalachian region (\$billion), 2009

Table 4.2.2.3. Calculation of cost of diabetes for the Appalachian region (\$billion), 2009

Table 4.2.2.4. Calculation of cost of heart diseases for the Appalachian region ( $\$$ billion), 2009

Table 4.2.2.5. Calculation of cost of hypertension for the Appalachian region (\$billion), 2009

Table 4.2.3. Total economic costs of six obesity-related diseases for adults in Appalachia (\$billion), 2009

Table 4.3.3 Total economic costs of obesity in Appalachia at different obesity rates (\$million), 2009

Table 4.4.1: Descriptive statistics for obesity prevention analysis

Table 4.4.2: Results for system of equations for obesity prevention analysis 


\section{LIST OF FIGURES}

Page

Figure 1.1: Map of Appalachian Region, 2009 5

Figure 1.2: County Economic Levels in Appalachia, 2011 6

Figure 1.2: Unemployment rates in Appalachia, 2009 8

Figure 3.1: Flow chart of objectives and analytical ways 36 


\section{CHAPTER 1: INTRODUCTION}

\subsection{Problem statement}

Obesity is ranked among the leading global public health problems (WHO, 2005). It is considered the biggest health problem in the world in the $21^{\text {st }}$ century; approximately half a billion people worldwide are affected by either obesity or overweight (Rossner, 2002). In the United States, obesity is a major health problem, and approximately 34 percent of the U.S. adult population is obese (over 72 million people), with nearly 67 percent of adults overweight (Sabate and Wien, 2010; Finkelstein et al., 2009). According to Dor et al. (2010), if the current trend of obesity continues, 50 percent of the U.S. population will be obese in 2030. Two U.S. studies, Behavior Risk Factor Surveillance System [BRFSS](CDC, 2009; CDC, 2010), and the National Health and Nutritional Examination Survey [NHANES] (2009) show that obesity in the United States will increase from its current level of 31.3 percent to 42.8 percent in 2018.

Several diseases, such as heart disease, diabetes (type II), hypertension, cancer, arthritis, asthma, and some psychological disorders (like depression) are linked with obesity (Sturm et al., 2004; Malnick and Knobler, 2006; Miljkovic and Nganje, 2008). Moreover, obesity increases the risk of premature mortality (WHO, 2005) and nearly 300,000 annual deaths are associated with obesity in the United States (Miljkovic and Nganje, 2008). Meanwhile, the World Health Organization (WHO) reports that non-communicable chronic diseases will become the predominant cause of morbidity and mortality in the near future, and those diseases will probably be responsible for about two-thirds of all disease costs by the year 2020 (Chopra et al., 2002).

The economic burden associated with obesity is high. Expenditures on health have outpaced economic growth in many countries, putting pressure on government budgets (Rosin, 2008). Obesity accounts for 2 to 9 percent of the total health budget in high-income countries, 
excluding the cost of all obesity-related conditions. Hammond and Levine (2010) identified four major categories of economic impacts associated with obesity: direct medical costs, productivity costs, transportation costs, and human capital costs. In 1998, the United States spent $\$ 78.5$ billion on medical costs related to obesity (Center for Disease Control and Prevention [CDC], 2004). According to the U.S. Department of Health and Human Services (2010), the annual cost of obesity was $\$ 147$ billion in 2008 and people who were obese had annual medical costs that were $\$ 1,429$ higher than the cost for people of normal body weight. Based on the BRFSS and NHANES data, the cost of obesity could increase up to $\$ 343.9$ billion in 2018 in the United States. The data indicate that if the prevalence of obesity at today's level could be halted, the United States could save $\$ 821$ per adult in 2018 ; that is a total of $\$ 198$ billion. At present, the overall annual cost of being obese is $\$ 2,646$ for an obese man and $\$ 4,879$ for an obese woman (Dor et al., 2010).

High obesity is linked with more disease and less quality of life. It leads to high economic losses to individuals and to society. Individuals who have health problems due to obesity have to bear the direct costs for medication, physician visits, hospital stays, etc. Obesity also reduces efficiency and productivity of employees through work absenteeism, early retirement, and premature death. This reduces potential benefits to society while incurring additional costs to the healthcare system. However, the magnitude of health impacts depends on the levels of obesity-related diseases, socioeconomic and behavioral characteristics of individuals (Cawley et al., 2005; Sacerdote, 2007), and environmental and geographical characteristics (Inagmi et al., 2006; Wang et al., 2007) of a particular region. Thus, studying the health implications of obesity would assist in examining and understanding the economic cost associated with these impacts on health. The results will help policymakers achieve public health 
gains by reconsidering the present healthcare policies used to reduce obesity. In addition, understanding the impacts of reduced calorie intake and engagement in physical activities on weight control would be useful in achieving applicable policy interventions. Overall, the findings will assist in achieving economic gains in the long run, which ultimately improves the living conditions of people, especially in a region like Appalachia that exhibits poverty and lags in development.

\subsection{Background information}

\subsubsection{Defining obesity}

Obesity is defined in terms of Body Mass Index (BMI). BMI is a proxy for human body fat based on an individual's weight and height. BMI is generally defined as the individual's body weight divided by the square of his/her height and produces a unit measure of $\mathrm{kg} / \mathrm{m}^{2}$. BMI charts can also be utilized to display BMI as a function of weight and height using contour lines for different values of BMI or colors for different BMI categories. There is no specific chart for men as opposed to women. Also, BMI calculators can be used to measure BMI. Since the 1980s the World Health Organization (WHO) has been using BMI as the standard measure for recording obesity.

According to U.S. National Institute of Health (NIH) guidelines, from 25 to 29.9 BMI is defined as overweight, and from 30 to $34.9 \mathrm{BMI}$ is defined as obese. When the value is more than $35 \mathrm{BMI}$, it is normally called 'severe obesity' (Table 1.1). Obesity is a complex medical condition that has social and psychological dimensions and some major economic consequences. It affects people of all ages and socioeconomic groups, and both genders. It is not restricted to developed countries (Rosin, 2008). One region within the U.S. that has high rates of obesity is Appalachia (CDC, 2010). Consequently, this study will focus on the Appalachian region. 
Table 1.1 Classifications of obesity

\begin{tabular}{cc}
\hline BMI & Classification \\
\hline$<18.5$ & underweight \\
$18.5-24.9$ & normal weight \\
$25.0-29.9$ & overweight \\
$30.0-34.9$ & class I obesity \\
$35.0-39.9$ & class II obesity \\
$\geq 40.0$ & class III obesity \\
\hline
\end{tabular}

Source: National Institute of Health

\subsubsection{Study area}

The Appalachian Region has an area of 205,000 square miles that follows the spine of the mountains from southern New York to northern Mississippi (Appalachian Regional Commission [ARC]). It consists of 420 counties in 13 states: New York, Pennsylvania, Ohio, Maryland, West Virginia, Kentucky, Virginia, North Carolina, Tennessee, South Carolina, Georgia, Alabama, and Mississippi. The Appalachian region has relatively homogeneous characteristics of topography, demographics, and economic background. In 2009, ARC classified the region into five sub-regions for better analysis by using economic and transportation data: Northern, North Central, Central, South Central, and Southern (Figure 1.1). 


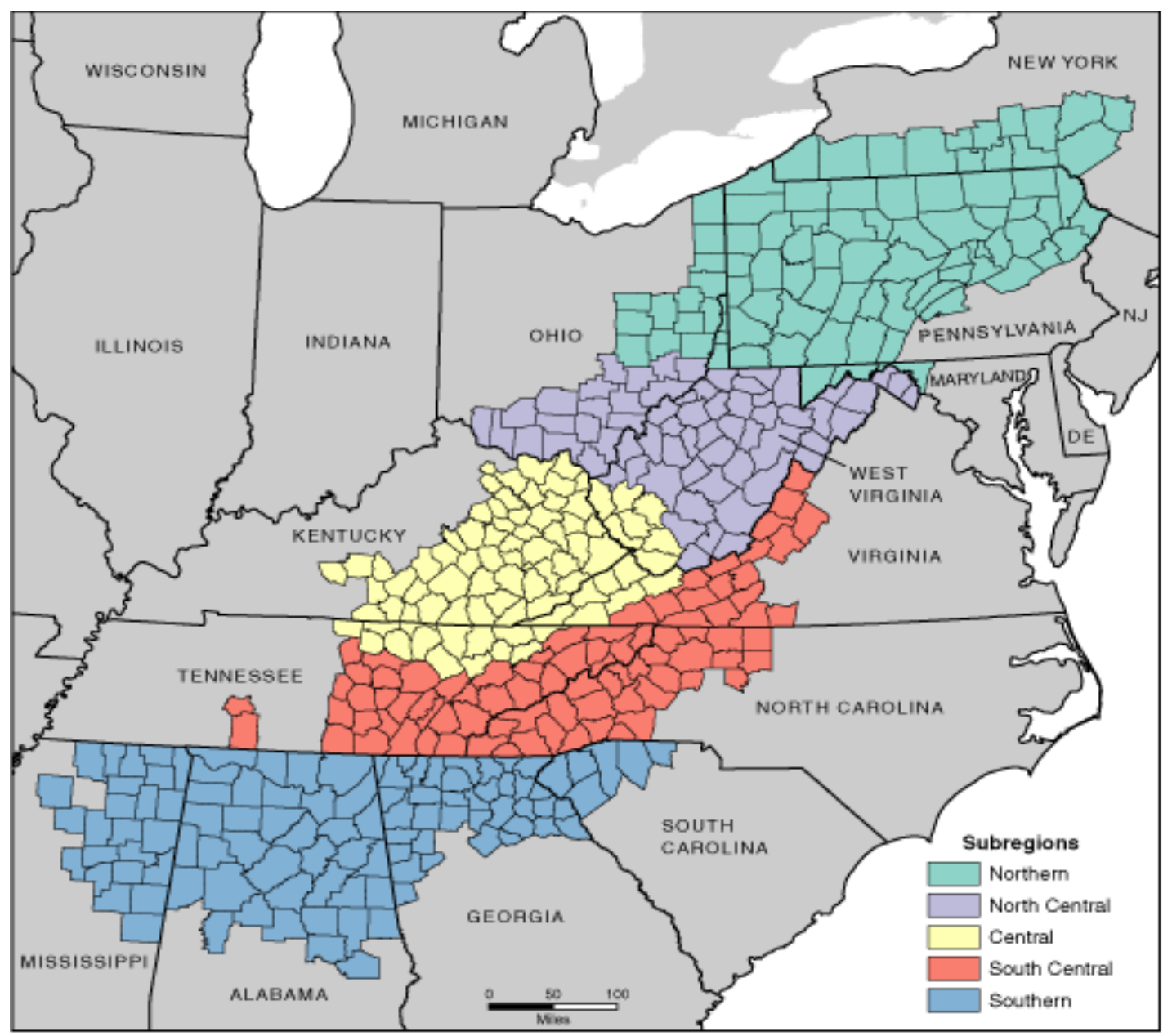

Map by: Appalachian Regional Commission, November 2009.

Figure 1.1 Map of Appalachian region, 2009

The region's economy is highly dependent on mining, forestry, agriculture, chemical industries, professional service, and manufacturing. Dependence on employment in the traditional industries of the region, mining, manufacturing, textiles, and paper and wood products has led to declining economic growth due to global competition (ARC, 2011). Except in the Central Appalachian region, farming, utilities, and government services are also declining (ARC, 2010). However, the auto-manufacturing, finance, insurance, real estate, tourism, health, and education sectors are booming in the region (ARC, 2010). ARC investment creates some employment opportunities for economic growth, especially in public water supply and sewerage 
systems (ARC, 2011). Ninety-six Appalachian counties were considered economically distressed in 2011 (Figure 1.2). Also, 90 counties are at risk and 219 have transitional economies. Central Appalachia exhibits high economic distress with high poverty, poor healthcare services, and high educational disparities (ARC, 2011). Further, the region is facing a lack of human, financial, and technical resources due to its geographic isolation, disproportionate social and economic distress, low household incomes, and a declining tax base.

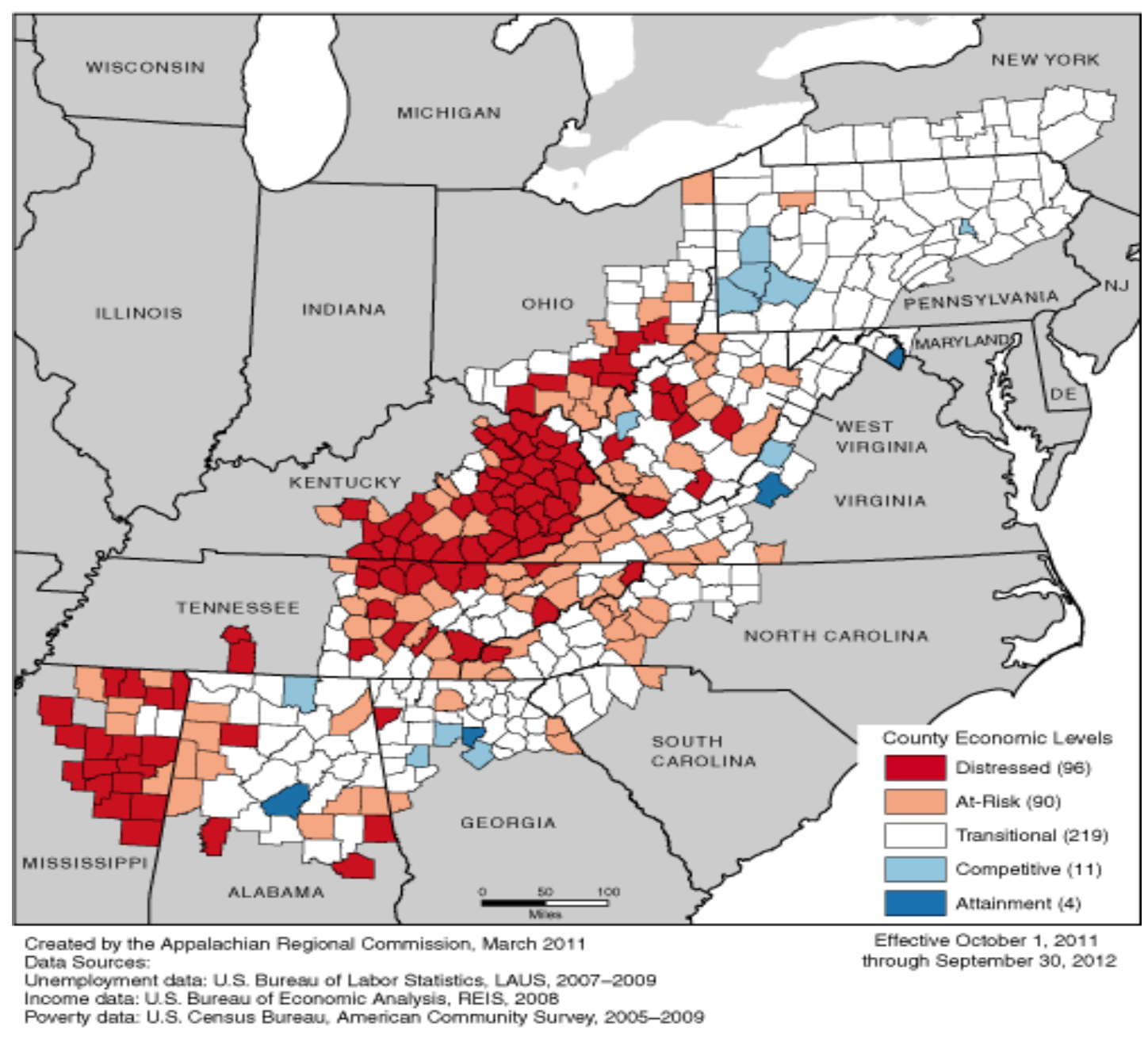

Figure 1.2 County economic levels in Appalachia, 2011

The Appalachian region is home for nearly 24.8 million people, and its population growth from 2000 to 2008 was slower than the national rate (ARC, 2010). The highest 
population is reported in Northern Appalachia while the lowest is in Central Appalachia (Table 1.2). In many parts of Appalachia young people are moving out and retirees are moving in (ARC, 2010). According to the economic overview of Appalachia (ARC, 2011), unemployment rates in two thirds of Appalachian counties are higher than the national rate. The average unemployment rate is 9.7 percent, which is 0.4 percent higher than the 2009 national rate (Figure 1.3). Central, Southern and South Central Appalachia have an unemployment rate greater than 11 percent. Per capita personal income, average earnings, and per capita investment income are lower than national averages. According to the economic assessment of Appalachia (2010), educational levels in the region are low, and all parts of the Appalachian region lag behind the nation in college attendance and completion. Among sub-regions Central Appalachia reports the lowest educational attainment.

Table 1.2 Sub-regional population in Appalachia

\begin{tabular}{lrr}
\hline Region & Total 2008 & Change (2000-2008 ) \\
\hline Appalachian Region & $24,826,000$ & $1,189,000$ \\
Northern Appalachia & $8,293,000$ & $-155,000$ \\
North Central Appalachia & $2,373,000$ & 53,000 \\
Central Appalachia & $1,914,000$ & 25,000 \\
South Central Appalachia & $4,612,000$ & 322,000 \\
Southern Appalachia & $7,634,000$ & 945,000 \\
\hline
\end{tabular}

Source: Economic Assessment of Appalachia, 2010

As a whole, Appalachia reports higher rates of serious disease and mortality rates than national levels (ARC, 2010). The presence of cancer, heart disease and diabetes are higher than national averages, and lack of healthcare access is significant in the region. The presence of adults with disabilities is higher in Appalachia (Table 1.3), which limits the scope of 
employment and demands far more publicly provided services. (Disability is defined as limited in any way in any activities because of physical, mental or emotional problems.)

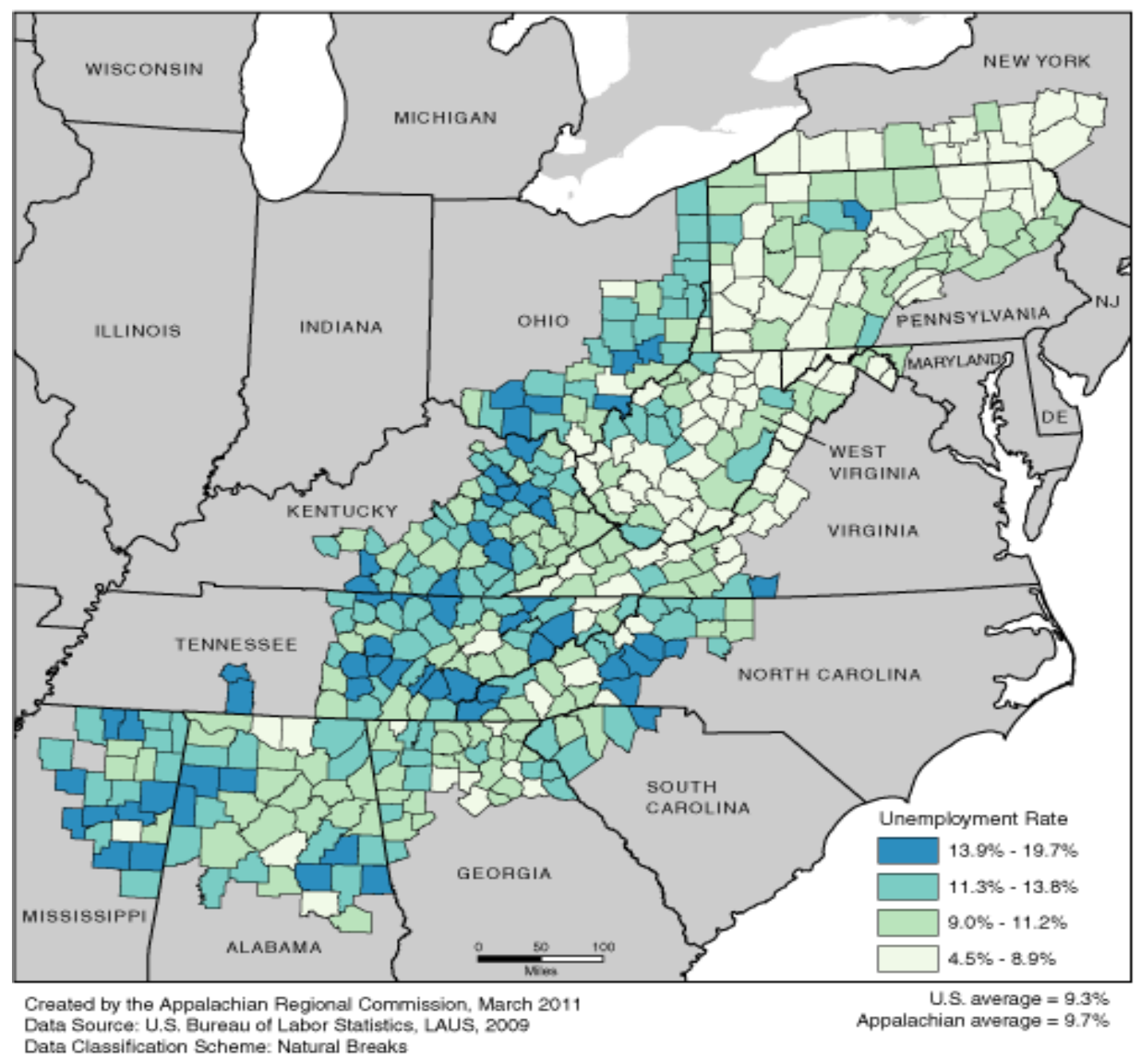

Figure 1.3 Unemployment rates in Appalachia, 2009

Table 1.3 Percent of persons age 21 to 64 with disabilities

\begin{tabular}{ll}
\hline United States & 19.2 \\
Appalachian Region & 21.3 \\
Northern Appalachia & 17.1 \\
North Central Appalachia & 22.5 \\
Central Appalachia & 31.8 \\
South Central Appalachia & 22.0 \\
Southern Appalachia & 21.4 \\
\hline
\end{tabular}

Source: Economic Assessment of Appalachia, 2010 
Nearly 44 percent of the Appalachian population is obese with the highest rate reported in southeast Appalachia (Wewers et al., 2006). One out of every three adults is considered overweight and roughly 10 percent of the population is suffering from diabetes, which may be highly related with obesity (Wewers et al., 2006). According to the morbidity and mortality report of the CDC (2009), the prevalence of obesity (more than 31 percent) and diabetes (more than 10.6 percent) is higher in West Virginia, Tennessee, Kentucky, Mississippi, Louisiana, middle Alabama, south Georgia, and the coastal regions of North and South Carolina than the national average. The report further reveals that 81 percent of the counties in Kentucky, Tennessee, and West Virginia have the highest rates of diabetes and obesity. Meanwhile, 77 percent of the counties in Alabama, Georgia, Louisiana, Mississippi, and South Carolina report cases of diabetes and obesity. Counties on the "high end" of obesity prevalence are Dallas County (41.6 percent) and Greene County (43.7 percent) in Alabama; and Holmes County (42.6 percent), Humphreys County (41.9 percent), and Jefferson County (41.3 percent) in Mississippi. Counties that report high prevalence of diseases, like diabetes, cancer, and heart disease are Greene County (15.3 percent), Lowndes Country (15.2 percent), and Perry County (15.2 percent) in Alabama; and Holmes County (15.0 percent) and Jefferson County (14.9 percent) in Mississippi.

The prevalence of heart disease is another health problem in the Appalachian region. Central and southern portions of the region show significantly higher rates of heart disease (ARC, 2010). Counties in the southern portion of Appalachia, and along the Alabama-Georgia and Alabama-Mississippi borders indicate high rates of health problems. According to Wingo et al. (2008), incidence of cancer is high in the Appalachian region compared to other parts of the United States. High incidence of lung, colon, rectum, and other tobacco-related cancers are also 
reported in the region. Central Appalachia reports the highest rates of lung cancer for both men and women, and northern Appalachia reports the highest rates for prostate and female breast cancer (Wing et al., 2008). Nearly 13.5 percent of adults have a serious psychological distress problem compared to only 11.6 percent of adults outside of Appalachia. Cigarette usage by adults in Appalachia is higher than the rest of the United States (Kaiser State Health Facts, 2008). Also, high alcohol consumption by adolescents is reported in the region compared to the rest of the United States (Zhang et al., 2008). In Appalachian counties in Kentucky, where 28 percent of the state's population lives, prevalence of both current and lifetime asthma are higher than for other parts of the state (Kentucky Asthma Program, 2010).

\subsection{Objectives of the study}

The main objective of this study is to examine the health implications and costs of adult obesity of the Appalachian region. The specific objectives are to:

1. Examine the impacts of obesity on public health in the Appalachian region.

2. Estimate the costs of major diseases linked to obesity.

3. Measure reductions in healthcare costs associated with reductions in obesity.

4. Examine the use of reduced calorie intake and increased exercise for reducing obesity of individuals.

5. Propose health-related policies for regional development.

\subsection{Organization of the study}

This study is composed of five chapters. Chapter 1 presents the problem statement and background of the study. Chapter 2 is a literature review on obesity, health implications and costs of obesity, and prevention methods of obesity. Chapter 3 provides methodology with hypotheses and theoretical foundations. Empirical results of model estimations and discussion 
are presented in Chapter 4. Finally, Chapter 5 provides a summary of findings, conclusions, policy suggestions, and recommendations for future studies. 


\section{CHAPTER 2}

\section{LITERATURE REVIEW}

\subsection{Prevalence of obesity}

Obesity is one of the major health problems in the United States and more than 60 percent of adults are either obese or overweight (Miljkovic and Nganje, 2008). According to health data (2011) of the Organization for Economic Co-operation and Development (OECD), the United States reports the highest obesity rates in the world. According to the National Health and Nutritional Examination Survey (NHANES) obesity prevalence from 2007 to 2008 was more than 32 percent for adult males and nearly 35 percent for adult females. The figures show more than a 100 percent increase from 1976 to 1980, and a 50 percent increase from 1988 to 1994 (Flegal et al., 2010). According to Finkelstein (2010), roughly 5 percent of adults are severely obese, i.e. their BMI is more than 35. The Center for Disease Control and Prevention (CDC) also shows that 27 percent of the U.S. population is obese with the highest rate among adults 50 to 69 years of age (Muth, 2010). This estimation was based on self-reported height and weight data from 400,000 individuals in 2009. Interestingly, the majority of the obese are African-Americans with less than a high school education. Further, the study reports a high prevalence of obesity in the Midwest and Southern United States. According to NHANES data (2007 to 2008) the prevalence of class II and III obesity is 14.3 percent of the U.S. population 20 years of age or older (Ryan and Kushner, 2010). Using a cohort of 8,834 individuals aged 12 to 21 years enrolled in 1996 in the U.S. National Longitudinal Study of Adolescent Health (NLSAH), Natalie et al. (2010) show that class III obesity (BMI>40) is increasing rapidly and severe health complications are highly likely to occur in the future. The study reveals that the 
highest prevalence of class III obesity is among African-American women, especially those who are less educated.

Since 1980, the prevalence of overweight children and adolescents in the United States rose by threefold (Rosin, 2008). Among American children aged 12-19 years in 2003-2004, 17.1 percent were overweight (Ogden et al., 2002). Among children 6-19 years old, nearly 14 percent are facing the problem of obesity. The prevalence of obesity in children aged 6 to 11 years has tripled from 6.5 percent to 19.6 percent from 1980 to 2008; for those aged 12-19 years, prevalence increased from 5.0 percent to 17.6 percent and the children are at great risk of developing serious medical problems like diabetes (type II), high cholesterol levels, and high blood pressure (Childhood Obesity Statistics, 2010).

Childhood overweight has negative health impacts during childhood and adolescence as well as in adulthood (Sabate and Wien, 2010). Moreover, increase in obesity is one of the major determinants of the increasing prevalence of diabetics (type II) among children.

\subsection{Health impacts of obesity}

Obesity is a major risk factor for many chronic conditions including cardiovascular disease (CVD), stroke, hypertension, cancer, diabetes (type II), asthma, musculoskeletal diseases, and sleep apnea (Flegal et al., 2002; Schmid et al., 2005). According to Wolin et al. (2010), overweight and obesity account for approximately 20 percent of all cancer cases. Using data from the last 25 years, the study shows that 14 percent of cancer deaths in men and 20 percent of cancer deaths in women are associated with overweight and obesity. Further, Wolin et al. (2010) show that increasing physical activity and controlling weight gain after cancer reduce the risk and have substantial benefits, especially regarding breast cancer. Obesity increases the risk of several types of cancer: common cancers, breast cancer in postmenopausal women and 
prostate cancer (Morimoto et al., 2002). However, International Agency for Research on Cancer (IARC) found limited evidence for the association of cancer and overweight by evaluating the data through 2000 (IARC, 2002).

Obesity is a major influence on the development of CVD and it affects physical and social functioning and the quality of life. According to Gregg et al. (2005), prevalence of obesity-related risk factors has decreased from 1960 to 2000 in the United States. However, Kumanyika et al. (2008) indicated that risk factors for the obese are still high. Controlling heart disease needs lifetime therapies, and even under medical intervention, obesity or overweight may affect heart disease positively. Effective treatment for reducing weight can significantly reduce CVD risk factors (NIH, 1998).

Overweight and obesity are established risk factors for hypertension. Studies show that hypertension is approximately twice as prevalent among the obese as in the non-obese population (Flegal et al., 2002; Ogden et al., 2002). The prevalence of obesity-related hypertension varies with age, race, and gender of the population studied (Aronne and Segal, 2002). According to MacMahon et al. (1984) about 30 percent of cases of hypertension may be attributable to obesity of men. Even though evidence supporting a relationship between obesity and hypertension is plausible, the relationship between overweight or obesity and hypertension is complex (Kotchen, 2008).

The prevalence of diabetes (type II) continued to increase with increasing obesity in the United States (Gregg et al., 2005). It requires a lifetime of medical care and drug therapy from the beginning in controlling diabetes (type II) which lowers quality of life. Further, childhood obesity shows a positive relationship with diabetes (type II) among children, especially between 10-17 years old (Kumanyika et al., 2008). 
There is a significant relationship between obesity and asthma, especially among children. Within the 20th century the increase in asthma is paralleled with that of obesity (Akinbami, 2006). Prevalence of asthma may lead to obesity as asthma limits physical activity. According to CDC (2011), the number of people diagnosed with asthma grew by 4.3 million from 2001 to 2009. Also, asthma costs in the United States grew from about \$53 billion in 2002 to about $\$ 56$ billion in 2007 , about a 6 percent increase.

The relationship between obesity and arthritis remains unclear. However, arthritis rates increase with higher body weights and overweight individuals are more likely to report doctordiagnosed arthritis than normal weight individuals (CDC, 2009). According to studies of the Johns Hopkins Arthritis Center (Bartlett, n.d.), obese women have four times the risk of knee osteoarthritis than their non-obese counterparts. The study reveals that overweight men are five times more at risk than normal-weight males. Moreover, the study shows the possibility of reducing a woman's risk of knee arthritis by 50 percent by losing only 11 pounds. According to Morbidity and Mortality Weekly Report [MMWR] (2010), about 21 percent of overweight and 31 percent of obese people report doctor-diagnosed arthritis. Arthritis limits the ability to work. According to MMWR (2005), nearly 5 percent of U.S. adults between the ages of 18 and 64 have arthritis and are affected by arthritis-attributable work limitations. Shih et al. (2005) show that nearly 44 percent of adults with doctor-diagnosed arthritis report no leisure time physical activity or exercise compared with 36 percent of adults without arthritis.

According to Sturm (2002), an increase in mortality rates is associated with obesity, particularly with higher levels of obesity. Obese people have a 50 to 100 percent increased risk of death from all causes compared with normal weight individuals (Mokdad et al., 2003; Flegal et al., 2010). Fontaine et al. (2003) estimated that the expected number of years of life lost due 
to being overweight across the life span of an adult is decreased, especially among young adults. According to the research, for severely obese white men aged 20-30 years, a 22 percent life reduction (13 years) is expected from their remaining life span. For white women the value of life reduction expected is 8 years. The study further reveals that for any given degree of overweight, younger adults had greater years of life lost compared to their elders. Sturm et al. (2004) showed a significant relationship between obesity and disability and extrapolated the effects of unhealthy weight gains.

Anderson and Butcher (2006a) show that increasing childhood obesity is highly related to increasing adult obesity. This is in addition to the long-term risks and immediate medical and psychological consequences of being overweight in children and adolescents (Johnson et al., 2006). Furthermore, overweight children tend to suffer from cardiovascular problems, metabolic disorders and lower quality health.

\subsection{Factors affecting obesity}

Problematic levels of obesity were reported within the last 2 to 3 decades along with various changes in lifestyle and consumption patterns. However, obesity is affected by biological, social, cultural, educational, behavioral and economic factors (Nayga, 2000; Smith and Tasnadi, 2003; Drewnowski and Specter, 2004; Classen and Hokayem, 2005). Among the major causal factors of obesity is a positive balance of calories (Cawley, 1999; Richards et al., 2004; Rosin, 2008). World Health Organization [WHO] states that the fundamental causes of obesity are sedentary lifestyles and high-fat energy-dense diets (Becker and Murphy, 1988; Cawley et al., 2005; Anderson and Butcher, 2006a).

Genetic factors are another reason for obesity. Being overweight among children and adolescents can be explained by parents being overweight. Classen and Hokayem (2005) found 
strong evidence that a higher degree of obesity among mothers leads to a significantly increased likelihood of obese children. According to Smith and Tasnadi (2003), overeating might have a biological basis, arising from the will to survive. Smith (2004) indicated that eating preferences evolved in former environments in which risk aversion led to a natural equilibrium of food consumption. According to the theory built by Becker and Murphy (1988), obesity could be explained as a consequence of widespread addictive behavior of overeating. An addiction to food means that increased current eating raises both future weight and desire to eat more in the future. The idea was researched by Cawley (1999) and Richards et al. (2004) who found support for the hypothesis that consumption of calories is addictive.

Changing the relative prices of food also affects obesity. French et al. (2001) bring some evidence from vending machines, showing that price reduction strategies which change price differentials between high-fat and low-fat snack substitutes may affect consumption behavior. Chou et al. (2004) empirically show that price differences in restaurants affect obesity and its trend. Rashad et al. (2006) indicate that an increasing per capita number of restaurants increased obesity. The rapid increase in obesity over time, especially during the 1980s, was due in part to an increase in the per capita number of restaurants. There are inconsistencies in western societies where people are eating better and improving their understanding of the benefits of a healthy lifestyle though many are becoming obese and suffering from diet-related illnesses (Mancino, 2003).

Education and schooling play a major role in obesity. Higher education lowers obesity rates as health promotion occurs through knowledge (Nayga, 2000). According to Drewnowski and Specter (2004), the highest poverty rates and the lowest level of education result in the highest obesity. Lack of physical exercise is another factor of obesity. Cawley et al. (2005) show 
that the impact of decreased physical education (PE) classes in schools on youth was a higher probability of students being overweight.

Working mothers seem to be another possible reason for obesity. The argument is that eating more fast food and junk food by children of working mothers leads to obesity. However, Anderson et al. (2003) show that impacts of working mothers are small; the increased hours worked per week among mothers between 1975 and 1999 were associated with only about 0.40.7 percentage point increase in overweight.

Urbanization could have a role in the growth of obesity. Examining the relationship between urban sprawl and physical activity, Ewing et al. (2003) show that urbanization is associated with increased weight. Also, increasing pollution from urbanization fuels obesity, especially childhood obesity. An investigation by Loureiro and Nayga (2006) of cross-country differences in obesity rates in OECD countries reveals that urbanization is strongly related to growth of obesity rates. But Kumanyika et al. found that a higher prevalence of obesity is reported from rural areas compared to urban areas (2008). Rural obesity may be related to local poverty and lack of resources, especially in certain rural areas (Khan et al., 1998). According to BRFSS data in 2005, the highest prevalence of obesity was reported from Louisiana, Mississippi, and West Virginia. The lowest was reported in Colorado and Hawaii where poverty is lower compared to many parts of the United States (CDC, 2006).

Neighborhood characteristics are associated with obesity (Frank et al., 2004; Boardman et al., 2005; Inagmi et al., 2006; Wang et al., 2007). In a study measuring the association of perceived neighborhood safety on BMI with a random sample of 2,255 adults from the Los Angeles Family and Neighborhood survey (2000 to 2001), Fish et al. (2010) found that a higher proportion of African-American and Latino residents, barriers in the built environment, lack of 
access to fresh fruits and vegetables, and higher density of fast food restaurants significantly affect obesity. According to Amarasinghe et al. (2006), obesity tends to be spatially correlated and also affected by sprawl in West Virginia. Obesity apparently declines with an increase in mixed land use and fewer hours spent in a car. In another study, researchers reveal that an educated population, availability of food stores, commuting time, annual wage and the built environment significantly affect obesity in Appalachia (Amarasinghe et al., 2009).

Presence of fast food outlets close by shows some impacts on obesity. According to Currie et al. (2010) a fast food restaurant within a half mile of one's residence could result in a 1.6 percent increase in the probability of gaining over 20 kilograms of weight for a child. The effect is larger with African-Americans than others. Morland et al. (2006) indicate that the presence of convenience stores is positively correlated with obesity while the presence of supermarkets is related with a lower prevalence of obesity. This suggests that the characteristics of local food environments can play a role in the prevention of obesity.

One of the reasons for high incidence of obesity in developed countries could be rapid technological change. With technological changes employment has shifted from manufacturing and mining to services and sedentary jobs that involve less on-the-job exercise. Technology has also led to reduced caloric expenditures in household work. Thus, the decline of overall physical activity may have resulted in overweight (Rosin, 2008). According to Philipson and Posner (1999; 2003) technological change has lowered the cost of calories through agricultural innovation which has led to higher consumption of food. This was proved by Lakdawalla and Philipson (2002), who observe that about 40 percent of the increase in weight was due to expansion in the supply of food through agricultural innovation as a result of technological changes. 
Poverty is a well-known issue related to health and nutrition. In developed countries, especially in the United States, those with a lower socioeconomic status have higher rates of obesity (BRFSS, various years). According to Shahar et al. (2005) obesity is higher among low socioeconomic populations, compared to high socioeconomic populations. Lack of credible information on the nutritional value of food or information on the health consequences of poor eating habits may increase obesity. For instance, children and students are less likely to have this kind of information, which could prevent them from eating junk food (Rosin, 2008). Cawley (1999) comments that a typical consumer has less information about the calorie content of foods s/he eats away from home. According to Apovian (2004), several studies show a relationship between sugar-sweetened beverages and child obesity in the United States.

Time preferences are another factor that affects obesity. The marginal rate of time preference is a measure of the rate that a person is willing to trade current pleasure for future pleasure. The concept of time preference reflects the degree of impatience of an individual. The higher is the time preference, the lower is the value of future utility. Thus, a higher marginal rate of time preference values current consumption more and may influence the rise of obesity. According to Komlos et al. (2004), a higher rate of time preference may reduce investment in physical exercise and may increase caloric intake that leads to overweight. Mancino, Lin, and Ballinger (2004) revealed that individuals who exercise more frequently, watch less television, drink fewer sugary beverages, and eat a high quality diet are less likely to be overweight or obese.

Even though alcohol consumption is assumed to be a risk factor for obesity, epidemiological studies have not provided consistence evidence for this (Wang et al., 2010). However, Wang et al. (2010) indicate that alcohol consumption increases intake of meat and 
high-fat food items and decreases intake of grains and low-fat meals, which may affect overweight and obesity. Smoking is associated with some obesity-related diseases like cancer and heart disease. A multiplicative interaction between the risks of smoking and overweight is well established in the discussion of coronary heart disease (Manson et al., 1995). However, according to Peters et al. (2003) the serious increase in health risks when smoking and overweight are combined are not widely understood. According to Gangwisch et al. (2005), sleep deprivation could also play a significant role in the problem of obesity in some individuals.

\subsection{Economic and Social burden of obesity}

Obesity has major economic impacts. According to a WHO report (Chopra et al., 2002) non-communicable chronic diseases will become the predominant cause for morbidity and mortality in a few years, and those diseases will probably be responsible for about two-thirds of all disease costs by the year 2020. WHO (2007) reveals that western governments spend a large share of their expenditures on health, and this share is increasing over time. Obesity results in both direct and indirect economic costs. Direct costs comprise all the costs that are incurred directly from treatment and prevention (medication, physician visits, hospital stays). Indirect costs include productivity losses (lost wages) caused by the disease through work absenteeism, early retirement, and premature death. Hammond and Levine (2010) identified four major categories of economic impacts attached to obesity: direct medical costs, productivity costs, transportation costs, and human capital costs. Not only do employers and government find it increasingly difficult to finance the high costs of obesity-related medical treatments, but obese individuals are more likely to be absent from work and be less productive or efficient while on the job (Finkelstein et al., 2010). Tsai et al. (2008) found that Shell Oil Company had productivity losses of $\$ 11.2$ million per year due to absenteeism related to obesity. Trogdon et al. 
(2008) provided a range of estimates for nationwide annual productivity losses associated with absenteeism, from $\$ 3.38$ billion to $\$ 6.38$ billion in the United States. In addition to worker inefficiency and absenteeism, obesity may increase disability payments and disability insurance payments which become an additional burden to society as a whole (Finkelstein et al., 2010; Burkhauser and Cawley, 2005). According to BRFSS and NHANES, the total cost of obesity could increase to $\$ 344$ billion by 2018 . NIH estimates that direct and indirect costs due to obesity-related diseases were around \$75-125 billion in 2010. Dor et al. (2010) showed that the overall annual cost of being obese is $\$ 2,646$ for an obese man and $\$ 4,879$ for an obese woman.

Obesity also has an impact on the labor market. Averett and Korenman (1996) show that obese women have lower family incomes than normal-weight women, even after controlling for family background differences. Further, the lower economic status of obese women is explained mostly by differences in the marriage market and partly by labor market discrimination against obese women. According to Cawley and Danziger (2005) and Zagorsky (2004, 2005) there is evidence of weight-based discrimination of women in wages and employment.

The epidemic of obesity absorbs increasingly greater health care budgets in the United States. For instance, health expenditures (as a share of GDP) were 15.2 percent in 2003 (Hagist and Kotlikoff, 2009). According to Colditz (1992), economic costs attributable to obesity were $\$ 11.3$ billion for diabetes (type II), $\$ 2.2$ billion for cardiovascular disease, $\$ 2.4$ billion for gallbladder disease, $\$ 1.5$ billion for hypertension, and $\$ 1.9$ billion for colon and postmenopausal breast cancer. The total estimated cost was $\$ 39.3$ billion for obesity in 1986 . According to Sturm (2002), Finkelstein et al. (2004) and Raebel et al. (2004), obese adults under the age of 65 incur annual medical expenditures that are 37 percent higher than an adult of normal weight in that age group. Strum (2002) shows that obesity is associated with a 35 percent increase in inpatient and 
outpatient spending, and a 77 percent increase in prescription medication expenditures. According to Finkelstein et al. (2009), obesity increases per capita inpatient expenditures by 45.5 percent, outpatient and physician office expenditures by 26.9 percent, and prescription drug expenditures by 80.4 percent compared with normal weight expenditures. Generally, medical treatments of chronic diseases tend to be very expensive and treatments of diabetes, CVD and stroke are especially expensive (Rosin, 2008).

According to Hammond and Levine (2010) nearly 500 million people were overweight in the world in 2002. Obesity is associated with various consequences for these individuals as well as for society. Most interestingly, it reduces the quality of life and leads to social stigmatization and discrimination. The result may be lower-salary jobs, unemployment or lost employment opportunities (Muth, 2010). According to Must et al. (1999), the high prevalence of obesityrelated co-morbidities highlights the impacts of this disease burden on society. Rapidly rising healthcare costs associated with obesity hinder other potential investments that could upgrade living standards and quality of life for society as a whole. Thus, obesity influences policy considerations regarding financial burdens, health-care management, social inequalities, cultural issues, welfare support, and farm and food industry drivers (Lang and Rayner, 2005).

\subsection{Overcoming obesity}

Combating obesity is one of the major concerns of healthcare developers. Various research has shown potential methods of weight control. Using longitudinal data from 1991 to 1999 among women in the Nurses' Health Study II (NHS II), Schulze et al. (2004) found that reduction of soft drink consumption leads to lower weight gain compared to fruit juice consumption. Based on an average 8-year weight gain of 14 to 16 pounds in adults enrolled in the Coronary Artery Risk Development in Young Adults study (CARDIA), Hill et al. (2003) 
revealed that a deficit of $100 \mathrm{kcal} /$ day could prevent weight gain by many people in the U.S. This could be achieved by reducing consumption of one can of soda per day per person. A health study in 2002 across the United States and Canada showed that vegetarian diets provide higher protection against overweight (Sabate and Wein, 2010). Culter et al. (2003) revealed that higher consumption of calories outside the main meals positively affects obesity. In a study conducted at the University of Pittsburgh from 2007 to 2010 with 130 severely obese adult participants without diabetes, Goodpaster et al. (2010) showed that people in obesity classes II and III can reduce their weight through lifestyle change and moderate-intensity physical activity. In overcoming severe obesity, diet, exercise, and behavioral modifications are recommended that result in 5 to10 percent weight loss in the short term (Natalie et al., 2010). Lakdawalla and Philipson (2002) imply that increased physical activity, both at home and on the job, reduces weight gain. Fish et al. (2010) reveal that public health interventions aimed at reducing obesity need to improve coping mechanisms, promote behavior modifications that lead to healthier dietary plans, reduce stress and encourage engagement in community level efforts to reduce physical and psychological hazards in their neighborhoods.

This research on obesity and health implications is unique from other studies. First, the study applies to all of Appalachia; previous obesity-related studies on the Appalachian region are limited in geographic scope. Second, the study examines obesity-related diseases and attempts to measure the costs associated with those diseases, which has not been attempted before. Third, the study discusses possibilities of cost reduction by preventing obesity-related diseases. Fourth, by analyzing the behavioral methods of mitigating obesity for adults, the study attempts to reveal potential ways that obesity might be reduced in Appalachia. Thus, this study examines obesityrelated health issues, costs of obesity and obesity prevention. It is a comprehensive study of 
obesity that can help policymakers understand obesity in Appalachia from different angles. In addition, the methodology used, a simultaneous equations-based analysis appears to be unique for obesity studies in the Appalachian region.

Most of the previous literature on obesity-related studies has used multiple regressions with logit and probit analyses for examining obesity impacts (Chou et al., 2004; Loureio et al., 2006; Amarasinghe et al., 2006). However, with prevailing complexities of the obesity situation, a methodology that recognizes the interactions among obesity, diseases, socioeconomic factors, behavioral factors and environmental factors is needed. Thus, an approach with a system of simultaneous equations makes for better understanding of obesity-related issues. Systems of simultaneous equations are used by some researchers, especially in development economics (Rosenberger et al., 2005; Deller et al., 2001), however, none of those studies used a system of simultaneous equations to analyze obesity-related health issues in Appalachia. 


\section{CHAPTER 3}

\section{METHODOLOGY}

\subsection{Theoretical Framework}

In a consumer's utility maximization context, Becker (1965) and Lancaster (1966) used household production models where desirable attributes were created from market goods and household labor, subject to budget and time constraints. In 1972, Grossman extended this framework in a health context to derive the demand for the commodity 'good health,' a desirable attribute that is produced by an individual and enters into the individual's utility function. Investments in healthcare or conditions for good health can be explained by a household's production function. The time of the consumer and market goods such as medical care, diet, exercise, recreation, and housing as well as exogenous or given socioeconomic and demographic characteristics are combined (Grossman, 1972) to create good health.

As the rational consumer tries to maximize his/her satisfaction by allocating time and other resources to produce the commodity 'good health' together with other desirable attributes, the $i^{\text {th }}$ individual's utility maximization problem can be represented as:

(1) $\quad \operatorname{Max} U_{i}=U_{i}\left(X, Y, Z, L_{a}, L_{p}, H_{i}\left(X, Y, Z, L_{a}, S F, E F, B F\right)\right)$,

where, $\mathrm{X}$ is a numeraire good, $\mathrm{Y}$ is healthy food (e.g. fruits and vegetables), $\mathrm{Z}$ is less healthy food (e.g. fast food, sugary beverages), $\mathrm{L}_{\mathrm{a}}$ is active leisure (e.g. time at a gym), $\mathrm{L}_{\mathrm{p}}$ is passive leisure (e.g. socialization, watching television), $\mathrm{H}_{\mathrm{i}}$ is a health production function, $\mathrm{SF}$ is a vector of socioeconomic factors, $\mathrm{EF}$ is a vector of environmental factors that affect health, and $\mathrm{BF}$ represents the behavioral factors of the individual.

It is assumed that the $i^{\text {th }}$ individual's utility function is separable with its arguments, quasi-concave and continuously differentiable. The marginal utilities, $\mathrm{d} \mathrm{U}_{\mathrm{i}} / \mathrm{dX}, \mathrm{dU}_{\mathrm{i}} / \mathrm{dY}, \mathrm{dU}_{\mathrm{i}} / \mathrm{dZ}$, 
and $\mathrm{dU}_{\mathrm{i}} / \mathrm{dH}_{\mathrm{i}}$, are all greater than or equal to zero. This implies that some positive marginal utility is derived from consuming the numeraire good $(\mathrm{X})$, healthy food $(\mathrm{Y})$, and less healthy food $(\mathrm{Z})$. Further, it assumes that better health $\left(\mathrm{H}_{\mathrm{i}}\right)$ yields positive marginal utility to the consumer. The impact of active leisure $\left(\mathrm{L}_{\mathrm{a}}\right)$ on utility, $\mathrm{d} \mathrm{U}_{\mathrm{i}} / \mathrm{d} \mathrm{L}_{\mathrm{a}}$, and passive leisure $\left(\mathrm{L}_{\mathrm{p}}\right)$ on utility, $\mathrm{dU}_{\mathrm{i}} / \mathrm{d}_{\mathrm{p}}$ can be greater than, less than, or equal to zero, with its impact depending on the individual's subjective preference towards these activities.

The health production function of the $i^{\text {th }}$ individual, $H_{i}\left(X, Y, Z, L_{a}, S F, E F, B F\right)$ is assumed to be a continuously differentiable function with respect to its inputs. The marginal impact of the numeraire good $(\mathrm{X}), \mathrm{dH}_{\mathrm{i}} / \mathrm{dX}_{\mathrm{i}}$ can be greater than, less than or equal to zero. While $\mathrm{dH}_{\mathrm{i}} / \mathrm{dY}$, the marginal impact of healthy food $(\mathrm{Y})$, and $\mathrm{dH}_{\mathrm{i}} / \mathrm{dL}_{\mathrm{a}}$, the marginal impact of active leisure $\left(\mathrm{L}_{\mathrm{a}}\right)$ should be greater than or equal to zero, $\mathrm{dH}_{\mathrm{i}} / \mathrm{dZ}$, the marginal impact of less healthy food $(\mathrm{Z})$ can be less than or equal to zero.

Utility maximization of the $\mathrm{i}^{\text {th }}$ individual is subject to the budget constraint:

(2) $\mathrm{P}_{\mathrm{Y}} \mathrm{Y}+\mathrm{P}_{\mathrm{Z}} \mathrm{Z}+\mathrm{P}_{\mathrm{X}} \mathrm{X}+\mathrm{D}(\mathrm{H}(\cdot)) \leq \mathrm{I}+\mathrm{W}\left(\mathrm{T}-\mathrm{L}_{\mathrm{a}}-\mathrm{L}_{\mathrm{p}}\right)$,

where $\mathrm{P}_{\mathrm{Y}}, \mathrm{P}_{\mathrm{Z}}$, and $\mathrm{P}_{\mathrm{X}}$ are respective prices of healthy foods $(\mathrm{Y})$, less healthy foods $(\mathrm{Z})$, and the numeraire good $(\mathrm{X})$. $\mathrm{D}(\mathrm{H}(\cdot))$ shows expenditures for medical services (doctor fees, medical fees, transport and time costs) that are assumed to be a function of an individual's health status. I is non-wage income, $\mathrm{W}$ is wages and $\mathrm{T}$ is total time available for market and non-market activities. Thus, $\mathrm{W}\left(\mathrm{T}-\mathrm{L}_{\mathrm{a}}-\mathrm{L}_{\mathrm{p}}\right)$ represents the labor income available after time on both passive and active leisure activities has been accounted for. First order conditions for utility maximization, and invoking the implicit function theorem, lead to the individual's demand function for health:

(3) $H_{i}=f\left(I, W, P_{X}, P_{Y}, P_{Z}, P_{H}, S F, E F, B F\right)$.

Thus, the individual health of the $\mathrm{i}^{\text {th }}$ person is a function of income, wages, prices of marketed 
goods, the marginal implicit price of health, $\mathrm{P}_{\mathrm{H}}$ (i.e. the marginal expenditure by an individual to remain healthy), socioeconomic factors (SF), environmental factors (EF), and behavioral factors (BF).

Using the first order conditions of the utility maximization function (equation one) and budget constraint (equation two), and setting the first order conditions equal the following conditions can be derived.

(4) $\frac{\mathrm{U}_{\mathrm{X}}(.)+\mathrm{U}_{\mathrm{H}} \mathrm{H}_{\mathrm{X}}}{\mathrm{P}_{\mathrm{X}}+\mathrm{P}_{\mathrm{H}} \mathrm{H}_{\mathrm{X}}}=\frac{\mathrm{Uy}_{\mathrm{y}}(.)+\mathrm{U}_{\mathrm{H}} \mathrm{H}_{\mathrm{y}}}{\mathrm{P}_{\mathrm{X}}+\mathrm{P}_{\mathrm{H}} \mathrm{H}_{\mathrm{y}}}=\frac{\mathrm{U}_{\mathrm{Z}}(.)+\mathrm{U}_{\mathrm{H}} \mathrm{H}_{\mathrm{Z}}}{\mathrm{P}_{\mathrm{Z}}+\mathrm{P}_{\mathrm{H}} \mathrm{H}_{\mathrm{Z}}}=\frac{\mathrm{U}_{\mathrm{La}}(.)+\mathrm{H}_{\mathrm{La}}}{\mathrm{W}}=\frac{\mathrm{U}_{\mathrm{Lp}}(.)}{\mathrm{W}}=\frac{\mathrm{U}_{\mathrm{H}}(.)}{\mathrm{P}_{\mathrm{H}}}=\lambda$

The equimarginal principle of optimality indicates that an individual rational consumer will allocate his/her resources up to the point that marginal benefits are equal across all commodities consumed as well as for the other factors such as health and leisure that provide maximized satisfaction.

\subsection{Hypotheses}

The study mainly hypothesizes the following statements in this study.

1. Asthma, hypertension, heart disease, arthritis, diabetes, and cancer are significantly and positively associated with obesity.

2. Preventing and mitigating obesity results in health gains.

3. Behavioral, socioeconomic, and environmental factors are highly correlated with obesity.

4. Significant reduction of obesity results in economic gains to society in the Appalachian region.

5. Obesity can be reduced by changing behavioral factors of individuals.

\subsection{Empirical models and specifications of variables}

3.3.1 Objective 1. Examine the impacts of obesity on public health in the Appalachian region. 
As explained previously, income, employment, obesity, and diseases are interdependent. Thus, to accomplish objective one, a model with a system of simultaneous equations is used to give better results than a single equation approach. A simultaneous equations approach accounts for interactions among the interdependent variables which gives comprehensive estimations. Also, simultaneity helps in overcoming inconsistency and bias and leads to efficient estimation. As the intention of this objective is to examine the impacts at a county level, county average values of income, employment, obesity and diseases are used in the model. Also, all other variables of social factors (SF), behavioral factors (BF) and environmental factors (EF) are applied at the county level.

The variables Income*, Employment ${ }^{*}$, Obesity $^{*}$, and Disease ${ }_{j}{ }^{*}$ represent the equilibrium levels of income, employment, obesity, and disease (where $\mathrm{j}$ goes from 1 to 6 for each of the six diseases: asthma, hypertension, heart disease, arthritis, diabetes, and cancer). $\Omega^{\mathrm{I}}, \Omega^{\mathrm{E}}, \Omega^{\mathrm{O}}$, and $\Omega^{\mathrm{Dj}}$ are a set of variables describing initial conditions that measure social factors (SF), environmental factors $(\mathrm{EF}$,$) and behavioral factors (\mathrm{BF})$ that are linked to obesity-related health implications. Thus, the general form of the four equations model is:

(5) Income $^{*}=\mathrm{f}\left(\right.$ Employment ${ }^{*}$, Obesity $^{*}$, Disease $\left._{\mathrm{j}}{ }^{*}, \Omega^{\mathrm{I}}\right)$

(6) Employment $^{*}=\mathrm{g}\left(\right.$ Income $^{*}$, Obesity $^{*}$, Disease $\left._{\mathrm{j}}{ }^{*}, \Omega^{\mathrm{E}}\right)$

(7) Obesity $^{*}=\mathrm{h}\left(\right.$ Income $^{*}$, Employment $^{*}$, Disease $\left._{\mathrm{j}}{ }^{*}, \Omega^{\mathrm{O}}\right)$

(8) $\quad$ Disease $_{\mathrm{j}}{ }^{*}=\mathrm{k}\left(\right.$ Employment ${ }^{*}$, Income $^{*}$, Obesity $\left.^{*}, \Omega^{\mathrm{Dj}}\right)$

From the equilibrium framework of the model, a simple linear relationship among the variables can be presented (where $\mathrm{I}$ is income, $\mathrm{E}$ is employment, $\mathrm{O}$ is obesity and $\mathrm{D}$ is disease):

$$
\begin{aligned}
& \mathrm{I}^{*}=\alpha_{\mathrm{OI}}+\beta_{1 \mathrm{I}} \mathrm{E}^{*}+\beta_{2 \mathrm{I}} \mathrm{O}^{*}+\beta_{3 \mathrm{I}} \mathrm{D}_{\mathrm{j}}^{*}+\sum \delta_{\mathrm{I}} \Omega^{\mathrm{I}} \\
& \mathrm{E}^{*}=\alpha_{\mathrm{oE}}+\beta_{1 \mathrm{E}} \mathrm{I}^{*}+\beta_{2 \mathrm{E}} \mathrm{O}^{*}+\beta_{3 \mathrm{E}} \mathrm{D}_{\mathrm{j}}^{*}+\sum \delta_{\mathrm{E}} \Omega^{\mathrm{E}}
\end{aligned}
$$




$$
\begin{aligned}
& \mathrm{O}^{*}=\alpha_{\mathrm{oO}}+\beta_{1 \mathrm{O}} \mathrm{I}^{*}+\beta_{2 \mathrm{O}} \mathrm{E}^{*}+\beta_{3 \mathrm{Oj}} \mathrm{D}_{\mathrm{j}}{ }^{*}+\sum \delta_{\mathrm{O}} \Omega^{\mathrm{O}} \\
& \mathrm{D}_{\mathrm{j}}{ }^{*}=\alpha_{\mathrm{oDj}}+\beta_{1 \mathrm{Dj}} \mathrm{I}^{*}+\beta_{2 \mathrm{Dj}} \mathrm{E}^{*}+\beta_{3 \mathrm{Dj}} \mathrm{O}^{*}+\sum \delta_{\mathrm{Dj}} \Omega^{\mathrm{Dj}}
\end{aligned}
$$

where $\alpha$ values indicate the intercepts of each equation, $\beta$ represents the coefficient estimates of each interdependent variable and $\delta$ indicates the coefficients of the set of variables that describe initial conditions.

Moreover, income, employment, obesity and diseases likely adjust to their equilibrium levels with substantial lags (i.e., initial conditions). Thus, partial adjustment equations to the equilibrium levels are:

$$
\begin{aligned}
& \mathrm{I}_{\mathrm{t}}=\mathrm{I}_{\mathrm{t}-1}+\phi_{\mathrm{I}}\left(\mathrm{I}^{*}-\mathrm{I}_{\mathrm{t}-1}\right) \\
& \mathrm{E}_{\mathrm{t}}=\mathrm{E}_{\mathrm{t}-1}+\phi_{\mathrm{E}}\left(\mathrm{E}^{*}-\mathrm{E}_{\mathrm{t}-1}\right) \\
& \mathrm{O}_{\mathrm{t}}=\mathrm{O}_{\mathrm{t}-1}+\phi_{\mathrm{O}}\left(\mathrm{O}^{*}-\mathrm{O}_{\mathrm{t}-1}\right) \\
& \mathrm{D}_{\mathrm{jt}}=\mathrm{D}_{\mathrm{jt}-1}+\phi_{\mathrm{Dj}}\left(\mathrm{D}_{\mathrm{j}}^{*}-\mathrm{D}_{\mathrm{jt}-1}\right) .
\end{aligned}
$$

The current, income, employment, obesity, and disease levels at time $\mathrm{t}$ are functions of their initial conditions and the change between the equilibrium values and initial conditions and their respective speed of adjustment values, where $\mathrm{I}_{\mathrm{t}-1}, \mathrm{E}_{\mathrm{t}-1}, \mathrm{O}_{\mathrm{t}-1}$ and $\mathrm{D}_{\mathrm{jt}-1}$ are initial conditions of income, employment, obesity and disease; $\phi_{\mathrm{I}}, \phi_{\mathrm{E}}, \phi_{\mathrm{O}}$, and $\phi_{\mathrm{Dj}}$ are the speed of adjustment coefficients related to the desired utility maximization level of income, employment, obesity and disease, respectively. Substituting equations 13 through 16 into equations 9 through 12, and rearranging, the model can be expressed as:

$$
\begin{aligned}
& \Delta \mathrm{I}=\alpha_{\mathrm{oI}}+\beta_{1 \mathrm{II}} \mathrm{I}_{\mathrm{t}-1}+\beta_{2 \mathrm{I}} \mathrm{E}_{\mathrm{t}-1}+\beta_{3 \mathrm{I}} \mathrm{O}_{\mathrm{t}-1}+\beta_{4 \mathrm{I}} \mathrm{D}_{\mathrm{jt}-1}+\mathrm{r}_{1 \mathrm{I}} \Delta \mathrm{E}+\mathrm{r}_{2 \mathrm{I}} \Delta \mathrm{O}+\mathrm{r}_{3 \mathrm{I}} \Delta \mathrm{D}_{\mathrm{j}}+\sum \delta_{\mathrm{I}} \Omega^{\mathrm{I}} \\
& \Delta \mathrm{E}=\alpha_{\mathrm{oE}}+\beta_{1 \mathrm{E}} \mathrm{I}_{\mathrm{t}-1}+\beta_{2 \mathrm{E}} \mathrm{E}_{\mathrm{t}-1}+\beta_{3 \mathrm{E}} \mathrm{O}_{\mathrm{t}-1}+\beta_{4 \mathrm{E}} \mathrm{D}_{\mathrm{jt}-1}+\mathrm{r}_{1 \mathrm{E}} \Delta \mathrm{I}+\mathrm{r}_{2 \mathrm{E}} \Delta \mathrm{O}+\mathrm{r}_{3 \mathrm{E}} \Delta \mathrm{D}_{\mathrm{j}}+\sum \delta_{\mathrm{E}} \Omega^{\mathrm{E}} \\
& \Delta \mathrm{O}=\alpha_{\mathrm{oO}}+\beta_{1 \mathrm{O}} \mathrm{I}_{\mathrm{t}-1}+\beta_{2 \mathrm{O}} \mathrm{E}_{\mathrm{t}-1}+\beta_{3 \mathrm{O}} \mathrm{O}_{\mathrm{t}-1}+\beta_{4 \mathrm{I}} \mathrm{D}_{\mathrm{jt}-1}+\mathrm{r}_{1 \mathrm{I}} \Delta \mathrm{I}+\mathrm{r}_{2 \mathrm{I}} \Delta \mathrm{E}+\mathrm{r}_{3 \mathrm{I}} \Delta \mathrm{D}_{\mathrm{j}}+\sum \delta_{\mathrm{O}} \Omega^{\mathrm{O}}
\end{aligned}
$$




$$
\Delta D_{j}=\alpha_{o I}+\beta_{1 D j} I_{t-1}+\beta_{2 D j} E_{t-1}+\beta_{3 D j} O_{t-1}+\beta_{4 D j} D_{j t-1}+r_{1 I} \Delta I+r_{2 I} \Delta E+r_{3 I} \Delta O+\sum \delta_{D j} \Omega^{D j}
$$

where $\Delta \mathrm{I}, \Delta \mathrm{E}, \Delta \mathrm{O}$, and $\Delta \mathrm{D}_{\mathrm{j}}$ are the changes in income, employment, obesity and disease, respectively. The speed of adjustment coefficients become embedded in the linear estimated parameters $\alpha, \beta, \mathrm{r}$ and $\delta$. The model captures structural relationships while simultaneously isolating the influence of obesity on public health. Equations 17-20 estimate short-term adjustments of income, employment, obesity and disease $\left(\Delta \mathrm{I}, \Delta \mathrm{E}, \Delta \mathrm{O}\right.$, and $\left.\Delta \mathrm{D}_{\mathrm{j}}\right)$ to their longterm equilibriums $\left(\mathrm{I}^{*}, \mathrm{E}^{*}, \mathrm{O}^{*}\right.$, and $\left.\mathrm{D}_{\mathrm{j}}^{*}\right)$.

3.3.2 Objective 2. Estimate the costs of major diseases linked to obesity.

To accomplish objective two logit analysis of a response function (equation 21) is used with the total expenditures for each main disease related to obesity. Individual level data related to diseases, socioeconomic factors, behavioral factors and environmental factors are used in the analyses.

A logit analysis of a response function for each obesity-related disease with obesity as a qualitative exogenous variable would give the coefficient for the marginal impact of obesity for that particular disease. If the logit equation is perfectly defined, this coefficient for obesity indicates the contribution of obesity to the particular disease. Thus, multiplying this value by the known healthcare expenditure of the disease would give the cost of that particular disease linked to obesity. These types of dose-response functions are common in cost calculations (Srivastava and Kumar, 2001; Zuidema and Nentjes, 1997). Several researchers have used dose-response functions in estimating morbidity and mortality related to air pollution (Alberini et al., 1997; Ostro, 1995; Lvovsky, 1998; Quah and Boon, 2002).

Assume, $\mathrm{D}_{\mathrm{ji}}$ represents the $\mathrm{j}^{\text {th }}$ disease of the $\mathrm{i}^{\text {th }}$ individual, which appears as a qualitative dependent variable equal to one if the individual has the disease and zero otherwise. $\mathrm{E}_{\mathrm{i}}$ is equal 
to one if the $\mathrm{i}^{\text {th }}$ individual is employed, and $\mathrm{O}_{\mathrm{i}}$ is equal to one if the $\mathrm{i}^{\text {th }}$ individual is obese. $\mathrm{I}_{\mathrm{i}}$ is household income for the $\mathrm{i}^{\text {th }}$ individual. The variables that represent socioeconomic factors (SF), behavioral factors (BF), and environmental factors (EF) are specified for each individual.

$$
D_{j i}=f\left(E_{i}, O_{i}, I_{i}, S F_{i}, E F_{i}, B F_{i}\right) .
$$

The marginal effect of the estimated equation can be expressed as:

$$
\mathrm{D}_{\mathrm{ji}}=\alpha_{0}+\alpha_{1} \mathrm{E}_{\mathrm{i}}+\alpha_{2} \mathrm{I}_{\mathrm{i}}+\alpha_{3} \mathrm{O}_{\mathrm{i}}+\sum \psi \mathrm{SF}_{\mathrm{i}}+\sum \delta \mathrm{EF}_{\mathrm{i}}+\sum \omega \mathrm{BF} \mathrm{F}_{\mathrm{i}}
$$

where $\alpha_{0}$ indicates the intercept of the equation, $\alpha_{1}, \alpha_{2}$, and $\alpha_{3}$ are coefficient estimations of $E_{i}$, $\mathrm{O}_{\mathrm{i}}$, and $\mathrm{I}_{\mathrm{i}}$. The summations of the coefficients of SF, EF and BF are indicated by $\psi, \delta$, and $\omega$.

To obtain the total economic cost $\left(\mathrm{TEC}_{\mathrm{j}}\right)$ in the Appalachian region of obesity related to a particular disease, the total expenditures on healthcare for disease $\mathrm{j}\left(\mathrm{THE}_{\mathrm{j}}\right)$ in the Appalachian counties, can be multiplied by the coefficient of $\mathrm{O}_{i}$ which is $\alpha_{3}$ from the marginal effects of the logit equation for that disease.

$$
\mathrm{TEC}_{\mathrm{j}}=\mathrm{THE}_{\mathrm{j}} \times \alpha_{3}
$$

Adding the estimated total economic cost of each disease would give the total economic cost of all six diseases linked to obesity in the Appalachian region. However, the resulting total economic cost would not account for any loss in productivity due to absenteeism or the loss to an individual over his/her lifetime of lost income.

3.3.3 Objective 3. Measure reductions in healthcare costs associated with reductions in obesity.

The estimated total economic cost in objective 2 can be used in measuring potential reduction possibilities of economic cost (RTEC) associated with obesity-related diseases in the Appalachian region. As the total economic cost estimate in objective 2 is under the prevailing obesity level in the Appalachian region, potential reductions can be measured by reducing the obesity rate to the national obesity rate, federal targeted obesity rate and obesity rate of 
Colorado, which is the state with the lowest obesity rate in the United States. If the obesity level is decreased to "Y" percent of the region's population from its current level, it would reduce healthcare costs related to the $\mathrm{j}^{\text {th }}$ disease as:

$$
\mathrm{RTEC}_{\mathrm{j}}=\left\{\left(\mathrm{THE}_{\mathrm{j}} \times \alpha_{3}\right) / \mathrm{COB}\right\} \times \mathrm{Y} .
$$

where $\mathrm{THE}_{\mathrm{j}}$ and $\alpha_{3}$ are as defined previously; COB is the current obesity level of the population. Subtracting these lower costs from the total economic costs estimated in objective 2 (equation 23) would provide an estimate of some of the gains to the Appalachia region that would be possible from reducing obesity and obesity-related diseases.

3.3.4 Objective 4. Examine the use of reduced calorie intake and increased exercise for reducing obesity of individuals.

To accomplish objective four, assume that obesity is a function of an individual's energy balance, which is the difference between calorie intake and energy expenditure for a particular time period. The context of considering obesity as a byproduct of other targets of Becker's (1965) household production theory of consumer behavior supplies a framework for examining the issues of calorie intake and calorie expenditure. Also, it recognizes a rational consumer that uses goods and services purchased in the market, together with his/her own time to produce more commodities that enter his/her utility function. Thus, consider health status as one of these commodities, which depends partly on diet and physical activities. To decrease weight an individual will reduce calorie consumption and/or will engage in physical activities. Because of the interdependence of caloric intake, physical activity, and obesity, a system of three simultaneous equations are used. A 3SLS analysis for the system of equations is conducted based on individual level data of the region. The first dependent variable, $\mathrm{CIT}_{\mathrm{i}}$, reflects the decision of individual $\mathrm{i}$ to reduce his/her caloric intake. When $\mathrm{CIT}_{\mathrm{j}}$ equals 1 that individual has decided to 
reduce calorie intake. The second equation, $\mathrm{PA}_{\mathrm{i}}$, represents the number of minutes engaged in physical activities by individual $\mathrm{i}$. The third dependent variable, $\mathrm{BMI}_{\mathrm{i}}$, is the current value of the body mass index of individual i.

$$
\begin{aligned}
& C I T_{i}=f\left(B M I_{i}, P A_{i}, D_{j i}, S F_{i}, E F_{i}, B F_{i}\right) \\
& \mathrm{PA}_{i}=g\left(B M I_{i}, C I T_{i}, D_{j i}, S_{i}, E_{i}, B F_{i}\right) \\
& \mathrm{BMI}_{i}=h\left(C_{1}, P_{i}, D_{j i}, S_{i}, E_{i}, B F_{i}\right),
\end{aligned}
$$

where $\mathrm{D}_{\mathrm{ji}}, \mathrm{SF}_{\mathrm{i}}, \mathrm{EF}_{\mathrm{i}}, \mathrm{BF}_{\mathrm{i}}$ are as defined previously. The equations to be estimated can be expressed as:

$$
\begin{aligned}
& \mathrm{CIT}_{\mathrm{i}}=\alpha_{0 \mathrm{CIT}}+\alpha_{1 \mathrm{CIT}} \mathrm{BMI}_{\mathrm{i}}+\alpha_{2 \mathrm{CIT}} \mathrm{PA}_{\mathrm{i}}+\alpha_{3 \mathrm{C}} \mathrm{D}_{\mathrm{ji}}+\sum \psi \mathrm{SF}_{\mathrm{i}}+\sum \delta \mathrm{EF}_{\mathrm{i}}+\sum \omega \mathrm{BF}_{\mathrm{i}} \\
& \mathrm{PA}_{\mathrm{i}}=\alpha_{0 \mathrm{PA}}+\alpha_{1 \mathrm{PA}} \mathrm{BMI}_{\mathrm{i}}+\alpha_{2 \mathrm{PA}} \mathrm{CIT}_{\mathrm{i}}+\alpha_{3 \mathrm{PA}} \mathrm{D}_{\mathrm{ji}}+\sum \psi \mathrm{SF}_{\mathrm{i}}+\sum \delta \mathrm{EF}_{\mathrm{i}}+\sum \omega \mathrm{BF} \mathrm{F}_{\mathrm{i}} \\
& \mathrm{BMI}_{\mathrm{i}}=\alpha_{0 \mathrm{BMIO}}+\alpha_{1 \mathrm{BMI}} \mathrm{CIT}_{\mathrm{i}}+\alpha_{2 \mathrm{BMI}} \mathrm{PA}_{\mathrm{i}}+\alpha_{3 \mathrm{BMI}} \mathrm{D}_{\mathrm{ji}}+\sum \psi \mathrm{SF}_{\mathrm{i}}+\sum \delta \mathrm{EF}_{\mathrm{i}}+\sum \omega \mathrm{BF}_{\mathrm{i}}
\end{aligned}
$$

where $\mathrm{CIT}_{\mathrm{i}}$ is equal to one if individual $\mathrm{i}$ has decided to reduce calories and equal to zero otherwise; $\mathrm{PA}_{\mathrm{i}}$ is minutes of physical activity engaged in per week (it does not include physical activity related to work); and $\mathrm{BMI}_{\mathrm{i}}$ is the Body Mass Index of individual $\mathrm{i}$.

\subsubsection{Objective 5. Propose health-related policies for regional development.}

The research findings are expected to show negative impacts of obesity-related diseases on quality of life and healthcare expenditures. However, the magnitudes of such impacts depend on the levels of obesity-related diseases, socioeconomic factors, behavioral factors, and other environmental and geographical factors of the region. Reduction of obesity would result in a decrease in the cost of healthcare and as a result may improve labor productivity. Finally, reducing obesity could improve the standard of living in the region. Accurate information pertaining to the magnitude of the impacts along with associated costs of reduction of obesityrelated diseases would contribute to establishing more efficient public health policies. 
Overall, the first objective of the study is to examine the major factors affecting obesity in Appalachia and the major obesity-related diseases, along with their interactions with income and employment. This should provide some insight into the interactions of these health conditions with economic conditions in Appalachia. The second objective is to reveal the impact the major obesity-related diseases have on healthcare expenditures in the Appalachia region. An estimate of the healthcare cost savings that could occur by reducing obesity-related diseases to be more in line with national rates of obesity or rates in healthier states would result from the third objective. The fourth objective reveals the potential of engaging in physical activity and lowering calories for weight control. The final objective suggests health-related policies for the Appalachian region. Figure 3.1 shows all objectives in a flow chart. 


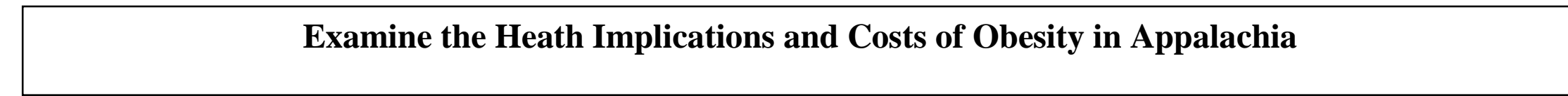

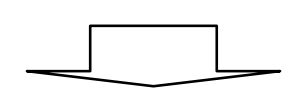

\section{Objective 1}

Examine the impacts of obesity on public health in the

Appalachian region

(county level data)

1. Asthma

2. Arthritis

3. Diabetes

4. Heart disease

5. Hypertension

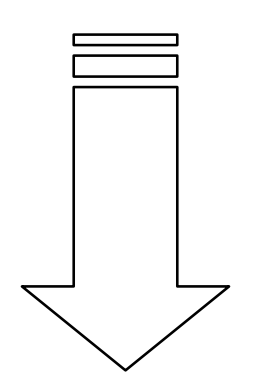

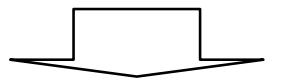

\section{Objective 2}

Estimate the costs of major diseases linked to obesity

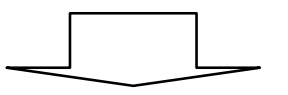

$\begin{aligned} & \text { Logit Analyses } \\ & \text { (individual level } \\ & \text { data) }\end{aligned}$
1. Asthma
2. Arthritis
3. Cancer
4. Diabetes
5. Heart disease
6. Hypertension

\section{Total}

Healthcare

Expenditure

1. Asthma

2. Arthritis

3. Cancer

4. Diabetes

5. Heart disease

6. Hypertension

Total Economic Cost of each obesityrelated disease

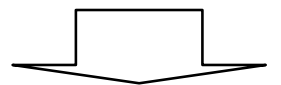

\section{Objective 4}

Examine the use of lower calorie intake and increased exercise for reducing obesity of individuals.

(individual level data)

Objective 5. Propose health-related policies for regional development

Figure 3.1 Flow chart of obejectives and analyses 


\subsection{Estimation methods}

Three-stage least squares (3SLS) estimations are used to solve the simultaneous equations in objectives one and four, while logit estimations are used for objectives two and three.

A system of equations estimates all the identified structural equations together as a set. The most important advantage of this method is to have a small asymptotic variance. Three-stage least squares is consistent and generally more efficient than a two-stage least squares (2SLS) estimator. According to Zellener and Thiel (1962), 3SLS "has full information characteristics to the extent that, if the moment matrix of the structural disturbances is not diagonal, the estimation of the coefficients of any identifiable equations gain in efficiency as soon as there are other equations that are over-identified." The method can take account of restrictions on parameters in different structural equations (Zellner and Theil, 1962). Also, if the disturbances in the different structural equations are uncorrelated, so that the contemporaneous variance-covariance matrix of the disturbances of the structural equations is diagonal, 3SLS reduces to 2SLS.

In the logit model the dependent variable is the log odds ratio, which is a linear function of the independent variables or regressors. The marginal effects of the logit estimation provide the unit change of the value of a regressor, with the effect of all other variables held constant (Gujarati, 2003). For all analyses STATA statistical software is used.

\subsection{Data collection}

This study concentrates on adult obesity in the Appalachian region and uses the most recently available data from 2001 to 2009. In achieving objective 1, county level data from both 2001 and 2009 are used. For objectives 2, 3, and 4 only 2009 data are used. For objectives 2 and 4 individual level data is used. Data relevant to the Appalachian region are mainly compiled 
from the Behavioral Risk Factor Surveillance System (BRFSS) years 2001 and 2009 and represent adult (more than 18 years) behavioral factors related to health. BRFSS data were collected from a stratified random sample through computer-assisted telephone interviewing by state health departments with the collaboration of the Center for Disease Control and Prevention (CDC). All data collected from BRFSS are at an individual level for adults 18 years of age and older.

Data for individuals on income, obesity (BMI), presence of diseases, socioeconomic factors (age, gender, race, marital status, education, health insurance), and behavioral factors (smoking, alcohol consumption, engage in physical activities, reduce calorie intake, get adequate sleep) are collected from BRFSS (CDC, 2001; CDC, 2009). Data for county level employment, income, number of adults, and population, are collected from Bureau of Economic Analysis (BEA, 2009). Total healthcare expenditures on each disease linked to obesity in the Appalachian region are calculated based on CDC reports (CDC, 2011), Yelin et al. estimations (Yelin et al., 2007), and estimations for chronic diseases of the Milken Institute (2007). In addition, the U.S. Census Reports (2000 and 2010) and National Health and Nutritional Examination Survey [NHANES] (2009) are also referred. Descriptions of the variables used in the analysis are listed in Table 3.1 and Table 3.2. 
Table 3.1 Definitions of variables used for county level analyses for objective 1

\begin{tabular}{|c|c|}
\hline Variable & Definition \\
\hline Income (INC) & County average household income (2001 and 2009) \\
\hline Employment (EMP) & Total number employed in the county 18 and older (2001 and 2009) \\
\hline Obesity (OBE) & $\begin{array}{l}\text { Percentage of individuals in the county } 18 \text { and older who have BMI } \\
\text { equal to } 30 \text { or above (2001 and 2009) }\end{array}$ \\
\hline Disease $_{j}$ & $\begin{array}{l}\text { Percentage of individuals in the county } 18 \text { and older having } \mathrm{j}^{\text {th }} \text { disease } \\
\text { (2001 and 2009) j goes from } 1 \text { to } 5 \text { for asthma (ASM), heart disease } \\
\text { (HRT), hypertension (HYP), diabetes (DIAB), arthritis(ARTH) }\end{array}$ \\
\hline INCC & $\begin{array}{l}\text { Change in county-level average household income between } 2001 \text { and } \\
2009\end{array}$ \\
\hline EMPC & Change in county employment rate between 2001 and 2009 \\
\hline OBEC & Change in county obesity rate between 2001 and 2009 \\
\hline DiseaseC $_{\mathrm{j}}$ & Change in county-level rate of $\mathrm{j}^{\text {th }}$ disease between 2001 and 2009 \\
\hline \multicolumn{2}{|c|}{ Socioeconomic factors (SF) for 2009} \\
\hline AGE & County level average age of population 18 and older \\
\hline EDU & $\begin{array}{l}\text { Percentage of county population } 18 \text { and older that has had some college, } \\
\text { completed a college degree or has a professional or graduate degree }\end{array}$ \\
\hline MALE & Percentage of males in the county \\
\hline MARRIED & Percentage of county population that was married \\
\hline POP & County population \\
\hline \multicolumn{2}{|c|}{ Behavioral factors $(B F)$ for 2009} \\
\hline SMOKE & Percentage of county's adult population 18 and older that smokes \\
\hline DRINK & $\begin{array}{l}\text { Percentage of county's adult population } 18 \text { and older that currently } \\
\text { consumes alcohol }\end{array}$ \\
\hline SLEEP & $\begin{array}{l}\text { County level average number of sleepless days for the previous month } \\
\text { for those } 18 \text { and older }\end{array}$ \\
\hline EXERCISE & $\begin{array}{l}\text { County average time engaged in physical activity per week for } \\
\text { population } 18 \text { and older }\end{array}$ \\
\hline GOODHLTH & $\begin{array}{l}\text { Percentage of county population } 18 \text { and older that report having good } \\
\text { health }\end{array}$ \\
\hline HLTHCRPLN & $\begin{array}{l}\text { Percentage of county population } 18 \text { and older that reported having any } \\
\text { kind of health coverage, including health insurance, prepaid plans or } \\
\text { government plans such as Medicare }\end{array}$ \\
\hline \multicolumn{2}{|c|}{ Environmental Factors (EF) for 2009} \\
\hline NORTH & $\begin{array}{l}\text { Equal to one if northern region of Appalachia; Equal to zero if southern } \\
\text { region of Appalachia }\end{array}$ \\
\hline RECREATION & $\begin{array}{l}\text { County average access rate to both indoor and outdoor recreational } \\
\text { facilities per } 100,000 \text { county population }\end{array}$ \\
\hline HLTHCRFAC & $\begin{array}{l}\text { County average access rate to healthcare facilities per } 100,000 \text { county } \\
\text { population in } 2009\end{array}$ \\
\hline
\end{tabular}


All the socioeconomic, behavioral and environmental variables used for the analyses of objectives 2 to 4 are shown in Table 3.2. All data are for 2009 .

Table 3.2 Definitions of variables used in individual level analyses for objectives 2, 3 and 4

\begin{tabular}{|c|c|}
\hline Variable & Definition \\
\hline Disease $_{\mathrm{ij}}$ & $\begin{array}{l}\text { Equal to one if individual } \mathrm{i} \text { has disease } \mathrm{j} \text { ( } \mathrm{j} \text { goes from } 1 \text { to } 6 \text { for } \\
\text { asthma, heart disease, hypertension, diabetes, arthritis, and } \\
\text { cancer }\end{array}$ \\
\hline Obesity $_{\mathrm{i}}$ & Equal to one if individual i's BMI is more than 29.9 \\
\hline Age & Number of years \\
\hline Marital status (MARRIED) & Equal to one if married, zero otherwise \\
\hline Education level (EDU) & $\begin{array}{l}\text { Equal to one if the individual has had some college, completed a } \\
\text { college degree or has a professional or graduate degree, zero if } \\
\text { the individual has a high school degree or less }\end{array}$ \\
\hline Employment status $_{\mathrm{i}}(\mathrm{EMP})$ & Equal to one if individual $\mathrm{i}$ is currently employed \\
\hline Income $_{i}(\mathrm{INC})$ & Household income of $\mathrm{i}^{\text {th }}$ individual (dollars) \\
\hline Gender & Equal to one if male, zero if female \\
\hline Race & Equal to one if white, zero otherwise \\
\hline Sleep & Number of sleepless days per month \\
\hline Exercise & $\begin{array}{l}\text { Number of minutes individual engaged in physical activities for } \\
\text { the previous week }\end{array}$ \\
\hline Smokes & Equal to one if individual smokes; zero otherwise \\
\hline Drinks & Equal to one if consumes alcohol currently; zero otherwise \\
\hline $\mathrm{BMI}_{\mathrm{i}}$ & Body Mass Index of the $\mathrm{i}^{\text {th }}$ individual \\
\hline REDUCE $_{\mathrm{i}}$ & Equal to one if individual $i$ is reducing caloric intake (2009) \\
\hline NMBRADULT & Number of adults in household \\
\hline NMBRKIDS & Number of children in household \\
\hline ANYDISEASE & 1 if individual has any of 6 obesity-related diseases; 0 otherwise \\
\hline DRADVICE & $\begin{array}{l}1 \text { if gets advice from doctor or any other health professional; } 0 \\
\text { otherwise }\end{array}$ \\
\hline HLTHCRFAC & Access to healthcare facilities (per 100,000 county population) \\
\hline RECREATION & $\begin{array}{l}\text { Access to recreation facilities (number of facilities per 100,000 } \\
\text { county population) }\end{array}$ \\
\hline NORTH & $\begin{array}{l}\text { Equal to one if northern region of Appalachia; Equal to zero if } \\
\text { southern region of Appalachia }\end{array}$ \\
\hline
\end{tabular}




\section{CHAPTER 4}

\section{EMPIRICAL RESULTS AND ANALYSIS}

This chapter concentrates on estimation of the empirical models for each specific objective to determine the health implications and costs of adult obesity in Appalachia. Results and estimations for each objective are discussed in five different sections.

Section 1 presents analyses and results for objective 1 which estimates the impacts of obesity on public health at a county level. Section 2 presents results for objective 2 which estimates costs of obesity-related diseases: asthma, arthritis, cancer, diabetes, heart disease and hypertension. This section has 3 sub-sections: logit analyses for the obesity-related diseases, healthcare cost calculations for the obesity-related diseases and calculation of total economic cost for these diseases. Section 3 presents results for objective 3 that estimates reduction in economic costs associated with reductions in obesity. Section 4 describes objective 4 which addresses the potential behavioral methods for reducing obesity, and section 5 presents policy suggestions (objective 5).

\section{Section 1}

\subsection{Objective 1. Determining the impacts of obesity on public health in the Appalachian} region

In achieving objective 1, data for year 2001 and 2009 are used. All data are averaged at the county level for analysis. For missing data for counties not surveyed by BRFSS in 2001 and 2009, average values are used based on county profile information from the U.S. Census Bureau. Six obesity-related diseases are initially considered for analyses but estimations for cancer were dropped due to inadequate data for 2001. 
All endogenous variables of employment, income, obesity, diabetes, asthma, arthritis, heart disease and hypertension are formulated as changes from 2001 to 2009. Thus, employment change (EMPC), income change (INCC), obesity change (OBEC), asthma change (ASMC), arthritis change (ARTHC), diabetes change (DIABC), heart disease change (HRTC), and hypertension change (HYPC) are used for analyses. Initial values of 2001: employment (EMP01), income (INC01), obesity (OBE01), diabetes (DIAB01), asthma (ASM01), arthritis (ARTH01), heart disease (HRT01) and hypertension (HYP01) are also used. County average age of adults in 2009 (AGE), percentage of county population with education up to college, completed a college degree or has a professional or graduate degree in 2009 (EDU), percentage of county population that was married in 2009 (MARRIED), and percentage of county that were males in 2009 (MALE) are the other socioeconomic variables used.

Among behavioral factors, average number of sleepless days in the previous month in 2009 for adults in the county (SLEEP), 2009 percentage of a county's population that smokes (SMOKE), percentage of a county's population that 'drinks alcohol' in 2009 (DRINK), percentage of county population that reported having any kind of health coverage, including health insurance, prepaid plans or government plans such as Medicare in 2009 (HLTHCRPLN), and county average total minutes of exercise per week (EXERCISE) are included in the analyses. The percentage of those in good health (GOODHLTH) was calculated based on individuals' response of 'excellent,' 'very good' and 'good' for health. Those who responded 'fair' or 'poor' were not considered to be in good health.

Considering environmental factors, county average access rate to healthcare facilities per 100,000 population in 2009 (HLTHCRFAC) and county average access rate to recreation facilities per 100,000 population in 2009 (RECREATION) are used for analyses. A dummy 
variable (NORTH) is equal to one to show the difference between northern Appalachia and southern Appalachia (equal to zero).

\subsubsection{Descriptive Analysis}

Descriptions of variables used for estimation are presented in Tables 4.1, 4.2 and 4.3. As seen in Table 4.1 and Table 4.2, nearly 24 percent of individuals in Appalachia were obese in 2001 and that increased to 31 percent by 2009. Average annual household income for the Appalachian region has increased from $\$ 26,616$ in 2001 to $\$ 37,450$ in 2009 . Number of individuals employed declined slightly over those years and obesity-related diseases increased. Average age of Appalachian adults was 55, and, on average, only 37 percent were male (2009). Nearly 44 percent of Appalachia's population has had some college, completed a college degree or has a professional or graduate degree.

Table 4.1 County-level descriptive statistics of variables for all Appalachian counties, 2001

\begin{tabular}{|c|c|c|c|c|c|}
\hline Variable & Description & Mean & Std. Dev. & Min & Max \\
\hline $\mathrm{INC} 01$ & Average annual household income & $\$ 26,616$ & $\$ 5,617$ & $\$ 13,947$ & $\$ 60,913$ \\
\hline EMP01 & $\begin{array}{l}\text { Number of adults } 18 \text { and older who } \\
\text { were employed }\end{array}$ & 26,481 & 45,891 & 1,050 & 616,088 \\
\hline OBE01 & $\begin{array}{l}\text { Percentage of obese adults } 18 \text { and } \\
\text { older }\end{array}$ & 23.7 & 3.5 & 9.8 & 37.5 \\
\hline ASM01 & $\begin{array}{l}\text { Percentage of adults } 18 \text { and older } \\
\text { with asthma }\end{array}$ & 10.8 & 2.5 & 2.4 & 23.9 \\
\hline DIAB01 & $\begin{array}{l}\text { Percentage of adults } 18 \text { and older } \\
\text { with diabetes }\end{array}$ & 8.1 & 4.6 & 1.2 & 67.1 \\
\hline HYP01 & $\begin{array}{l}\text { Percentage of adults } 18 \text { and older } \\
\text { with hypertension }\end{array}$ & 29.7 & 4.6 & 12.8 & 52.5 \\
\hline ARTH01 & $\begin{array}{l}\text { Percentage of adults } 18 \text { and older } \\
\text { with arthritis }\end{array}$ & 28.1 & 5.4 & 15.9 & 61.4 \\
\hline HRT01 & $\begin{array}{l}\text { Percentage of adults } 18 \text { and older } \\
\text { with heart disease }\end{array}$ & 7.1 & 7.8 & 1.1 & 52.8 \\
\hline
\end{tabular}

As seen in Table 4.2, the average smoking rate across all Appalachian counties is 25 percent, while 31 percent consume alcohol. Nearly 72 percent believe they have 'good health' 
while 86 percent report that they have some sort of 'a healthcare plan'. Access to healthcare facilities (HLTHCRFAC) is 52 facilities per 100,000 population, while there are only 7 recreational facilities per 100,000 (RECREATION).

Table 4.2 County-level descriptive statistics of variables for all Appalachian counties, 2009

\begin{tabular}{|c|c|c|c|c|c|}
\hline Variable & Description & Mean & Std. Dev. & Min & Max \\
\hline INC09 & $\begin{array}{l}\text { Average annual household } \\
\text { income }\end{array}$ & $\begin{array}{r}\$ 37,46 \\
0\end{array}$ & $\$ 7,849$ & $\$ 21,177$ & $\$ 84,567$ \\
\hline EMP09 & $\begin{array}{l}\text { Number of adults } 18 \text { and older } \\
\text { who were employed }\end{array}$ & 26,091 & 45,176 & 995 & 584,369 \\
\hline OBE09 & $\begin{array}{l}\text { Percentage of obese adults } 18 \\
\text { and older }\end{array}$ & 30.8 & 5.4 & 12.5 & 58.8 \\
\hline ASM09 & $\begin{array}{l}\text { Percentage of adults } 18 \text { and } \\
\text { older with asthma }\end{array}$ & 13.4 & 57.8 & 1.8 & 44.4 \\
\hline DIAB09 & $\begin{array}{l}\text { Percentage of adults } 18 \text { and } \\
\text { older with diabetes }\end{array}$ & 15.5 & 6.5 & 3.0 & 54.5 \\
\hline HYP09 & $\begin{array}{l}\text { Percentage of adults } 18 \text { and } \\
\text { older with hypertension }\end{array}$ & 42.1 & 9.5 & 14.3 & 72.7 \\
\hline ARTH09 & $\begin{array}{l}\text { Percentage of adults } 18 \text { and } \\
\text { older with arthritis }\end{array}$ & 39.5 & 9.9 & 10.0 & 70.6 \\
\hline HRT09 & $\begin{array}{l}\text { Percentage of adults } 18 \text { and } \\
\text { older with heart disease }\end{array}$ & 8.6 & 4.4 & 0.7 & 40.0 \\
\hline POP & County population & 59,399 & 96,730 & 2,237 & $1,218,494$ \\
\hline AGE & $\begin{array}{l}\text { Average age of adults } 18 \text { and } \\
\text { older }\end{array}$ & 54.9 & 4.5 & 33.5 & 66.1 \\
\hline MARRIED & $\begin{array}{l}\text { Percentage of population that } \\
\text { was married }\end{array}$ & 56.0 & 10.0 & 19.2 & 87.5 \\
\hline EDU & $\begin{array}{l}\text { Percentage of population that } \\
\text { has had some college, completed } \\
\text { a college degree or has a } \\
\text { professional or graduate degree }\end{array}$ & 44.2 & 12.3 & 9.0 & 76.5 \\
\hline MALE & Percentage of males & 36.8 & 8.7 & 11.53 & 74.3 \\
\hline
\end{tabular}


Table 4.3 County-level descriptive statistics for behavioral and environmental variables for all Appalachian counties, 2009

\begin{tabular}{|c|c|c|c|c|c|}
\hline Variable & Description & Mean & Std. Dev. & Min & Max \\
\hline SMOKE & $\begin{array}{l}\text { Percentage of county's } \\
\text { population } 18 \text { and older who } \\
\text { smoke }\end{array}$ & 24.0 & 9.2 & 6.7 & 70.0 \\
\hline DRINK & $\begin{array}{l}\text { Percentage of county's } \\
\text { population } 18 \text { and older who } \\
\text { consume alcohol }\end{array}$ & 30.7 & 16.6 & 1.7 & 87.8 \\
\hline SLEEP & $\begin{array}{l}\text { Average number of sleepless } \\
\text { days of an adult } 18 \text { and older }\end{array}$ & 8.5 & 2.4 & 0.5 & 17.0 \\
\hline GOODHLTH & $\begin{array}{l}\text { Percentage of county's } \\
\text { population } 18 \text { and older that } \\
\text { reported having good health }\end{array}$ & 71.6 & 12.6 & 21.2 & 100.0 \\
\hline HLTHCRPLN & $\begin{array}{l}\text { Percentage of county's } \\
\text { population } 18 \text { and older that } \\
\text { reported having a healthcare } \\
\text { plan }\end{array}$ & 85.6 & 7.7 & 50.0 & 100.0 \\
\hline EXERCISE & $\begin{array}{l}\text { Average total minutes of } \\
\text { exercise per week by an adult } 18 \\
\text { and older }\end{array}$ & 368.8 & 157.3 & 70.0 & $1,101.4$ \\
\hline NORTH & $\begin{array}{l}1 \text { if county is in northern } \\
\text { regions of Appalachia; } 0 \\
\text { otherwise }\end{array}$ & 35.5 & 47.9 & 0 & 1.0 \\
\hline HLTHCRFAC & $\begin{array}{l}\text { Access to healthcare facilities } \\
\text { (per } 100,000 \text { population) }\end{array}$ & 52.0 & 24.1 & 0 & 100.0 \\
\hline RECREATION & $\begin{array}{l}\text { Access to recreation facilities } \\
\text { (per } 100,000 \text { population) }\end{array}$ & 6.5 & 4.9 & 0 & 29.0 \\
\hline
\end{tabular}

4.1.2 Determining the impacts of obesity on asthma in the Appalachian region

To measure the links between obesity and asthma from 2001 to 2009 a system of simultaneous equations with four endogenous variables is used. The variables used and results of the analysis are presented in Table 4.1.2. The results of these estimates are based on county level data. The first column of the table shows the exogenous variables used in each equation. Columns 2 and 3 indicate results for the income change (INCC) equation while columns 4 and 5 present results for employment change (EMPC). Results for the obesity change (OBEC) equation 
are shown in columns 6 and 7 and results for the asthma change (ASMC) equation are presented in columns 8 and 9 .

The estimated results in columns 2 and 3 show that income change (INCC) is significantly and positively related to employment change (EMPC), which means that increases in employment are associated with increases in income in Appalachian counties. The significant and positive relationship between income change (INCC) and asthma change (ASMC) indicates that average annual household income increased with an increasing number of adults with asthma. This indicates that asthma rates went up over these years and so did income levels; a reflection of what happened in the county over that time period. Estimation results for income in 2001 (INC01) and employment in 2001 (EMP01) also are significant but the impacts are minimal. Age is significantly and positively related to income change (INCC); when age increases by 1 year, income increases by 0.4 percent. This is not surprising as income increases as individuals advance in their careers as they age.

Results for the employment change (EMPC) equation do not show significant relationships with any of the endogenous variables (ASMC, INCC, and OBEC). The significant and positive relationship between education (EDU) and employment change (EMPC) indicates that a 1 percent increase in the percentage of adults with a college education or better is associated with an increase in employment growth of 0.2 percent. This is due to more employment opportunities with higher levels of education.

Empirical results for the obesity change equation (OBEC) indicate that increases in income (INCC) are positively related with increases in obesity. Thus, a one percent increase in a county's average income level, is associated with an increase in county obesity rates of 1.74 percent. Generally, higher income at the individual level is associated with lower obesity or BMI 
(Loureiro, et al., 2006; Chou et al., 2004). The counterintuitive result found here is supported by Ewing et al. (2003), Loureiro and Nayga (2004), and Rosin (2008) who found that weight gain increased with urbanization and development and related increases in income. Also, the initial level of income in 2001 (INC01) shows a positive relationship with obesity change (OBEC). The initial level of obesity (OBE01) has a significant and negative relationship with obesity change (OBEC). This means that counties with higher initial rates of obesity had smaller increases in obesity than those with lower initial rates. The significant and negative relationship between the percentage of a county's population that drinks alcohol (DRINK) and obesity change (OBEC) indicates that greater alcohol consumption reduces obese rates in the Appalachian region. This may be from lower consumption of high calorie foods associated with alcohol consumption as found by Wang et al. (2010).

The empirical results for asthma change (ASMC) in columns 8 and 9 show that the percentage of income change (INCC) and percentage of asthma change (ASMC) are significant and positively related. A one percent increase in income is associated with a 2.19 percent increase in asthma. This could mean that higher incomes have been accompanied by increases in air pollution in a county, leading to a greater asthma risk, or that higher paying jobs are ones that increase asthma risk, such as coal mining. The significant and negative relationship between employment change (EMPC) and asthma change (ASMC) indicates that increasing employment opportunities decrease the number of asthma patients. This could be due to improved access to healthcare because of gaining employment, or that more opportunities for employment mean that individuals can leave jobs that increase their risk of asthma. Initial income and employment levels were also positively and negatively associated with asthma change, respectively. The negative and significant relationship between age and asthma is consistent with previous studies 
by the CDC (various years) that show asthma rates are lower in elderly populations. Most importantly, asthma change (ASMC) is significantly and positively related to obesity change (OBEC). When obesity change increases by one percent, asthma change increases by 0.8 percent among Appalachian adults. County rate of adult obesity in 2001 (OBE01) also is positively related to changes in asthma. This result is supported by the findings of Akinbami (2006) that high obesity leads to high rates of asthma. Also, the CDC (2011) shows that the prevalence of asthma may limit physical activities which subsequently could increase risk of obesity. Initial asthma rates (ASM01) are significant and negatively associated with changes in asthma such that in counties with higher rates of asthma in 2001, asthma rates did not increase as much from 2001 to 2009 compared to counties with lower initial rates of asthma. 
Table 4.1.2 Results for system of equations including change in asthma (ASMC)

\begin{tabular}{|c|c|c|c|c|c|c|c|c|}
\hline \multirow{2}{*}{ Variable } & \multicolumn{2}{|c|}{ Income Change } & \multicolumn{2}{|c|}{ Employment Change } & \multicolumn{2}{|c|}{ Obesity Change } & \multicolumn{2}{|c|}{ Asthma Change } \\
\hline & Coefficient & $\mathrm{P}>|\mathrm{Z}|$ & Coefficient & $\mathrm{P}>|\mathrm{Z}|$ & Coefficient & $\mathrm{P}>|\mathrm{Z}|$ & Coefficient & $\mathrm{P}>|\mathrm{Z}|$ \\
\hline INCC & & & -0.02167 & 0.88 & $1.73820 * * *$ & 0.00 & $2.18745 * * *$ & 0.00 \\
\hline EMPC & $0.26256 *$ & 0.10 & & & 0.11903 & 0.76 & $-1.44794 * *$ & 0.03 \\
\hline OBEC & 0.05599 & 0.52 & -0.06054 & 0.41 & & & $0.85780 * *$ & 0.02 \\
\hline ASMC & $0.18311 * * *$ & 0.00 & 0.02039 & 0.76 & 0.11790 & 0.61 & & \\
\hline INC01 & $0.00001 * * *$ & 0.00 & 0.00001 & 0.96 & $0.00015 * *$ & 0.02 & $0.00001 *$ & 0.10 \\
\hline EMP01 & $0.00001 * * *$ & 0.00 & $-0.00001 * * *$ & 0.00 & -0.00010 & 0.38 & $-0.00010 * *$ & 0.02 \\
\hline OBE01 & -0.01697 & 0.96 & -0.44309 & 0.13 & $-3.29903 * * *$ & 0.00 & $3.40222 * *$ & 0.02 \\
\hline ASM01 & $2.31533 * * *$ & 0.00 & 0.41517 & 0.46 & -1.17359 & 0.60 & $-9.04159 * * *$ & 0.00 \\
\hline AGE & $0.00443 * * *$ & 0.00 & & & 0.00417 & 0.24 & $-0.02129 * * *$ & 0.00 \\
\hline EDU & 0.00001 & 0.81 & $0.00187 * * *$ & 0.00 & & & & \\
\hline MALE & 0.00001 & 0.98 & & & & & & \\
\hline EXERCISE & & & & & & & 0.00010 & 0.91 \\
\hline GOODHLTH & & & & & -0.00031 & 0.84 & & \\
\hline POP & & & $0.00001 * * *$ & 0.00 & & & & \\
\hline HLTHCRPLN & & & -0.00060 & 0.49 & & & & \\
\hline SLEEP & & & & & 0.00717 & 0.46 & & \\
\hline SMOKE & & & & & 0.00001 & 0.99 & 0.00046 & 0.84 \\
\hline DRINK & & & & & $0.00470 * * *$ & 0.00 & 0.00429 & 0.12 \\
\hline NORTH & & & -0.01900 & 0.20 & & & & \\
\hline
\end{tabular}

Number of observations $=420$.

$\mathrm{R}^{2}$ values: $\mathrm{INCC}=0.79 ; \mathrm{EMPC}=0.20 ; \mathrm{OBEC}=0.11 ; \mathrm{ASMC}=0.29$.

$\mathrm{Chi}^{2}$ values: $\mathrm{INCC}=1755.38 ; \mathrm{EMPC}=113.98 ;$ OBEC $=204.79 ; \mathrm{ASMC}=80.61$.

$* * *, * *, *$ are significant at $1 \%, 5 \%$ and $10 \%$ respectively. 


\subsubsection{Determining the impacts of obesity on arthritis in the Appalachian region}

In analyzing the links of obesity with arthritis, a system of simultaneous equations was used. The variables and results of the analysis are presented in Table 4.1.3. The first column of the table shows exogenous variables used in each equation. Columns 2 and 3 indicate results for the income change (INCC) equation while columns 4 and 5 present results for employment change (EMPC). Results for the obesity change (OBEC) equation are shown in columns 6 and 7 and results for the arthritis change (ARTHC) equation are presented in columns 8 and 9.

According to the empirical results, income change (INCC) is significantly and positively related to employment change (EMPC), obesity change (OBEC), the initial level of obesity in 2001 (OBE01), the percentage of males in a county (MALE) and the northern region of Appalachia (NORTH). When employment change increases by 1 percent, income change increases by 0.5 . This is because more employment opportunities can lead to higher income in a county. Obesity change (OBEC) is associated with an increase in income change (INCC) of 0.5 percent, from 2001 to 2009. This could mean that more income generating opportunities occurred, along with increasing obesity. The positive relationship between the percentage of males and income change is not surprising since males earn more on average than women and more males are employed compared to women. Income in 2001 is significant and negative but the coefficient is very small. Counties in the northern region of Appalachia had greater income growth than the southern part due to high economic growth and development in the north during this time (ARC, 2010).

The significant and negative relationship of obesity change (OBEC) and employment change indicates that a 1 percent increase in obesity growth in Appalachia is associated with a decrease in employment growth of 0.12 percent. This implies that decreasing obesity levels are 
important for economic development in Appalachia. Also, high obesity rates may reduce job opportunities as obesity reduces efficiency and work capacity of an individual. This is supported by Cawley and Danziger (2005) and Zagorsky (2004, 2005), who discovered weight-based discrimination for wages and employment. A significant and positive relationship between education (EDU) and employment change highlights the benefit of employment growth that could occur by improving educational opportunities in Appalachia. Both population in 2009 (POP) and initial employment level (EMP01) indicate significant results but impacts are very small.

The empirical results for obesity change (OBEC) indicate that increasing income growth (INCC) has a positive relationship with growth in obesity. Regression results for the obesity change equation (OBEC) indicate a negative relationship with arthritis change, such that arthritis decreases from 2001 to 2009 are associated with positive changes in obesity rates. This result is unexpected as those who suffer from arthritis face limitations on physical activity because of their disease, which can lead to increasing weight (Hendrick, 2010). Obesity rates tend to be higher among arthritis patients. The initial condition of obesity (OBE01) indicates that the counties that reported higher initial obesity rates, report less increase in obesity.

Employment change (EMPC) has a significant and positive relationship with arthritis change (ARTHC) in Appalachia; a one percent increases in employment change, increases arthritis rates by 2.7 percent. This might be due to changing jobs that now include less active tasks. This result is supported by findings that nearly 5 percent of adults suffering from arthritis face arthritis-attributable work limitations (MMWR, 2005). Age in 2009 (AGE) also has a positive relationship with arthritis change. This implies that counties with more elderly have higher percentages of their population with arthritis, as arthritis is commonly found among 
seniors and increases with age. The results show a negative relationship between arthritis change and obesity change in Appalachian counties, indicating that counties with higher arthritis rates have lower obesity rates. This is an unexpected result as arthritis patients are more at risk for being obese (CDC, various years). The initial condition of obesity (OBE01) shows a significant and negative relationship with arthritis change. This means that counties that reported higher percentages of obesity in their population in 2001, reported lower increases in arthritis. The initial income level (INC01) also is significant, but its impact is very small. 
Table 4.1.3 Results for system of equations including change in arthritis (ARTHC)

\begin{tabular}{|c|c|c|c|c|c|c|c|c|}
\hline \multirow{2}{*}{ Variable } & \multicolumn{2}{|c|}{ Income Change } & \multicolumn{2}{|c|}{ Employment Change } & \multicolumn{2}{|c|}{ Obesity Change } & \multicolumn{2}{|c|}{ Arthritis Change } \\
\hline & Coefficient & $\mathrm{P}>|\mathrm{Z}|$ & Coefficient & $\mathrm{P}>|\mathrm{Z}|$ & Coefficient & $\mathrm{P}>|\mathrm{Z}|$ & Coefficient & $\mathrm{P}>|\mathrm{Z}|$ \\
\hline INCC & & & 0.12380 & 0.23 & $0.94482 * *$ & 0.04 & 0.26087 & 0.86 \\
\hline EMPC & $0.45845^{* * *}$ & 0.01 & & & 0.35971 & 0.50 & $2.63966^{* *}$ & 0.05 \\
\hline OBEC & $0.47101 * * *$ & 0.00 & -0.11880 & 0.04 & & & $-3.26766 * * *$ & 0.00 \\
\hline ARTHC & 0.06177 & 0.15 & 0.00668 & 0.71 & $-0.2329 * *$ & 0.02 & & \\
\hline INC01 & $-0.00001 * * *$ & 0.00 & 0.00018 & 0.68 & -0.00001 & 0.81 & $-0.00032 *$ & 0.10 \\
\hline EMP01 & 0.00001 & 0.19 & $-0.00001 * * *$ & 0.00 & 0.00001 & 0.79 & 0.00010 & 0.13 \\
\hline OBE01 & $1.77784 * * *$ & 0.00 & $-0.76561 * * *$ & 0.00 & $-3.04716^{* * *}$ & 0.00 & $-9.81924 * * *$ & 0.00 \\
\hline ARTH01 & -0.10816 & 0.53 & 0.06040 & 0.64 & 0.54240 & 0.27 & 2.05632 & 0.17 \\
\hline AGE & -0.00084 & 0.79 & & & 0.00826 & 0.18 & $0.05222 * * *$ & 0.00 \\
\hline EDU & 0.00028 & 0.66 & $0.00110 * *$ & 0.03 & & & & \\
\hline MALE & $0.00182 * *$ & 0.04 & & & & & & \\
\hline MARRIED & & & 0.00116 & 0.13 & & & 0.00394 & 0.44 \\
\hline SLEEP & & & & & -0.00435 & & & \\
\hline POP & & & $0.00093 * * *$ & 0.00 & & 0.53 & & \\
\hline SLEEP & & & & & & & & \\
\hline GOODHLTH & & & -0.00032 & 0.57 & & & & \\
\hline SMOKE & & & & & 0.00050 & 0.76 & -0.00063 & 0.90 \\
\hline DRINK & & & & & 0.00025 & 0.91 & 0.00394 & 0.62 \\
\hline NORTH & $0.04200^{* * *}$ & 0.00 & & & & & & \\
\hline
\end{tabular}

Number of observations $=420$.

$\mathrm{R}^{2}$ values: $\mathrm{INCC}=0.68 ; \mathrm{EMPC}=0.12 ; \mathrm{OBEC}=0.25 ; \mathrm{ARTHC}=0.45$.

$\mathrm{Chi}^{2}$ values: $\mathrm{INCC}=2093.33 ; \mathrm{EMPC}=105.58 ; \mathrm{OBEC}=141.03 ; \mathrm{ARTHC}=62.91$.

$* * *, * *, *$ are significant at $1 \%, 5 \%$ and $10 \%$ respectively. 
4.1.4 Determining the impacts of obesity on diabetes in the Appalachian region

A system of four simultaneous equations was used to measure the links between obesity and diabetes in Appalachia. The variables used and the results are presented in Table 4.1.4. The first column of the table shows the exogenous variables used in each equation. Columns 2 and 3 indicate results for the income change (INCC) equation while columns 4 and 5 present results for employment change (EMPC). Results for the obesity change (OBEC) equation are shown in columns 6 and 7 and results for the diabetes change (DIABC) equation are presented in columns 8 and 9.

The empirical results show that income change (INCC) is significantly and positively related to employment change (EMPC) such that a one percent increase in employment increases income by 0.4 percent in Appalachian counties. Obesity change (OBEC) is significant and positively related to income change (INCC); when obesity change increases by one percent, income change increases by 0.2 percent. Age has a positive relationship with income change; a one year increase in age, increases income growth by 0.08 percent. Initial values of income (INC01) and employment (EMP01) show significant results but impacts are minimal.

Results for the employment change equation indicate that a one percent change in income growth increases employment growth by 0.33 percent. One reason for this could be that high income leads to more savings and investment which increases employment. Also, high income in a county may lead to improved educational facilities, healthcare facilities and other local amenities that increase the number of jobs. Results further indicate that growth in diabetes rates (DIABC) has a negative relationship with employment growth. The initial level of diabetes (DIAB01) also has a negative relationship with employment growth. Thus, an increasing percentage of diabetic patients decreases employment growth in Appalachia. The initial level of 
employment (EMP01) is significant and negative but the coefficient is small. Education (EDU) has a significant and positive relationship with employment growth, as expected. There is a significant and positive relationship between the percentage of a county's population that is married and employment growth.

The empirical results for the obesity change (OBEC) equation indicate that increasing income change (INCC) increases obesity change as in the previous analyses of asthma and arthritis. Results also show that income in 2001 (INC01) has a positive relationship with obesity change. The significant and negative relationship with the initial obesity rate and changing obesity rates is the same as found in the arthritis analysis.

The results for diabetes change (DIABC) show that income change (INCC) and diabetes change are significantly and negatively related. When income growth increases by 1 percent, growth in diabetes rates decreases by 1.1 percent. This may be due to greater attention to diabetes care with increasing county income. As expected, obesity increases are significantly and positively related with increases in diabetes; a 1 percent increase in obesity change, increases diabetes change by 0.8 percent. This result is supported by Gregg et al. (2005) who found a continuous increase of diabetes with increasing obesity in the United States. The negative impact of the initial income level indicates that when average county income was high in 2001, increases in the rates of diabetes were lower in those counties. 
Table 4.1.4 Results for system of equations including change in diabetes (DIABC)

\begin{tabular}{|c|c|c|c|c|c|c|c|c|}
\hline \multirow{2}{*}{ Variable } & \multicolumn{2}{|c|}{ Income Change } & \multicolumn{2}{|c|}{ Employment Change } & \multicolumn{2}{|c|}{ Obesity Change } & \multicolumn{2}{|c|}{ Diabetes Change } \\
\hline & Coefficient & $\mathrm{P}>|\mathrm{Z}|$ & Coefficient & $\mathrm{P}>|\mathrm{Z}|$ & Coefficient & $\mathrm{P}>|\mathrm{Z}|$ & Coefficient & $\mathrm{P}>\mid \mathrm{Z}$ \\
\hline INCC & & & $0.33449 * * *$ & 0.00 & $1.17347 * *$ & 0.04 & $-1.15299 * *$ & 0.02 \\
\hline EMPC & $0.41022 * * *$ & 0.00 & & & $0.00513 * *$ & 0.99 & 0.07031 & 0.88 \\
\hline OBEC & $0.19912 * * *$ & 0.00 & 0.02846 & 0.64 & & & $0.81553 * * *$ & 0.00 \\
\hline DIABC & -0.04215 & 0.43 & $-0.22660 * * *$ & 0.00 & 0.29984 & 0.58 & & \\
\hline INC01 & $-0.00001 * * *$ & 0.00 & -0.00010 & 0.37 & & & $-0.00001 *$ & 0.06 \\
\hline EMP01 & $0.00001 *$ & 0.06 & $-0.00001 * * *$ & 0.00 & 0.00010 & 0.47 & 0.00010 & 0.76 \\
\hline OBE01 & & & 0.08273 & 0.72 & $-1.89317 * * *$ & 0.00 & 1.29238 & 0.26 \\
\hline DIAB01 & -0.05195 & 0.88 & $-1.57932 * * *$ & 0.00 & 1.80850 & 0.60 & $-6.09294 * * *$ & 0.00 \\
\hline AGE & $0.00841 * * *$ & 0.00 & & & -0.00245 & 0.89 & 0.02592 & \\
\hline EDU & -0.00028 & 0.68 & $0.00098 * *$ & 0.06 & & & & \\
\hline MALE & 0.00045 & 0.52 & & & -0.00241 & 0.20 & & 0.71 \\
\hline POP & & & $0.00001 * * *$ & 0.00 & & & & \\
\hline MARRIED & & & $0.00241 * * *$ & 0.01 & & & & \\
\hline GOODHLTH & & & & & 0.00246 & 0.74 & & \\
\hline RECREATION & & & & & -0.00215 & 0.68 & & \\
\hline SMOKE & & & & & 0.00146 & 0.21 & -0.00035 & 0.83 \\
\hline DRINK & & & & & -0.00142 & 0.33 & -0.00193 & 0.36 \\
\hline NORTH & & & $-0.02657 * *$ & 0.05 & & & & \\
\hline
\end{tabular}

Number of observations $=420$.

$\mathrm{R}^{2}$ values: $\mathrm{INCC}=0.84 ; \mathrm{EMPC}=0.40 ; \mathrm{OBEC}=0.10 ; \mathrm{DIABC}=0.57$.

$\mathrm{Chi}^{2}$ values: $\mathrm{INCC}=2715.95 ; \mathrm{EMPC}=119.70 ;$ OBEC $=222.58 ;$ DIABC $=868.95$.

$* * *, * *, *$ are significant at $1 \%, 5 \%$ and $10 \%$ respectively. 
4.1.5 Determining the impacts of obesity on heart disease in the Appalachian region

In determining the impacts of obesity on heart disease, a system of simultaneous equations was again used. Table 4.1.5 shows the results. The first column shows the variables used for analysis. Columns 2 and 3 indicate results for the income change (INCC) equation while columns 4 and 5 show results for the employment change (EMPC) equation. The results for the obesity change (OBEC) equation are shown in columns 6 and 7. The last two columns in the table show results for the heart disease change (HRTC) equation.

The empirical results for income change show a significant and positive relationship between income change and employment change, same as for the previous three analyses. Both obesity change and heart disease change have significant and positive relationships with income change. When obesity change increases by one percent, income change increases by 0.25 percent. A one percent increase in growth in heart disease change, is associated with increases in income growth by a 0.18 percent. The initial obesity rates and heart disease rates also have positive relationships with income growth. Thus, counties with a high prevalence of heart disease in 2001 show higher income growth. As expected, education is significantly and positively related with income change. The positive relationship of a higher percentage of males in a county and income growth indicates that males contributed more to income growth in Appalachia from 2001 to 2009 than women.

Results for employment change show that changes in heart disease rates do not have a significant relationship with employment growth. Both the initial obesity rate and initial employment levels are significant and negative, such that when the percentage of obesity is initially (2001) low, employment growth is higher. This could be the result of more investment on economic development because the healthcare burden is perceived to be lower since there are 
fewer obese people. Counties where a higher percentage of the population is married have higher employment growth rates: a one percent increase in the married population increases employment growth by 0.2 percent.

According to the results, income change and obesity change are significantly and positively related, as in previous analyses. Heart disease rates have a positive impact on obesity change; when heart disease changes increase by one percent, obesity change increases by 0.5 percent. This result is supported by Kumanyika et al. (2008) who found that the prevalence of heart disease risk factors for obese individuals is higher than for non-obese individuals. The initial level of obesity (OBE01) is significantly and negatively associated with obesity change as in previous analyses. The initial value for heart disease (HRT01) shows a significant and positive relationship with obesity change. This means that counties that reported higher percentages of heart disease in their population in 2001, reported higher increases in obesity. Interestingly, percentages of drinkers and smokers in a county had a negative relationship with obesity growth. This could be due to the previously mentioned relationship between calorie consumption and alcohol consumption found by Wang et al. (2010) and to the appetite suppressing characteristic of cigarettes.

Results for the heart disease change (HRTC) equation show high significant impacts of obesity change; when obesity growth increases by one percent, growth in heart disease increases by 0.7 percent. This result is supported by Hendrick (2011), who shows there is a higher potential for heart disease with increasing obesity. The initial value of heart disease (HRT01) has a negative and significant relationship with heart disease change; thus, counties that reported high initial percentages of heart disease had lower growth rates of heart disease. According to the results for the initial value for obesity (OBE01), counties that reported higher percentages of 
obesity in 2001, had increases rates in growth of heart disease compared to counties that had an initial lower percentage of obesity. 
Table 4.1.5 Results for system of equations including change in heart disease (HRTC)

\begin{tabular}{|c|c|c|c|c|c|c|c|c|}
\hline \multirow{2}{*}{ Variable } & \multicolumn{2}{|c|}{ Income Change } & \multicolumn{2}{|c|}{ Employment Change } & \multicolumn{2}{|c|}{ Obesity Change } & \multicolumn{2}{|c|}{ Heart disease Change } \\
\hline & Coefficient & $\mathrm{P}>|\mathrm{Z}|$ & Coefficient & $\mathrm{P}>|\mathrm{Z}|$ & Coefficient & $\mathrm{P}>|\mathrm{Z}|$ & Coefficient & $\mathrm{P}>|\mathrm{Z}|$ \\
\hline INCC & & & 0.06408 & 0.54 & $1.63921 * * *$ & 0.00 & 0.51583 & 0.26 \\
\hline EMPC & $0.40684 * * *$ & 0.00 & & & -0.13244 & 0.69 & -0.76083 & 0.13 \\
\hline OBEC & $0.25186^{* * *}$ & 0.00 & -0.08219 & 0.13 & & & $0.62960 * * *$ & 0.01 \\
\hline HRTC & $0.18344 * * *$ & 0.00 & -0.02498 & 0.60 & $0.49992 * * *$ & 0.00 & & \\
\hline INC01 & $-0.00001 * * *$ & 0.00 & -0.00011 & 0.79 & $0.00001 * * *$ & 0.00 & -0.00010 & 0.26 \\
\hline EMP01 & $0.00001 * * *$ & 0.01 & $-0.00001 * * *$ & 0.00 & 0.00010 & 0.98 & $-0.00001 * * *$ & 0.01 \\
\hline OBE01 & $0.85440 * * *$ & 0.00 & $-0.52637 * * *$ & 0.01 & $-3.42710 * * *$ & 0.00 & $2.15928 * *$ & 0.04 \\
\hline HRT01 & $1.26519 * * *$ & 0.00 & -0.24686 & 0.42 & $2.84044 * * *$ & 0.00 & $-6.33350 * * *$ & 0.00 \\
\hline AGE & 0.00010 & 0.62 & & & -0.00271 & 0.39 & & \\
\hline EDU & 0.00060 & 0.36 & & & & & & \\
\hline MALE & $0.00125^{*}$ & 0.06 & & & & & & \\
\hline EXERCISE & & & & & -0.00011 & 0.20 & & \\
\hline POP & & & $0.00001 * * *$ & 0.00 & & & & \\
\hline HLTHCRPLN & & & & & -0.00010 & 0.94 & & \\
\hline RECREATION & & & 0.00144 & 0.35 & & & & \\
\hline MARRIED & & & $0.00164 * * *$ & 0.00 & & & & \\
\hline SLEEP & & & & & & & -0.00649 & 0.41 \\
\hline SMOKE & & & & & $-0.00239 *$ & 0.10 & 0.00242 & 0.20 \\
\hline DRINK & & & & & $-0.00437 * * *$ & 0.00 & $0.00507 * * *$ & 0.00 \\
\hline HEALTH & & & & & & & 0.02848 & 0.52 \\
\hline
\end{tabular}

Number of observations $=420$.

$\mathrm{R}^{2}$ values: $\mathrm{INCC}=0.76 ; \mathrm{EMPC}=0.12 ; \mathrm{OBEC}=0.45 ; \mathrm{HRTC}=0.59$.

$\mathrm{Chi}^{2}$ values: $\mathrm{INCC}=2021.15 ; \mathrm{EMPC}=108.67 ; \mathrm{OBEC}=197.64 ; \mathrm{HRTC}=500.16$.

$* * *, * *, *$ are significant at $1 \%, 5 \%$ and $10 \%$ respectively. 
4.1.6 Determining the impacts of obesity on hypertension in the Appalachian region

A system of simultaneous equations was used to determine the impacts of obesity on hypertension in Appalachia. Results of the three stage least squares analysis are presented in Table 4.1.6. The first column shows the variables used for analysis. Columns 2 and 3 indicate results for the income change (INCC) equation while columns 4 and 5 show results for the employment change (EMPC) equation. The results for the obesity change (OBEC) equation are shown in columns 6 and 7. The last two columns in the table show results for the hypertension change (HYPC) equation.

The empirical results for the income change equation indicate that income change (INCC) is significantly and positively related to employment change (EMPC), that a one percent increase in employment growth increases income growth by 0.8 percent. Also, as in previous analyses for other diseases, a positive relationship is observed between income change (INCC) and obesity change (OBEC). Hypertension change and income change are significantly and positively related, when hypertension change increases by one percent income change increases by 0.33 percent. Also, the coefficient of the initial value of hypertension (HYP01) indicates that counties that reported higher hypertension rates in 2001 had higher rates of income growth compared to other counties. This result is supported by Lee et al. (2009) who found that hypertension has increased in all income groups: by 85 percent in the lowest income group, by 80 percent in the lower middle income group, by 91 percent in the upper middle income group and by 117 percent in the highest income group. Initial values of income (INC01) and employment (EMP01) are significant but the impacts are minimal. A more educated county population (EDU) means income growth will be higher. A significant and positive value for 
NORTH means that northern Appalachia has had higher income growth compared to southern Appalachia, as reported by the ARC (2010).

The empirical results for employment change (EMPC) indicate that the initial value of income (INC01) increases employment growth at the county level. The significant and positive results for education show that a one percent increase in education rates increases employment growth by 0.2 percent. The significant and negative relationship between MALE and employment growth indicates that females contributed more to employment growth from 2001 to 2009. This could be associated with creation of more jobs for females in the healthcare sector.

The empirical results for obesity change indicate that income change and obesity change are significantly and positively related, as in previous analyses. The significant and positive relationship of hypertension change and obesity change implies that a one percent increase in hypertension change increases obesity change by 0.9 percent. This result is also supported by the findings of Lee et al. (2009). A significant result for the initial hypertension rate indicates that counties that reported a high percentage of its population with high blood pressure in 2001, had higher rates of obesity growth compared to others. The initial income level has a significant and negative relationship with obesity change but the impact is minimal. While smoking has positive impacts on obesity growth rates, drinking was found to have negative impacts; both impacts are minimal. Smoking was expected to have a negative relationship with obesity, however, Peters et al. (2003) found that the relationship between smoking and overweight is not widely understood.

Results for hypertension change (HYPC) show that employment change and hypertension change are significantly and negatively related; when employment change increases by one percent, hypertension change decreases by 1.1 percent. This implies that the greater the employment opportunities, the lower the growth of high blood pressure. This result is supported 
by Brackbill et al. (1995), who reveal lower rates of hypertension with more employment opportunities. Obesity change and hypertension change have a positive and significant relationship; when obesity change increases by one percent hypertension change increases by 0.7 percent. This outcome is supported by the findings of Kotchen (2008), which shows obesity leads to high rates of hypertension. The initial obesity rate (2001) also has a significant and positive relationship with hypertension change. Results show that age increases hypertension growth in Appalachian counties. It is common that high blood pressure increases in men after the age of 35 and women after the age of 50 (Stibich, 2007). Results show that smoking reduces hypertension growth, and drinking increases hypertension growth at the county level. According to medical research, smoking can increase hypertension of an individual (Rosen et al., 2006) and too much alcohol consumption can affect hypertension negatively. Populations living in northern Appalachia have less growth in hypertension compared to those in southern Appalachia. This may be due to better socioeconomic conditions in the north compared to southern parts of Appalachia. 
Table 4.1.6 Results for system of equations including change in hypertension (HYPC)

\begin{tabular}{|c|c|c|c|c|c|c|c|c|}
\hline \multirow{2}{*}{ Variable } & \multicolumn{2}{|c|}{ Income Change } & \multicolumn{2}{|c|}{ Employment Change } & \multicolumn{2}{|c|}{ Obesity Change } & \multicolumn{2}{|c|}{ Hypertension Change } \\
\hline & Coefficient & $\mathrm{P}>|\mathrm{Z}|$ & Coefficient & $\mathrm{P}>|\mathrm{Z}|$ & Coefficient & $\mathrm{P}>|\mathrm{Z}|$ & Coefficient & $\mathrm{P}>|\mathrm{Z}|$ \\
\hline INCC & & & 0.18826 & 0.13 & $0.93141 * * *$ & 0.01 & 0.16245 & 0.58 \\
\hline EMPC & $0.33796 * *$ & 0.08 & & & 0.53178 & 0.20 & $-1.14777 * * *$ & 0.00 \\
\hline OBEC & 0.08125 & 0.29 & -0.09051 & 0.27 & & & $0.70674 * * *$ & 0.00 \\
\hline HYPC & $0.33902 *$ & 0.01 & -0.07970 & 0.30 & $0.90910 * * *$ & 0.00 & & \\
\hline INC01 & $-0.00001 * * *$ & 0.00 & $0.00001 * * *$ & 0.01 & $0.00010 * * *$ & 0.00 & -0.00010 & 0.31 \\
\hline EMP01 & 0.00001 & 0.06 & -0.00010 & 0.29 & -0.00010 & 0.56 & -0.00010 & 0.79 \\
\hline OBE01 & 0.17429 & 0.62 & -0.46794 & 0.19 & $-3.92042 * * *$ & 0.00 & $2.84366 * * *$ & 0.00 \\
\hline HYP01 & $1.11248 * * *$ & 0.00 & -0.05832 & 0.83 & $2.50849 * * *$ & 0.00 & $-2.83706 * * *$ & 0.00 \\
\hline AGE & -0.00159 & 0.53 & & & -0.00862 & 0.17 & $0.00615^{* * *}$ & 0.02 \\
\hline EDU & $0.00115^{* *}$ & 0.07 & $0.00209 * * *$ & 0.00 & & & & \\
\hline MALE & & & $-0.00216 * * *$ & 0.00 & & & & \\
\hline MARRIED & 0.00062 & 0.35 & & & & & & \\
\hline EXERCISE & & & & & 0.00011 & 0.85 & & \\
\hline HLTHCRPLN & & & -0.00047 & 0.55 & & & & \\
\hline SLEEP & & & & & & & -0.00308 & 0.44 \\
\hline SMOKE & & & & & $0.00290 * *$ & 0.07 & $-0.00203 * *$ & 0.03 \\
\hline DRINK & & & & & $-0.00512 * * *$ & 0.00 & $0.00415^{* * *}$ & 0.00 \\
\hline NORTH & $0.07305 * * *$ & 0.00 & & & & & $-0.06597 * * *$ & 0.00 \\
\hline
\end{tabular}

Number of observations $=420$.

$\mathrm{R}^{2}$ values: $\mathrm{INCC}=0.86 ; \mathrm{EMPC}=0.10 ; \mathrm{OBEC}=0.04 ; \mathrm{HYPC}=0.39$.

$\mathrm{Chi}^{2}$ values: $\mathrm{INCC}=2093.54 ; \mathrm{EMPC}=77.96 ; \mathrm{OBEC}=170.75 ; \mathrm{HYPC}=883.81$.

$* * *, * *, *$ are significant at $1 \%, 5 \%$ and $10 \%$ respectively. 


\section{Section 2}

\subsection{Objective 2. Estimating the costs of major diseases linked to obesity}

Data for 2009 was used in achieving objective two. To estimate costs of major diseases linked to obesity the results of logit analyses were applied to total expenditures on each main obesity-related disease in the Appalachian region. The results from the logit analyses supply the probabilities of an individual having each obesity-related disease. These probabilities are used to estimate the costs of each disease.

\subsubsection{Logit Analyses}

For logit analyses, individual data were used for each obesity-related disease, after removing data for individuals who were pregnant or who had any kind of missing data of exogenous variables, like income, BMI, or education. Thus, the sample size was around 22,000 individuals for all of Appalachia. The presence of asthma, arthritis, cancer, diabetes, heart disease, and hypertension were the dependent variables. For each individual the presence of obesity, age, marital status, education level, employment status, annual household income, gender, and race were the socioeconomic variables used. Among behavioral factors, sleepless days in the last month (Sleep), if the individual consumes alcohol (Drinks), if the individual smokes (Smokes), and total minutes an individual engaged in exercise in the previous week (Exercise) were used. Descriptive statistics of the variables used in the logit analyses are presented in Table 4.2.1. 
Table 4.2.1 Descriptive Statistics for obesity-related diseases, 2009

\begin{tabular}{llrrrr}
\hline Variable & Description and unit & Mean & Std. Dev. & Min & Max \\
\hline Asthma & 1 if has asthma; 0 otherwise & 0.1266 & 0.3325 & 0 & 1 \\
Arthritis & 1 if has arthritis; 0 otherwise & 0.4145 & 0.4926 & 0 & 1 \\
Cancer & 1 if has cancer; 0 otherwise & 0.1464 & 0.3535 & 0 & 1 \\
Diabetes & 1if diabetic; 0 otherwise & 0.1449 & 0.3527 & 0 & 1 \\
Hypertension & 1if has hypertension; 0 otherwise & 0.4333 & 0.4955 & 0 & 1 \\
Heart disease & 1 if has heart disease; 0 & 0.0701 & 0.2553 & 0 & 1 \\
obesity & 1 if obese; 0 otherwise & 0.3079 & 0.4656 & 0 & 1 \\
Age & In years & 55.4600 & 16.0680 & 27 & 99 \\
Marital status & 1 if married; 0 otherwise & 0.5668 & 0.4955 & 0 & 1 \\
Education & 1 if some college or higher; 0 & 0.5114 & 0.4998 & 0 & 1 \\
level & otherwise & & & & \\
Employment & 1 if employed; 0 otherwise & 0.4017 & 0.4902 & 0 & 1 \\
status & Annual income in dollars & $\$ 40,774$ & $\$ 24,815$ & $\$ 5,000$ & $\$ 80,000$ \\
Income & 1 if male; 0 if female & 0.3821 & 0.4859 & 0 & 1 \\
Gender & 1 if white; 0 if race other than & 0.9041 & 0.2944 & 0 & 1 \\
Race & white & & & & \\
Sleep & $\begin{array}{l}\text { Number of sleepless days in } \\
\text { previous month }\end{array}$ & 8.5038 & 10.5570 & 0 & 15 \\
& $\begin{array}{l}\text { Number of minutes engaged in } \\
\text { physical activities for the }\end{array}$ & 403.5700 & 674.9500 & 0 & 1092 \\
previous week & & & & \\
Drinks & 1 if drinks alcohol; 0 otherwise & 0.3375 & 0.4728 & 0 & 1 \\
Smokes & 1 if smokes; 0 otherwise & 0.2093 & 0.4068 & 0 & 1 \\
\hline
\end{tabular}

\subsubsection{Logit Analysis for Asthma}

The logit estimation results for asthma are presented in Table 4.2.1.2, including marginal effects. The predicted value of 0.1112 indicates that the probability of getting asthma is 11.12 percent in Appalachia. Most of the variables are statistically significant with expected signs. The significant and positive relationship between obesity and asthma indicates that obese individuals are at greater risk of getting asthma. Previous literature shows the same positive relationship (Akinbami, 2006; CDC, 2011). Age and asthma are significantly and negatively related, where 
the older the person the lower the potential of getting asthma. Results for race, marital and employment status also indicate significant impacts on the likelihood of getting asthma. If an individual is 'white,' s/he is 2 percent more likely to get asthma. This result goes against findings of a higher prevalence of asthma among non-white individuals compared to white individuals (Akinbami, 2003), however, the percentage of white individuals is more than 90 percent in the Appalachian region. If an individual is employed, s/he is 3 percent less at risk for getting asthma. This value is 1.5 percent less for a married individual in Appalachia. Income and asthma have a negative relationship, where the lower the income the higher the potential of getting asthma; however, the impact of income is minimal.

Table 4.2.1.1 Logit regression results: marginal effects of asthma

\begin{tabular}{|c|c|c|c|}
\hline \multicolumn{4}{|c|}{ Predicted probability of asthma $=0.1112$} \\
\hline Variable & Marginal Effects & Std. Err & $\mathbf{P}>|\mathbf{z}|$ \\
\hline Obesity & $0.05060 * * *$ & 0.0049 & 0.00 \\
\hline Age & $-0.00050^{* * *}$ & 0.0001 & 0.00 \\
\hline Marital status & $-0.01510^{* * *}$ & 0.0048 & 0.00 \\
\hline Education level & 0.00610 & 0.0046 & 0.18 \\
\hline Employment status & $-0.03220 * * *$ & 0.0048 & 0.00 \\
\hline Income & $-0.00001^{* * * *}$ & 0.0000 & 0.00 \\
\hline Gender & $-0.02720 * * *$ & 0.0043 & 0.00 \\
\hline Race & $0.02180^{* * *}$ & 0.0061 & 0.00 \\
\hline Sleep & $0.00230 * * *$ & 0.0001 & 0.00 \\
\hline Exercise & 0.00001 & 0.0000 & 0.98 \\
\hline Drinks & -0.00700 & 0.0047 & 0.14 \\
\hline Smokes & $0.01280^{*}$ & 0.0055 & 0.02 \\
\hline
\end{tabular}

Number of Observations $=21,524$.

LR $\operatorname{chi}^{2}(12)=592.00 ;$ Prob $>\operatorname{chi}^{2}=0.0000$.

Log likelihood = -7635.7391; Pseudo $\mathrm{R}^{2}=0.0373$.

$* * *, * *, *$ are significant at $1 \%, 5 \%$ and $10 \%$ respectively.

A significant and negative result for gender indicates that an adult male is less likely to get asthma compared to an adult woman. This result is supported by CDC (2001), who found that women have a higher percentage of asthma. Number of sleepless days is positively 
associated with asthma. This may be due to high occurrence of asthma symptoms with less sleep (Henry and Kaliner, 2006). According to the results, an increase of one additional sleepless day per month increases the risk of getting asthma by 0.2 percent. The results show that smokers have a higher risk of getting asthma compared to non-smokers, as confirmed by CDC studies (various years).

\subsubsection{Logit Analysis for Arthritis}

Table 4.2.1.2 Logit regression results: marginal effects of arthritis

\begin{tabular}{lcrr}
\hline \multicolumn{2}{l}{ Predicted probability of arthritis $=\mathbf{0 . 3 8 3 4 9 6}$} & & \\
\hline Variable & Marginal Effects & Std. Err & P>|z| \\
\hline Obesity & $0.16533^{* * *}$ & 0.0081 & 0.00 \\
Age & $0.09809^{* * *}$ & 0.0003 & 0.00 \\
Marital status & 0.01191 & 0.0083 & 0.15 \\
Education level & $-0.01442^{*}$ & 0.0080 & 0.07 \\
Employment level & $-0.08791^{* * *}$ & 0.0085 & 0.00 \\
Income & $-0.00001^{* * *}$ & 0.0000 & 0.00 \\
Gender & $-0.07922^{* * *}$ & 0.0075 & 0.00 \\
Race & 0.01085 & 0.0125 & 0.38 \\
Exercise & -0.00001 & 0.0000 & 0.72 \\
Drinks & $-0.01903^{* *}$ & 0.0081 & 0.02 \\
Smokes & $0.10003^{* * *}$ & 0.0097 & 0.00 \\
\hline
\end{tabular}

Number of Observations $=20,767$.

LR $\operatorname{chi}^{2}(12)=268.39 ;$ Prob $>\operatorname{chi}^{2}=0.0000$.

Log likelihood = -12358.37; Pseudo $\mathrm{R}^{2}=0.1168$.

$* * *, * *, *$ are significant at $1 \%, 5 \%$ and $10 \%$ respectively.

Logit estimation results for arthritis show a predicted probability of developing arthritis of 38 percent under prevailing conditions in Appalachia. Obesity is highly significant and positively related to arthritis, which corresponds with CDC (2009) results showing high rates of arthritis among obese and overweight individuals. According to the results, an obese person is 16.5 percent more at risk of getting arthritis than a non-obese person. As expected, age of an individual affects arthritis positively. For instance, if age increases by 1 year, the probability of 
getting arthritis increases by 9.8 percent. Results indicate that more education decreases the risk of getting arthritis. Employed individuals are less likely to get arthritis. For instance, if an individual is employed s/he has a 9 percent lower probability of getting arthritis. Even though the impact is low, an increase in income decreases the potential of getting arthritis. This may be due to having more time or resources for engaging in exercise or recreational activities. A significant and negative result for gender indicates that adult women are more likely to get arthritis compared to adult men. This may be due to a higher percentage of obese women compared to obese men (CDC, 2010). While smokers have a higher probability of getting arthritis, alcohol consumers have a lower probability. This result is supported by Eustice (2006) who found that rheumatoid arthritis increases with smoking.

\subsubsection{Logit Analysis for Cancer}

Table 4.2.1.3 Logit regression results: marginal effects of cancer

\begin{tabular}{|c|c|c|c|}
\hline \multicolumn{4}{|c|}{ Predicted probability of cancer $=0.119916$} \\
\hline Variable & Marginal Effects & Std. Err & $\mathbf{P}>|\mathbf{z}|$ \\
\hline Obesity & $0.01414 * * *$ & 0.0049 & 0.00 \\
\hline Age & $0.00474 * * *$ & 0.0002 & 0.00 \\
\hline Marital status & 0.00773 & 0.0049 & 0.11 \\
\hline Educational level & $0.02770 * * *$ & 0.0047 & 0.00 \\
\hline Employment level & $-0.04023^{* * *}$ & 0.0055 & 0.00 \\
\hline Income & $0.00001^{* *}$ & 0.0000 & 0.04 \\
\hline Gender & -0.00642 & 0.0046 & 0.16 \\
\hline Race & $0.03910^{* * *}$ & 0.0068 & 0.00 \\
\hline Exercise & -0.00001 & 0.0000 & 0.95 \\
\hline Drinks & -0.00131 & 0.0049 & 0.80 \\
\hline Smokes & $0.02045^{* * *}$ & 0.0064 & 0.01 \\
\hline
\end{tabular}

Number of Observations $=20,652$.

LR $\operatorname{chi}^{2}(12)=1379.79 ;$ Prob $>\operatorname{chi}^{2}=0.0000$.

Log likelihood = -7840.01; Pseudo $\mathrm{R}^{2}=0.0809$.

$* * *, * *, *$ are significant at $1 \%, 5 \%$ and $10 \%$ respectively. 
The logit estimation results for cancer indicate that the predicted probability of getting cancer is 12 percent in Appalachia. Obesity has a significant and positive relationship with cancer, such that an obese person is 0.014 times more at risk of getting cancer than a non-obese person. This positive relationship was also found by Mariomoto et al. (2002). Age increases the likelihood of getting cancer. Yancik (1997) also found high rates of cancer with ageing. Higher education is associated with a 3 percent greater risk of getting cancer. This is unexpected, but studies are limited on the impacts of education on cancer risk. The significant and negative result for employment status indicates that those employed are 4 percent less at risk of getting cancer. Income also has a positive and significant relationship with cancer, but the impact is very low. White individuals have more risk of getting cancer compared to other races; a white individual is 0.04 times more at risk of getting cancer in Appalachia. However, according to the National Cancer Institute (2008) African-Americans have higher probabilities for many types of cancer except breast cancer which is mostly prevalent among white women. Smoking increases the risk of getting cancer, most likely this is due to lung cancer associated with smoking. This result is supported by Sasco et al. (2004) who explained the significant relationship between smoking and cancer.

\subsubsection{Logit Analysis for Diabetes}

The logit estimation results for diabetes indicate that the expected probability of diabetes is 10 percent. Most of the independent variables are significant and have the expected signs. Obesity is significantly and positively related to diabetes; an obese person is 11 percent more likely to become diabetic than a non-obese person. Diabetes and age have a positive relationship, as expected. According to the Mayo Foundation (Mayo Clinic, 2011), getting older increases one's vulnerability to diabetes (type II), especially after 45 years of age. 
Those who are employed show significantly lower probabilities of getting diabetes. This may be due to better income, education and other facilities associated with greater employment opportunities. Even though the impact value is low, increasing income decreases the potential of becoming a diabetic. A significant and positive result for gender indicates that adult men are more vulnerable to diabetes than adult women. However, there is not adequate research to support this result. Examining race, white individuals are less likely to get diabetes compared to non-white individuals. More time spent on physical exercise decreases the potential of becoming a diabetic. Both smoking and drinking alcohol have negative associations with diabetes, and these results are supported by many studies (Eliasson, 2003; Carlsson et al. 2005).

Table 4.2.1.4 Logit regression results: marginal effects of diabetes

\begin{tabular}{llrr}
\hline \multicolumn{2}{l}{ Predicted probability of diabetes $=\mathbf{0 . 1 0 2 5}$} & & \\
\hline Variable & Marginal Effects & Std. Err & P>|z| \\
\hline Obesity & $0.10855^{* * *}$ & 0.0038 & 0.00 \\
Age & $0.00268^{* * *}$ & 0.0001 & 0.00 \\
Marital status & -0.00362 & 0.0043 & 0.40 \\
Education level & -0.00533 & 0.0042 & 0.20 \\
Employment status & $-0.04043^{* * *}$ & 0.0049 & 0.00 \\
Income & $-0.00001^{* * *}$ & 0.0000 & 0.00 \\
Gender & $0.03434^{* * *}$ & 0.0041 & 0.00 \\
Race & $-0.04061^{* * *}$ & 0.0058 & 0.00 \\
Exercise & $-0.00002^{* * *}$ & 0.0000 & 0.00 \\
Drinks & $-0.05757^{* * *}$ & 0.0048 & 0.00 \\
Smokes & -0.00284 & 0.0053 & 0.59 \\
\hline
\end{tabular}

Number of Observations $=21,225$.

$\operatorname{LR} \operatorname{chi}^{2}(12)=2315.23 ;$ Prob $>\operatorname{chi}^{2}=0.0000$.

Log likelihood = -7494.72; Pseudo $\mathrm{R}^{2}=0.1338$.

***, **, * are significant at $1 \%, 5 \%$ and $10 \%$ respectively.

\subsubsection{Logit Analysis for Heart Disease}

Logit estimations for heart disease show that the predicted probability of getting heart disease is 4 percent. As expected, obesity is significant and positively related to heart disease; an 
obese person is 0.015 times more at risk of getting heart disease than a non-obese person. The significant result for age indicates that the higher the age, the higher the potential of getting heart disease; if age increases by one year, vulnerability to heart disease increases by 4 percent. This potential of increasing heart disease with age is supported by the findings of Franklin et al. 2001, which reveal a high prevalence of heart disease after 50 years of age. Education decreases the potential of getting heart disease. White individuals are more likely to get heart disease compared to individuals of other races in Appalachia. This outcome is not well supported by previous literature which in many cases found that African-Americans are more vulnerable to heart disease (Olstein, 2011; Brooks and Morley, 2011).

Table 4.2.1.5 Logit regression results: marginal effects of heart disease

\begin{tabular}{|c|c|c|c|}
\hline \multicolumn{4}{|c|}{ Predicted probability of heart disease $=\mathbf{0 . 0 3 8 3 8}$} \\
\hline Variable & Marginal Effects & Std. Err & $\mathbf{P}>|\mathbf{z}|$ \\
\hline Obesity & $0.01496^{* * *}$ & 0.0026 & 0.00 \\
\hline Age & $0.00183 * * *$ & 0.0001 & 0.00 \\
\hline Marital status & -0.00157 & 0.0024 & 0.51 \\
\hline Education level & $-0.00936^{* * *}$ & 0.0025 & 0.00 \\
\hline Employment status & $-0.02240 * * *$ & 0.0031 & 0.00 \\
\hline Income & $-0.00001 * * *$ & 0.0000 & 0.00 \\
\hline Gender & $0.04498^{* * * *}$ & 0.0030 & 0.00 \\
\hline Race & $0.00734 * *$ & 0.0035 & 0.03 \\
\hline Exercise & $-0.00010 * * *$ & 0.0000 & 0.00 \\
\hline Drinks & $-0.01260 * * *$ & 0.0025 & 0.00 \\
\hline Smokes & $-0.01873 * * *$ & 0.0036 & 0.00 \\
\hline
\end{tabular}

Number of Observations $=20,495$.

$\operatorname{LR} \operatorname{chi}^{2}(12)=1490.43 ;$ Prob $>\operatorname{chi}^{2}=0.0000$.

Log likelihood $=-4331.62$; Pseudo $\mathrm{R}^{2}=0.1468$.

$* * *, * *, *$ are significant at $1 \%, 5 \%$ and $10 \%$ respectively.

The result for employment status shows that employed individuals are less likely to get heart disease. If an individual is employed, s/he is 2 percent less likely to get heart disease. An increase in income decreases the potential of getting heart disease. This may be due to better 
living conditions and having more time and/or resources for exercise or recreational activities. A significant result for gender indicates that adult men are more vulnerable to heart disease than adult women. This high significance could be associated with age of the study sample, as men are more vulnerable to heart disease at a young age compared to women who typically get heart disease at the age of 55 to 65 (CDC, 2011). Both smokers and alcohol consumers have lower probabilities of getting heart disease. This result for smoking is unexpected as previous studies show that smoking increases the risk of heart disease (Kannel and Belanger, 1991; CDC, 2011). Also, according to the American Heart Association (AHA, 2011), excessive alcohol consumption could increase the risk of heart disease.

\subsubsection{Logit Analysis for Hypertension}

Table 4.2.1.6 Logit regression results: marginal effects of hypertension

\begin{tabular}{llrr}
\hline \multicolumn{3}{l}{ Predicted probability of hypertension $=\mathbf{0 . 4 0 9 7 9 6}$} & \\
\hline Variable & Marginal Effect & Std.Err & P>|z| \\
\hline Obesity & $0.23481^{* * *}$ & 0.0081 & 0.00 \\
Age & $0.01121^{* * *}$ & 0.0003 & 0.00 \\
Marital status & $-0.01450^{*}$ & 0.0086 & 0.09 \\
Education level & $-0.04972 * * *$ & 0.0083 & 0.00 \\
Employment status & $-0.07721^{* * *}$ & 0.0088 & 0.00 \\
Income & $-0.00002^{* * *}$ & 0.0000 & 0.00 \\
Gender & $0.05112^{* * *}$ & 0.0079 & 0.00 \\
Race & $-0.12674^{* * *}$ & 0.0132 & 0.00 \\
Exercise & $-0.00004^{* * *}$ & 0.0001 & 0.00 \\
Drinks & -0.00474 & 0.0084 & 0.57 \\
Smokes & 0.00471 & 0.0098 & 0.62 \\
Number of Observations $=20,706$. & & \\
LR chi ${ }^{2}(12)=4015.07 ;$ Prob $>$ chi $^{2}=0.0000$. & & \\
Log likelihood $=-2122.86 ;$ Pseudo $\mathrm{R}^{2}=0.1421$. & & \\
$* * *, * *, *$ are significant at $1 \%, 5 \%$ and $10 \%$ respectively. &
\end{tabular}

The predicted probability of hypertension in Appalachia is 41 percent, and obesity is highly significant and positively related to hypertension. An obese person is 23 percent more 
likely to get hypertension than a non-obese person. Some studies show that hypertension is approximately twice as prevalent among the obese as in non-obese people (Flegal et al., 2002; Ogden et al., 2002).

As expected, age of an individual increases hypertension potential. If age increases by one year, the probability of getting hypertension increases by 1.1 percent. Education decreases the potential for getting hypertension. This may be due to better attention to healthcare with better education. If an individual is employed, s/he is 8 percent less likely to get high blood pressure. Even though the impact is low, an increase in income decreases the potential of getting hypertension, as does an individual's positive employment status. A significant result for gender indicates that adult men have a higher probability ( 5 percent) of getting hypertension compared to adult women. This result is supported by McMahon et al. (1984) which showed that about 30 percent of hypertension cases are attributable to obese men. White individuals are less likely to get hypertension compared to individuals of other races; studies of African-Americans found the same results (Martins and Norris, 2004).

4.2.2 Calculating total healthcare expenditures of major diseases linked to obesity in the Appalachian region

As data for total healthcare expenditures is limited, the total healthcare expenditures $\left(\mathrm{THE}_{\mathrm{j}}\right)$ of each disease $\mathrm{j}$ : asthma, arthritis, cancer, diabetes, heart disease and hypertension, are calculated based on the results and findings of various studies in previous literature. Costs of asthma and arthritis are calculated based on CDC findings and the estimations of Yelin et al. (2007). Costs of cancer, diabetes, heart disease and hypertension are calculated based on the estimations of the Milken Institute (2007).

4.2.2.1 Calculating healthcare expenditures for asthma 
According to CDC-Vital signs (2011), the total cost of asthma, which included medical costs and other indirect costs, increased from $\$ 53$ billion in 2002 to $\$ 56$ billion in 2007, about a 6 percent increase. Based on this value, and assuming the same rate of increase, total healthcare expenditures for asthma for 2009 are estimated to be $\$ 57.135$ billion for the US for both youth and adults. According to the CDC, nearly 8 percent of adults and 10 percent of children reported asthma in 2009. Taking these rates into consideration, total healthcare expenditures for adults were calculated to be $\$ 25.4$ billion. To calculate the total cost of asthma for adults in Appalachia, this number is multiplied by the percentage of adults in Appalachia (of total adults in the US), which was 8.24 percent in 2009. Thus, the cost of asthma for adults in Appalachia is estimated to be $\$ 2.09$ billion for 2009. Adult population in the Appalachian counties was calculated using county-level data from the US Census Bureau.

\subsubsection{Calculating healthcare expenditures for arthritis}

In a detailed study on national and state medical expenditures and lost earnings, Yelin et al. (2007) show that the total cost of arthritis was $\$ 128$ billion in 2003 , including $\$ 81$ billion in medical costs and $\$ 47$ billion in indirect costs. Importantly, the study shows that the cost of arthritis is in a range from 0.3 to 2.6 percent of each state's GDP. In calculating the cost of arthritis in Appalachia for 2009, this range of percentages of GDP is used, assuming that costs are still the same percentages of a state's GDP in 2009 as Yelin et al. (2007) found for 2003.

Table 4.2.2.1 presents results of the calculations. The first column shows the states included in the Appalachian region. The second column of the table indicates GDP values for each Appalachian state. West Virginia is the only state where all of its counties are in Appalachia; only some counties of each of the other states are in Appalachia. The percentage of a state's population that is in the Appalachian counties was used to calculated the values 
presented in column three by multiplying this percentage times the state level GDP. This assumes that GDP in these counties is proportional to population in these counties. The fourth and fifth columns show the total costs of arthritis for 2003 and the cost of arthritis as a percentage of GDP in 2003 (based on Yelin et al., 2007). The last column shows the cost of arthritis for 2009, which was calculated by multiplying arthritis cost as a percentage of GDP in column 5 by GDP for the Appalachia counties in column 3. Thus, total cost of arthritis is $\$ 15.56$ billion in Appalachia in 2009. As arthritis is mainly an adult disease and the rate of arthritis among children is very low (only 0.26 percent), the calculated cost of arthritis is assumed to be the total cost to adults in Appalachia.

Table 4.2.2.1 Calculation of the cost of arthritis for the Appalachian region (\$billion), 2009

\begin{tabular}{|c|c|c|c|c|c|}
\hline $\begin{array}{l}\text { Appalachian } \\
\text { States }\end{array}$ & $\begin{array}{l}\text { State } \\
\text { GDP } \\
\text { (\$billion) }\end{array}$ & $\begin{array}{l}\text { GDP for } \\
\text { Appalachian } \\
\text { counties for } \\
\text { 2009*(\$billion) }\end{array}$ & $\begin{array}{l}\text { Cost of } \\
\text { Arthritis } \\
2003 \\
\text { (\$billion) }\end{array}$ & $\begin{array}{l}\text { Cost of } \\
\text { Arthritis } \\
\text { as \% of } \\
\text { GDP } 2003\end{array}$ & $\begin{array}{l}\text { Cost of } \\
\text { Arthritis for } \\
\text { Appalachian } \\
\text { counties for } \\
\text { 2009* } \\
\text { (\$billion) }\end{array}$ \\
\hline Alabama & 130.84 & 105.57 & 2.597 & 1.98 & 2.095 \\
\hline Georgia & 324.65 & 118.99 & 3.911 & 1.20 & 1.433 \\
\hline Kentucky & 125.24 & 42.88 & 2.426 & 1.94 & 0.831 \\
\hline Maryland & 216.69 & 12.24 & 2.479 & 1.14 & 0.140 \\
\hline Mississippi & 361.97 & 77.65 & 1.495 & 0.41 & 0.321 \\
\hline New York & 843.29 & 59.26 & 8.726 & 1.03 & 0.613 \\
\hline North Carolina & 310.82 & 70.95 & 4.112 & 1.32 & 0.938 \\
\hline Ohio & 409.97 & 80.62 & 5.745 & 1.40 & 1.130 \\
\hline Pennsylvania & 441.41 & 24.68 & 6.578 & 1.49 & 3.678 \\
\hline South Carolina & 130.40 & 40.08 & 2.133 & 1.64 & 0.656 \\
\hline Tennessee & 200.60 & 10.76 & 3.271 & 1.63 & 1.755 \\
\hline Virginia & 307.64 & 34.90 & 3.466 & 1.13 & 0.393 \\
\hline West Virginia & 61.04 & 61.04 & 1.188 & 2.59 & 1.578 \\
\hline \multicolumn{5}{|c|}{ Total cost of Arthritis for Appalachia } & 15.563 \\
\hline
\end{tabular}

*Calculated by author

Sources: BEA (2009); U.S. Census Bureau (2010); Yelin et al. (2007). 


\subsubsection{Calculating healthcare expenditures for cancer}

Calculation of the cost of cancer for Appalachia is based on estimations of the Milken Institute (2007), who calculated treatment costs as well as productivity lost due to chronic diseases. Based on the Medical Expenditure Panel Survey (MEPS), National Household Education Survey (NHES) and other data from 2003 the Milken Institute projects costs for cancer up to 2023 for each state in the United States. The estimations of the Milken Institute for 2009 were used to calculate the cost of cancer for the Appalachian region.

The calculations are presented in Table 4.2.2.2. The first column shows the Appalachian States; the second column shows total population in those states. The third column gives the total population in the Appalachian counties of each state. The fourth column presents the cost of cancer for each state according to the estimations of the Milken Institute (2007). These numbers include direct medical costs and indirect costs of cancer. The fifth column shows the costs of cancer for Appalachian counties of each state, which were calculated by multiplying costs of cancer in each state in column 3, by percentage of the population in the Appalachian counties of each state. Thus, the cost of cancer for Appalachia is $\$ 39$ billion. The sixth column shows the per capita cost of cancer for adults in Appalachia which was calculated by dividing the cost of cancer in column 5 by Appalachian population in column 3. To calculate the cost of cancer only for adults, the total cost for Appalachia was multiplied by the percentage of adults in Appalachia (77.84 percent), which gives $\$ 30.3$ billion. Because separate expenditures for child cancer as distinguished from those for adult cancer are not clear in the literature, costs were assumed to be proportional to the percentage of adults and children. 
Table 4.2.2.2 Calculation of cost of cancer for the Appalachian region, 2009

\begin{tabular}{|c|c|c|c|c|c|}
\hline $\begin{array}{l}\text { Appalachian } \\
\text { States }\end{array}$ & $\begin{array}{l}\text { Total } \\
\text { population } \\
\text { in the state }\end{array}$ & $\begin{array}{l}\text { Population } \\
\text { in } \\
\text { Appalachian } \\
\text { counties }\end{array}$ & $\begin{array}{l}\text { Cost of } \\
\text { Cancer } \\
\text { for state } \\
\text { (\$billion) }\end{array}$ & $\begin{array}{l}\text { Cost of } \\
\text { Cancer for } \\
\text { Appalachia* } \\
\text { (\$billion) }\end{array}$ & $\begin{array}{l}\text { Per Capita cost } \\
\text { of Cancer for } \\
\text { Appalachia* }(\$)\end{array}$ \\
\hline Alabama & $4,779,736$ & $3,024,719$ & 6.97 & 4.41 & $1,457.98$ \\
\hline Georgia & $9,687,653$ & $2,924,921$ & 14.95 & 4.51 & $1,541.92$ \\
\hline Kentucky & $4,339,367$ & $1,194,500$ & 7.41 & 2.04 & $1,707.82$ \\
\hline Maryland & $5,773,552$ & 247,997 & 9.78 & 0.42 & $1,693.56$ \\
\hline Mississippi & 2,967,297 & 623,260 & 5.29 & 1.12 & $1,797.00$ \\
\hline New York & $19,378,102$ & $1,049,686$ & 29.25 & 1.58 & $1,505.21$ \\
\hline North Carolina & $9,535,483$ & $1,662,282$ & 12.95 & 2.26 & $1,359.57$ \\
\hline Ohio & $11,536,504$ & $2,013,203$ & 15.87 & 2.77 & $1,375.91$ \\
\hline Pennsylvania & $12,702,379$ & $5,736,617$ & 19.89 & 8.98 & $1,565.38$ \\
\hline South Carolina & $4,625,364$ & $1,167,523$ & 7.15 & 1.80 & $1,541.72$ \\
\hline Tennessee & $6,346,105$ & $2,801,826$ & 11.38 & 5.03 & $1,795.25$ \\
\hline Virginia & $8,001,024$ & 681,686 & 12.07 & 1.03 & $1,510.96$ \\
\hline West Virginia & $1,819,777$ & $1,819,777$ & 3.07 & 3.07 & $1,687.02$ \\
\hline \multicolumn{4}{|c|}{ Total cost of Cancer for Appalachia } & 39.017 & \\
\hline
\end{tabular}

*Calculated by author

Sources: U.S. Census Bureau (2010) and Milken Institute (2007).

\subsubsection{Calculating healthcare expenditures for diabetes}

The calculation of the cost of diabetes in Appalachia is again based on the estimations of the Milken Institute (2007), who calculated the treatment costs as well as costs due to lost productivity. The Milken Institute projected costs for diabetes up to 2023 for each state using Medical Expenditure Panel Survey (MEPS), National Household Education Survey (NHES) and other data from 2003. The estimation for 2009 was used to calculate the cost of diabetes for the Appalachian region.

The calculations are presented in Table 4.2.2.3. The first column shows the Appalachian states, and the second column shows the total population in those states. The third column lists the total population in only the Appalachian counties of each state. The fourth column presents the cost of diabetes of each state according to the projections of the Milken Institute (2007) for 
2009. The fifth column shows the cost of diabetes for the Appalachian counties of each state, which were calculated by multiplying the cost of diabetes for each state in column 3 , by the percentage of the population in the Appalachian counties of each state. Thus, the total cost of diabetes for Appalachia is $\$ 17.8$ billion. As the percentage of young people (less than 18 years) having diabetes is less than 1 percent $(0.26)$, the total calculated cost is assumed to be the total cost of diabetes of adults in Appalachia. The sixth column shows the per capita cost of diabetes for adults in Appalachia which was calculated by dividing the cost of diabetes in column 5 by Appalachian population in column 3.

Table 4.2.2.3 Calculation of cost of diabetes for the Appalachian region (\$billion), 2009

\begin{tabular}{|c|c|c|c|c|c|}
\hline $\begin{array}{l}\text { Appalachian } \\
\text { States }\end{array}$ & $\begin{array}{l}\text { Total } \\
\text { Population } \\
\text { in State } \\
\end{array}$ & $\begin{array}{l}\text { Total } \\
\text { Population in } \\
\text { Appalachian } \\
\text { Counties } \\
\end{array}$ & $\begin{array}{l}\text { Cost of } \\
\text { Diabetes* } \\
\text { (\$billion) }\end{array}$ & $\begin{array}{l}\text { Cost of } \\
\text { Diabetes for } \\
\text { Appalachia* } \\
\text { (\$billion) }\end{array}$ & $\begin{array}{l}\text { Per Capita } \\
\text { Cost of } \\
\text { Diabetes for } \\
\text { Appalachia*(\$) }\end{array}$ \\
\hline Alabama & $4,779,736$ & $3,024,719$ & 3.39 & 2.15 & 710.80 \\
\hline Georgia & $9,687,653$ & $2,924,921$ & 6.04 & 1.82 & 622.23 \\
\hline Kentucky & $4,339,367$ & $1,194,500$ & 3.09 & 0.85 & 711.59 \\
\hline Maryland & $5,773,552$ & 247,997 & 3.33 & 0.14 & 564.52 \\
\hline Mississippi & $2,967,297$ & 623,260 & 2.77 & 0.58 & 930.59 \\
\hline New York & $19,378,102$ & $1,049,686$ & 13.72 & 0.74 & 704.97 \\
\hline North Carolina & $9,535,483$ & $1,662,282$ & 6.14 & 1.07 & 643.69 \\
\hline Ohio & $11,536,504$ & $2,013,203$ & 8.26 & 1.44 & 715.27 \\
\hline Pennsylvania & $12,702,379$ & $5,736,617$ & 9.64 & 4.35 & 758.28 \\
\hline South Carolina & $4,625,364$ & $1,167,523$ & 2.20 & 0.56 & 479.64 \\
\hline Tennessee & $6,346,105$ & $2,801,826$ & 4.89 & 2.16 & 770.92 \\
\hline Virginia & $8,001,024$ & 681,686 & 4.68 & 0.40 & 586.78 \\
\hline West Virginia & $1,819,777$ & $1,819,777$ & 1.56 & 1.56 & 857.24 \\
\hline \multicolumn{4}{|c|}{ Total cost of Diabetes for Appalachia } & 17.826 & \\
\hline
\end{tabular}

*Calculated by author

Sources: U.S. Census Bureau (2010) and Milken Institute (2007) 
4.2.2.5 Calculating healthcare expenditures for heart disease

Table 4.2.2.4 Calculation of cost of heart disease for the Appalachian region (\$billion), 2009

\begin{tabular}{|c|c|c|c|c|c|}
\hline $\begin{array}{l}\text { Appalachian } \\
\text { States }\end{array}$ & $\begin{array}{l}\text { Total } \\
\text { Population } \\
\text { in State }\end{array}$ & $\begin{array}{l}\text { Total } \\
\text { Population } \\
\text { in } \\
\text { Appalachian } \\
\text { Counties } \\
\end{array}$ & $\begin{array}{l}\text { Cost of } \\
\text { Heart } \\
\text { disease* } \\
\text { (\$billion) }\end{array}$ & $\begin{array}{l}\text { Cost for } \\
\text { Heart } \\
\text { disease in } \\
\text { Appalachia* } \\
\text { (\$billion) }\end{array}$ & $\begin{array}{l}\text { Per Capita Cost } \\
\text { of Heart disease } \\
\text { for Appalachia* } \\
\text { (\$) }\end{array}$ \\
\hline Alabama & $4,779,736$ & $3,024,719$ & 4.33 & 2.74 & 905.86 \\
\hline Georgia & $9,687,653$ & $2,924,921$ & 5.78 & 1.75 & 598.30 \\
\hline Kentucky & $4,339,367$ & $1,194,500$ & 3.85 & 1.06 & 887.40 \\
\hline Maryland & $5,773,552$ & 247,997 & 4.17 & 0.17 & 685.49 \\
\hline Mississippi & $2,967,297$ & 623,260 & 2.90 & 0.61 & 978.72 \\
\hline New York & $19,378,102$ & $1,049,686$ & 16.12 & 0.87 & 828.81 \\
\hline North Carolina & $9,535,483$ & $1,662,282$ & 6.45 & 1.12 & 673.77 \\
\hline Ohio & $11,536,504$ & $2,013,203$ & 10.69 & 1.87 & 928.86 \\
\hline Pennsylvania & $12,702,379$ & $5,736,617$ & 10.66 & 4.81 & 838.47 \\
\hline South Carolina & $4,625,364$ & $1,167,523$ & 3.44 & 0.87 & 745.16 \\
\hline Tennessee & $6,346,105$ & $2,801,826$ & 5.54 & 2.45 & 874.42 \\
\hline Virginia & $8,001,024$ & 681,686 & 5.07 & 0.43 & 630.78 \\
\hline West Virginia & $1,819,777$ & $1,819,777$ & 2.12 & 2.12 & $1,164.97$ \\
\hline \multicolumn{4}{|c|}{ Total cost of Heart Disease for Appalachia } & 20.87 & \\
\hline
\end{tabular}

*Calculated by author

Sources: U.S. Census Bureau (2010) and Milken Institute (2007)

Calculation of the cost of heart disease for Appalachia is again based on the estimations of the Milken Institute (2007). Their estimation for 2009 was used to calculate the cost of heart disease for the Appalachian region. The calculations are presented in Table 4.2.2.4. The first column shows the Appalachian states; the second column shows the total population in each of those states. The third column presents the total population in only the Appalachian counties of each state, and the fourth column presents the cost of heart disease as according to the estimations of the Milken Institute (2007). The fifth column shows the cost of heart disease for Appalachia, which was calculated by multiplying the costs of heart disease for each state in column 3, by the percentage of the population in the Appalachian counties of each state. Thus, 
the total cost of heart disease for Appalachia is $\$ 20.87$ billion. As the percentage of children having heart disease is minimal, the total calculated cost is assumed to be the total cost of heart disease for adults in Appalachia. The sixth column shows the per capita cost of heart disease for adults in Appalachia, which was calculated by dividing the cost of heart disease in column 5 by population in column 3 .

4.2.2.6 Calculating healthcare expenditures for hypertension

Table 4.2.2.5 Calculation of cost of hypertension for the Appalachian region (\$billion), 2009

\begin{tabular}{|c|c|c|c|c|c|}
\hline $\begin{array}{l}\text { Appalachian } \\
\text { States }\end{array}$ & $\begin{array}{l}\text { Total } \\
\text { Population } \\
\text { in State }\end{array}$ & $\begin{array}{l}\text { Total } \\
\text { Population } \\
\text { in } \\
\text { Appalachian } \\
\text { Counties }\end{array}$ & $\begin{array}{l}\text { Cost of } \\
\text { Hypertension } \\
\text { (\$billion)* }\end{array}$ & $\begin{array}{l}\text { Cost for } \\
\text { Hypertension } \\
\text { in } \\
\text { Appalachia } \\
\text { (\$billion)* }\end{array}$ & $\begin{array}{l}\text { Per Capita } \\
\text { Cost of } \\
\text { Hypertension } \\
\text { for } \\
\text { Appalachia* } \\
(\$)\end{array}$ \\
\hline Alabama & $4,779,736$ & $3,024,719$ & 8.95 & 5.66 & $1,871.24$ \\
\hline Georgia & $9,687,653$ & $2,924,921$ & 15.15 & 4.57 & $1,562.43$ \\
\hline Kentucky & $4,339,367$ & $1,194,500$ & 7.38 & 2.03 & $1,699.45$ \\
\hline Maryland & $5,773,552$ & 247,997 & 8.28 & 0.36 & $1,451.63$ \\
\hline Mississippi & $2,967,297$ & 623,260 & 5.82 & 1.22 & $1,957.45$ \\
\hline New York & $19,378,102$ & $1,049,686$ & 29.65 & 1.61 & $1,533.79$ \\
\hline North Carolina & $9,535,483$ & $1,662,282$ & 15.15 & 2.64 & $1,588.17$ \\
\hline Ohio & $11,536,504$ & $2,013,203$ & 18.12 & 3.16 & $1,569.63$ \\
\hline Pennsylvania & $12,702,379$ & $5,736,617$ & 19.84 & 8.96 & $1,561.89$ \\
\hline South Carolina & $4,625,364$ & $1,167,523$ & 1.20 & 0.31 & 265.51 \\
\hline Tennessee & $6,346,105$ & $2,801,826$ & 10.82 & 4.78 & $1,706.03$ \\
\hline Virginia & $8,001,024$ & 681,686 & 11.05 & 0.94 & $1,378.93$ \\
\hline West Virginia & $1,819,777$ & $1,819,777$ & 3.62 & 3.62 & $1,989.25$ \\
\hline \multicolumn{4}{|c|}{ Total cost of Hypertension for Appalachia } & 39.86 & \\
\hline
\end{tabular}

*Calculated by author

Sources: U.S. Census Bureau (2010) and Milken Institute (2007)

The cost calculations for hypertension in the Appalachian region are as before based on the estimations for 2009 of the Milken Institute (2007). The calculations are shown in Table 4.2.2.5. Again, the first column presents the Appalachian states, the second column shows the total population in those states, the third column gives the total population in only the 
Appalachian counties of each state, and the fourth column shows the cost of hypertension for each state according to the estimations of the Milken Institute (2007). The fifth column shows the costs of hypertension for Appalachia, which were calculated by multiplying the costs of hypertension from column 3, by the percentage of the population in Appalachian counties of each state. Thus, the total cost of hypertension for the Appalachian region is $\$ 39.85$ billion. As hypertension is not prevalent among children, the total calculated cost is assumed to be the total cost of hypertension for adults in Appalachia. The sixth column shows the per capita cost of hypertension for adults in Appalachia, which was calculated by dividing the cost of hypertension in column 5 by population in column 3 .

\subsubsection{Total economic cost of obesity-related diseases}

To obtain the total economic cost $\left(\mathrm{TEC}_{\mathrm{j}}\right)$ of an obesity-related disease, the total healthcare expenditures for that particular disease $\left(\mathrm{THE}_{\mathrm{j}}\right)$ are multiplied by the coefficient of obesity $\left(\mathrm{O}_{\mathrm{i}}\right)$. The coefficient of obesity was estimated using the marginal effects from the logit analyses of each disease. For example, to get the total economic cost of asthma ( TEC $\left._{\text {asthma }}\right)$, total healthcare expenditure for adult asthma is multiplied by 0.051 , the coefficient value for obesity with respect to asthma to get $\$ 106.7$ million. This is the total economic cost of asthma linked to obesity in Appalachia.

Table 4.2.3 shows the cost estimations for each disease. Column 1 lists the disease, and column 2 shows the total healthcare cost of each disease for adults in Appalachia; column 3 presents the coefficient value for obesity from the logit regressions with respect to the appropriate disease. Column 4 shows the total economic cost of each disease.

According to the calculations, total economic cost due to obesity for six diseases is $\$ 14.7$ billion. This cost is nearly 1.4 percent of the total GDP of the Appalachian region. According to 
Finkelstein et al. (2009), total medical care cost of obesity was \$147 billion for the US in 2009. Thus, the calculated value for Appalachia of these six obesity-linked diseases is nearly 10 percent of the national total medical cost of obesity.

Hypertension has the highest percentage of total economic cost due to obesity at 63.6 percent. Arthritis is second at 17.5 percent, followed by diabetes at 13.1 percent. Heart disease and cancer are next with 2.1 percent and 1.1 percent, respectively. Obesity-related asthma has the lowers percentage at only 0.7 percent.

Table 4.2.3 Total economic costs of six obesity-related diseases for adults in Appalachia, 2009

\begin{tabular}{lrrr}
\hline Disease & $\begin{array}{l}\text { Total Healthcare } \\
\text { Expenditure } \\
\text { (\$billion)* }\end{array}$ & $\begin{array}{l}\text { Marginal Effect of } \\
\text { Obesity Associated } \\
\text { with Each Disease* }\end{array}$ & $\begin{array}{l}\text { Total } \\
\text { Economic Cost } \\
\text { (\$billion)* }\end{array}$ \\
\hline Asthma & 2.092 & 0.0510 & 0.106 \\
Arthritis & 15.563 & 0.1653 & 2.572 \\
Cancer & 30.350 & 0.0141 & 0.428 \\
Diabetes & 17.826 & 0.1085 & 1.934 \\
Heart disease & 20.876 & 0.0149 & 0.311 \\
Hypertension & 39.851 & 0.2348 & 9.357 \\
\hline Total & $\mathbf{1 2 6 . 5 5 8}$ & & $\mathbf{1 4 . 7 0 8}$ \\
\hline
\end{tabular}

*Calculated by author

\section{Section 3}

\subsection{Objective 3. To measure reductions in economic costs associated with reductions in obesity of individuals.}

To measure reduction of economic costs with reductions in obesity of individuals, estimations of total economic cost of obesity in objective two (in Table 4.2.3) are used with the obesity rate for Appalachia in 2009 (31 percent). The intention is to estimate economic cost reductions that would occur with significant reductions in obesity from 31 percent. As explained in the methodology, if, say, the obesity level was decreased to "Y" percent of the region's 
population from its current level, healthcare costs related to the $\mathrm{j}^{\text {th }}$ disease would be reduced to $\mathrm{RTEC}_{\mathrm{j}}$.

Table 4.3.3 Total economic costs of obesity in Appalachia at different obesity rates (\$million), $2009 *$

\begin{tabular}{|c|c|c|c|c|}
\hline Disease & $\begin{array}{l}\text { Current Total } \\
\text { Economic Costs } \\
\text { with } 31 \% \text { Obesity } \\
\text { Rate }\end{array}$ & $\begin{array}{l}\text { Total Economic } \\
\text { Costs with } 21 \% \\
\text { Obesity Rate }\end{array}$ & $\begin{array}{l}\text { Total Economic } \\
\text { Costs with } 25 \% \\
\text { Obesity Rate }\end{array}$ & $\begin{array}{l}\text { Total } \\
\text { Economic } \\
\text { Costs with } \\
15 \% \text { Obesity } \\
\text { Rate }\end{array}$ \\
\hline Asthma & 106.69 & 72.27 & 86.04 & 51.62 \\
\hline Arthritis & $2,572.56$ & $1,742.70$ & $2,074.65$ & $1,244.79$ \\
\hline Cancer & 427.93 & 289.89 & 345.10 & 207.06 \\
\hline Diabetes & $1,934.12$ & $1,310.21$ & $1,559.77$ & 935.86 \\
\hline Heart disease & 311.00 & 210.67 & 250.86 & 150.48 \\
\hline Hypertension & $9,357.00$ & $6,338.61$ & $7,545.96$ & $4,527.58$ \\
\hline Total & $14,709.30$ & $9,963.89$ & $11,862.38$ & $7,117.39$ \\
\hline
\end{tabular}

*Calculated by author

Reduction possibilities in total economic cost are considered by comparing obesity rates in Appalachia to three values. First, the potential economic gains in the region are calculated compared to Colorado, which reports the lowest obesity rate of 21 percent. Second, potential gains are estimated compared to the national average obesity rate in 2009 , which was 25 percent. Third, gains are estimated compared to the federal target of reducing obesity to 15 percent. The potential gains are shown in Table 4.3.3. Column 1 lists each obesity-related disease. Column 2 shows the current total economic cost of each disease due to obesity in Appalachia. Column 3 presents economic costs to the region if obesity is reduced to the Colorado level (21\%); column 4 to the current national level (25\%), and column 5 if obesity is reduced to the federal target of 15 percent.

These estimations are conservative as all the costs of obesity-related diseases are not accounted for in these calculations. Also, it is assumed that reductions in costs are linearly 
related to reductions in obesity rates as actual impacts are not known. Thus, interpretation of these values should be done carefully.

\section{Section 4}

4.4 Objective 4. To examine the use of reduced calorie intake and increased exercise for reducing obesity of individuals

To identify potential behavioral methods of reducing obesity in Appalachia, a system of simultaneous equations at the individual level with three endogenous variables was used; decision to reduce calories consumed (REDUCE), minutes engaged in physical exercise (EXERCISE) and Body Mass Index (BMI). After removing all individuals who were pregnant or with missing data, 7,267 observations collected for 2009 were used. Due to inadequacy of data for the decision to reduce calories and engagement in physical activities for the Appalachian counties of Maryland, Mississippi and Pennsylvania, those states were dropped from the analysis.

Age of the individual (AGE), marital status (MARRIED), number of children in the household (NMBRKIDS), number of adults in the household (NMBRADULT), education level of some college or more (EDU), employment status (EMP), annual household income (INC), gender, and race were the socioeconomic variables used for analysis. Presence of any obesityrelated disease (ANYDISEASE): asthma, arthritis, cancer, diabetes, heart disease and hypertension was also included.

Advice received on diet from doctors or any other health professional (DRADVICE), smoking (SMOKES), alcohol consumption (DRINKS), and number of sleepless days in the previous month (SLEEP) were the behavioral variables used. Access to healthcare facilities (HLTHCRFAC), access to recreational facilities (RECREATION) and a dummy variable 
(NORTH) for the northern region of Appalachia were the environmental factors considered.

Recreational facilities include all available indoor and outdoor recreational facilities in a county.

Northern, North Central and Central sub-regions of Appalachia were considered as north in that dummy variable (NORTH).

\subsubsection{Descriptive Analysis}

Table 4.4.1 Descriptive statistics for obesity prevention analysis

\begin{tabular}{|c|c|c|c|}
\hline Variable & Description and unit & Mean & Std. Dev. \\
\hline REDUCE & 1 if decided to reduce calorie intake; 0 otherwise & 0.74 & 0.44 \\
\hline EXERCISE & Total minutes of exercise per week & 262.12 & 509.05 \\
\hline BMI & Body Mass Index & 29.87 & 6.69 \\
\hline AGE & Number of years & 61.16 & 13.72 \\
\hline MARRIED & 1 if married; 0 otherwise & 0.53 & 0.49 \\
\hline EDU & 1 if some college or more; 0 otherwise & 0.46 & 0.49 \\
\hline EMP & 1 if employed; 0 otherwise & 0.29 & 0.45 \\
\hline INC & Annual household income in dollars & 36,098 & 23,623 \\
\hline GENDER & 1 if male; 0 otherwise & 0.38 & 0.48 \\
\hline RACE & 1 if white; 0 otherwise & 0.88 & 0.32 \\
\hline NMBRADULT & Number of adults in household & 1.75 & 0.72 \\
\hline NMBRKIDS & Number of children in household & 0.27 & 0.69 \\
\hline ANYDISEASE & $\begin{array}{l}1 \text { if has any of } 6 \text { obesity-related diseases; } 0 \\
\text { otherwise }\end{array}$ & 0.38 & 0.48 \\
\hline DRADVICE & $\begin{array}{l}1 \text { if gets diet advice from doctor or any other } \\
\text { health professional ; } 0 \text { otherwise }\end{array}$ & 0.60 & 0.49 \\
\hline SMOKES & 1 if smokes; 0 otherwise & 0.19 & 0.39 \\
\hline DRINKS & 1 if drinks alcohol; 0 otherwise & 0.24 & 0.43 \\
\hline SLEEP & Number of sleepless days in previous month & 9.02 & 11.08 \\
\hline HLTHCRFAC & $\begin{array}{l}\text { Access to healthcare facilities (per 100,000 } \\
\text { county population) }\end{array}$ & 56.29 & 24.69 \\
\hline RECREATION & $\begin{array}{l}\text { Access to recreation facilities (number of } \\
\text { facilities per } 100,000 \text { county population) }\end{array}$ & 8.05 & 4.23 \\
\hline NORTH & 1 if lives in northern Appalachia; 0 otherwise & 0.21 & 0.41 \\
\hline
\end{tabular}

Descriptive statistics of the variables are shown in Table 4.4.1. Nearly 74 percent of the sample decided to reduce calorie intake and about 60 percent get advice on food and diet from 
their doctors or some other health professional. Average time an individual engaged in physical activities is 262 minutes per week and average BMI value of the sample is 29.87. Average annual income is just over $\$ 36,000$, but only 29 percent are employed. Nearly 38 percent of the sample are males. Education level shows that 46 percent of the sample are educated at the college level or beyond. Of the total sample, 38 percent indicate suffering from at least one of the obesity-related diseases, and 21 percent live in the north of Appalachia.

The empirical results are presented in Table 4.4.2. Logged values of BMI were used for analysis as this results in more statistically significant coefficients and higher $\mathrm{R}^{2}$ values for estimations. Also, using logged values of BMI increased the significance of the intercept term, which indicates that it is better to use the logged form rather than linear BMI values. Logging also helps to interpret results in percentage changes (Gujarati, 2003). While column 1 shows variables used for the 3SLS analysis, columns 2 and 3 show results for the calorie reduction estimation; columns 4 and 5 present results for physical activity, and columns 6 and 7 show results for BMI.

According to the calorie reduction results, BMI and calorie reduction are significantly and positively related. Thus, a one percent increase in BMI increases the probability of deciding to consume fewer calories by 63 percent. Physical activity has a significant and negative relationship with calorie reduction. A one percent increase in the time spent engaging in physical exercise, means individuals are less likely to reduce calories. Age has a significant and negative relationship with calorie reduction, but the impact is minimal. Results indicate that the higher the number of children in the household the less likely the decision to reduce calorie consumption. Results for income are significant and positive, but the value is low. According to the results, a female is 6 percent more likely to reduce calories than a male. Results for doctor's and health 
professional's diet advice indicate that those who are advised to control their diet are 22 percent more likely to reduce calories. Sabate and Wein (2010) found that vegetarian diets and lactovegetarian diets provide good protection against being overweight. Thus, advice from doctors and other health experts could be important for reducing calories and controlling obesity.

Table 4.4.2 Results for system of equations for obesity prevention analysis*

\begin{tabular}{|c|c|c|c|c|c|c|}
\hline \multirow{2}{*}{ Variable } & \multicolumn{2}{|c|}{ Reduced calories } & \multicolumn{2}{|c|}{ Physical activity } & \multicolumn{2}{|c|}{ Log of BMI } \\
\hline & Coefficient & $\mathrm{P}>|\mathrm{Z}|$ & Coefficient & $P>|Z|$ & Coefficient & $\mathrm{P}>|\mathrm{Z}|$ \\
\hline REDUCE & & & $-0.9661 * * *$ & 0.00 & $-0.1273 * * *$ & 0.00 \\
\hline EXERCISE & $-0.0261 * * *$ & 0.05 & & & $-0.2569 * * *$ & 0.00 \\
\hline LOGBMI & $0.6323 * * *$ & 0.00 & $-1.7702 * * *$ & 0.02 & & \\
\hline AGE & $-0.0020 * * *$ & 0.01 & $-0.0365 * * *$ & 0.00 & $-0.0481 * * *$ & 0.00 \\
\hline MARRIED & & & -0.0011 & 0.98 & & \\
\hline EDU & -0.0028 & 0.80 & $0.1365 * * *$ & 0.03 & 0.0059 & 0.28 \\
\hline EMP & & & $0.3830 * * *$ & 0.00 & & \\
\hline INC & $0.0001 * *$ & 0.04 & $0.0001 * * *$ & 0.00 & $0.0001 *$ & 0.06 \\
\hline GENDER & $-0.0615 * * *$ & 0.00 & $0.3911^{* * *}$ & 0.00 & $-0.3304 * * *$ & 0.00 \\
\hline RACE & & & & & $-0.0203 * * *$ & 0.00 \\
\hline NMBRADULT & 0.0144 & 0.03 & & & & \\
\hline NMBERKIDS & $-0.0144 * * *$ & 0.03 & & & & \\
\hline ANYDISEASE & -0.0212 & 0.13 & $-0.1732 * *$ & 0.03 & $0.0627 * * *$ & 0.00 \\
\hline DRADVICE & $0.2247 * * *$ & 0.00 & & & & \\
\hline SMOKES & & & & & $-0.0759 * * *$ & 0.00 \\
\hline DRINKS & & & & & $-0.0429 * * *$ & 0.00 \\
\hline SLEEP & & & $-0.0170 * * *$ & 0.00 & & \\
\hline HLTHCRFAC & & & & & -0.0001 & 0.29 \\
\hline RECREATION & & & $0.0247 * * *$ & 0.00 & & \\
\hline NORTH & & & $-0.4711 * * *$ & 0.00 & & \\
\hline Intercept & -4.5919 & 0.00 & 20.0165 & 0.00 & 8.2741 & 0.00 \\
\hline
\end{tabular}

Number of Observations $=7,267$.

$\mathrm{R}^{2}$ value: Reduced calories $=0.17$; Physical activity $=0.55 ;$ LOGBMI $=0.54$.

$\mathrm{Chi}^{2}$ value: Reduced calories $=628.83 ;$ Physical activity $=714.35 ;$ LOGBMI $=1023.13$.

$* * *, * *, *$ are significant at $1 \%, 5 \%$ and $10 \%$ respectively.

According to results for the physical activities equation, those who have decided to reduce calories for weight control engage in fewer minutes of physical exercise per week than those who have not made this calorie reduction decision. A significant and negative result for 
BMI indicates that those who have high BMI values (obese or overweight) engage in fewer minutes of physical exercise per week. The significant and negative relationship between physical activity and age shows that older individuals spend less time exercising. Physical activity and education have a significant and positive relationship. Those with some college or more spend more time doing physical exercises, thus, education encourages weight control. Nayga (2000) and Drewnowski and Specter (2004) highlight that higher education lowers obesity rates as health promotion occurs through knowledge (Nayga, 2000). A significant and positive relationship between physical activity and income indicates that those with higher education spend more time exercising, maybe due to having more time and resources for such activities. Employed individuals partake in 38 more minutes of exercise a week than unemployed individuals. Income has a significant and positive relationship with exercise, but the impact is low. Males engage in 39 more minutes of exercise a week than females. While sleepless days negatively affect time spent engaged in physical activities, access to more recreation facilities significantly increases minutes spent exercising. The results also indicate that individuals in northern Appalachia engage in less exercise a week compared to people in the southern part.

According to the BMI equation, those who decide to consume fewer calories, reduce log BMI by 0.13 points. Also, those who engage in exercise, reduce log BMI by 0.25 points. Similarly, Cawley et al. (2005) show that the impact of decreased physical education classes in schools has increased the probability of students being overweight.

Age is negatively related with BMI, thus, BMI goes down with age. In a West Virginia study, Amarasinghe et al. (2009) found that obesity risk increases at a lower rate with age. Income shows significant results, but the impact is low. The significant and negative relationship between BMI and gender implies that being male reduces log BMI by 0.33 units compared to 
being female. The result for race indicates that white individuals reduce log BMI by 0.02 points compared to non-white individuals. Presence of any obesity-related disease increases log BMI. Both smoking and drinking have a negative relationship with log BMI. This is supported by the findings of Wang et al. (2010) explained previously.

Overall, results show that people with a higher BMI are more likely to reduce calorie intake but spend less time exercising. Thus, encouraging more exercise is important. Males are less likely to reduce calories but engage more in exercise and are less likely to be obese. Thus, overweight men should be advised to reduce calories along with engaging in physical activity. Women, who are more likely to be obese, should not only be supported in their calorie reduction decision, but should also be encouraged to spend more time exercising.

\section{Section 5}

\subsection{Objective 5. To propose health-related policies for regional healthcare development}

The main purpose of this study was to examine the health implications and costs of adult obesity and its impacts on healthcare development in the Appalachian region. In achieving this purpose estimations were conducted under four specific objectives. The specific objectives were arranged to examine health impacts of obesity-related diseases, to calculate obesity-related healthcare costs, and to examine the potential use of reduced calorie intake and exercise for obesity control. Even though obesity-related health issues are mainly dependent on an individual's personal decisions of utility maximization, county level trends and impacts were analyzed within the context of employment change and income change. Thus, a system of simultaneous equations with county-based values of obesity, obesity-related diseases, employment and income was used. To examine obesity-related health impacts at an individual 
level, estimations were based on individual observations using logit analyses and simultaneous equations.

County level analysis based on the changes of income, obesity, obesity-related diseases and employment highlight a few important points regarding obesity and obesity-related health issues. First, these analyses reveal that obesity and income changes are positively related in the Appalachian region. This occurs because income levels as well as obesity rates have been increasing within the last one to two decades in Appalachia (ARC, 2011). Some obesity-related diseases, like asthma, heart disease and hypertension, also had positive relationships with income growth. The logit analyses show that obesity-related diseases are decreased with increasing income of individuals. Also, the analyses for preventive measures for obesity indicate that increasing income leads to more physical exercise and calorie reductions. Although overall income has gone up in the region and increasing income is associated with reductions in obesity and healthier behaviors, apparently income has not increased sufficiently to turn around increasing obesity rates in Appalachia. These results also could indicate that the Appalachian region has failed in implementing adequate policies to advocate healthier lifestyles in a proper framework parallel to income growth. This could be associated with lack of access to affordable healthcare and healthy food facilities, educational disparities, as well as inadequate physical infrastructure development, especially in rural counties (ARC, 2010). Compared to other parts of the US, Appalachia has slower economic growth and lower rates of investment and income generation (ARC, 2011). Also, some Appalachian communities lack critical physical infrastructure such as adequate water and sewerage systems and broadband access to create satisfactory local economies (ARC, 2010). However, according to the strategic plan of the Appalachian Regional Commission, there are plans to serve 120,000 households with improved 
water and sewerage facilities, while 150 miles of the Appalachian Development Highway System will be opened to traffic from 2011 to 2016 (ARC, 2011).

County-level analyses for employment change indicate that employment and income changes are positively related, as expected, but employment growth and obesity rate increases are negatively related. Thus, counties with more growth in employment show reductions in growth of obesity rates, and counties with increasing rates of obesity show decreases in employment growth. So high rates of obesity are bad for job creation, but creating jobs can help slow the growth in obesity rates. Thus, more attempts to increase job opportunities would be beneficial. According to the ARC (2010), only 35 counties of 420 in Appalachia reported positive employment growth from 2007 to 2010. But, according to the strategic plan of Appalachia, the region is expected to create 120,000 new jobs from 2011-2016 (ARC, 2011).

The county level analyses also highlight the positive role of education on employment growth, which subsequently could help control obesity in Appalachia. Logit analyses based at the individual level indicate the significant potential of higher education for decreasing obesityrelated diseases, which should help in controlling obesity and increasing employment growth. This implies that more investments should be made in education. Educational attainment raises productivity, increases income earnings, reduces poverty risk and improves living standards. Thus, investment in education, particularly targeting poor counties, would be essential for obesity control. Policies on education should extend to health improvement, food selection, nutrition, and other consumption patterns. With persistent high rates of out migration of the young from Appalachia with higher education (ARC, 2010), policies should be implemented that would give them employment opportunities within the region. One way of maintaining economic development is to maintain 'occupational competitiveness' with a higher share of the workforce 
employed in 'creative class' positions - those who specialize in knowledge and idea creation, such as engineers, designers, business managers and scientists (ARC, 2011).

County level analysis for asthma shows that obesity increases asthma growth, but asthma does not affect obesity growth. Although, counties that reported higher initial obesity rates had higher asthma growth rates but lower obesity growth rates. Counties with high initial levels of asthma had less growth in asthma, as did counties with more elderly. These results imply that obesity affects asthma levels, especially with adults who are younger and in areas that had higher obesity rates. Logit analysis for asthma at the individual level also indicates that obesity increases asthma. Further, those results highlight that being employed and having higher income reduce asthma. This implies that policies to reduce high obesity rates, by increasing employment opportunities, income and education could also decrease asthma rates. Policies to mitigate asthma without considering the impact of obesity would be less efficient.

The county level analysis for arthritis indicates that obesity growth and arthritis increases are, contrary to expectations, negatively related. Also, counties with high initial obesity rates had less arthritis growth. This contrasts with findings in previous literature that showed a positive link between arthritis and obesity (CDC, 2009). However, results from the individual level logit analysis for arthritis show arthritis is positively affected by obesity. The results also show that higher education, employment opportunities, as well as higher incomes reduce arthritis while age increases arthritis. The economic cost estimations indicate that $\$ 2.6$ billion of arthritis-related costs are associated with adult obesity in Appalachia. This suggests that policies to invest in higher education, employment creation and improved income earning opportunities may help to reduce arthritis and obesity in Appalachia. 
Analysis of diabetes at the county level indicates that obesity increases diabetes, but diabetes does not affect obesity. Counties with high initial levels of obesity had less obesity growth but more diabetes growth. Increasing income impacts negatively on diabetes growth. This implies that obesity needs to be controlled in order to control diabetes. The county level results are supported by the individual level logit analysis, which indicates a positive effect of obesity on diabetes. Also, being employed, higher income, as well as engaging in exercise reduce the prevalence of diabetes, while age increases diabetes. The economic cost calculation shows that nearly $\$ 1.9$ billion of the cost of diabetes is due to obesity. Thus, policies to control diabetes need adequate attention of obesity reduction.

The county level analysis for heart disease indicates that both obesity growth and the initial level of obesity increase growth of heart disease. Also, increasing heart disease and initial levels of heart disease increase obesity. This implies that obesity control policies could also reduce growth of heart disease and heart disease control polices could reduce rates of obesity. The individual level logit analysis indicates that heart disease is positively affected by obesity. Also, higher education, improved employment opportunities and engaging in exercise reduce the potential for developing heart disease while age increases one's chance of getting heart disease. The obesity-related cost of $\$ 0.3$ billion associated with heart disease also highlights the need for obesity and heart disease control policies along with adequate investments in education, employment creation, and recreational facilities.

Examining hypertension at the county level finds that both obesity and hypertension are positively related with each other. Higher initial levels of obesity increase hypertension while higher initial levels of hypertension increase obesity growth. Logit analysis at the individual level finds that obesity and age increase hypertension while employment, income, education and 
exercise reduce obesity. Thus, policies to control obesity or hypertension with more employment, income, education, and exercise opportunities would be beneficial for Appalachia. The economic cost of $\$ 9.4$ billion for hypertension associated with obesity indicates the potential gains of such policies for obesity control.

The individual level logit analysis for cancer indicates potential increases in cancer with increasing obesity in Appalachia. The analysis further reveals that the potential for cancer increases with age and decreases with employment opportunities. Economic cost estimation for cancer indicates that nearly $\$ 0.4$ billion of the cost of cancer is associated with obesity. Thus, an obesity control policy would be beneficial for controlling cancer in Appalachia.

The simultaneous equations analysis that examined the role that calorie reduction and exercise played in obesity reduction also highlights the importance of education, income and employment opportunities in controlling BMI in Appalachia. Most importantly, results show significant benefits for weight control from reducing calories and engaging in more physical activity, along with better access to recreational facilities. Results show that older individuals are less likely to engage in exercise and reduce their calorie intake, although they are also less likely to be obese. Males are more likely to engage in exercise while less likely to reduce calories. Also, employed individuals are more likely to be physically active. Accordingly, workplace exercise facilities could lead to increased physical activity levels among the employed. Increasing the number of and access to recreational facilities should also increase physical activity rates and reduced rates of obesity. Studies should be undertaken to understand why women are less likely to engage in physical activity so that their barriers to exercise could be reduced. The finding that a health professional's advice leads to calorie reduction implies that healthcare providers should be encouraged, even provided incentives, to provide such advice. In 
addition, improving access to more affordable healthcare facilities in the region would increase the ability of Appalachians to obtain advice from healthcare professionals on ways to reduce obesity.

Overall, the analyses for obesity-related diseases highlight the need for a comprehensive set of policies to control obesity and its health implications and to reduce the costs of obesity in Appalachia. These policies should adequately improve and increase educational facilities, employment and income earning opportunities, healthcare and recreational facilities, along with infrastructure development. According to the ARC (2010), the Appalachian region lacks the infrastructure to take full advantage of emerging economic gains and to create sustainable local economies. Thus, any policy interventions aimed at health improvement and/or obesity reduction without physical infrastructure development in Appalachia will be less effective. 


\section{CHAPTER 5}

\section{SUMMARY AND CONCLUSION}

\subsection{Summary and Conclusions}

The health burden of obesity in the United States has been recognized by previous literature but its costs and burden specifically to the Appalachian region has not been adequately examined. The 420 counties of the Appalachian region are relatively less developed and have seen less economic growth compared to other parts of the United States. The region has had fast growth of obesity rates, and some counties in the region report the highest obesity rates in the nation. Within the context of prevailing high poverty rates, unemployment, and less economic development, increasing obesity rates mean an additional healthcare cost to Appalachia, jeopardizing its future potential gains. Thus, the main objective of this research study was to examine the health and healthcare cost implications of adult obesity in Appalachia.

Based on previous literature six obesity-related diseases, asthma, arthritis, cancer, diabetes, heart disease and hypertension, were identified and used to examine health implications of obesity in Appalachia. Five specific objectives were used to meet the main goal of this study. The first objective examined the obesity-related health impacts at a county level using a system of simultaneous equations. Four equations with dependent variables income change, employment change, obesity change and changes in five of the abovementioned obesity-related diseases, were used for estimation. The second objective examined health implications of each obesity-related disease at an individual level using logit estimations. The costs due to obesity associated with each disease were calculated. The third objective calculated the economic gains that could occur with significant reductions of obesity in Appalachia. The fourth objective examined the potential behavioral methods of obesity control in Appalachia using a system of three simultaneous equations. The dependent variables were BMI, calorie intake and physical exercise. The final 
objective proposed some policy alternatives based on the results of the first four objectives. Results of the estimations generally support the main hypotheses tested in the study, showing evidence that obesity is related to the diseases that were considered, health and economic gains would occur through obesity control, and weight gain can be controlled by changing behavior.

County-level estimations show that asthma, diabetes, hypertension and heart disease have an increasing trend with increasing obesity in Appalachia. Arthritis did not have a positive relationship with changing levels of obesity. Generally, results indicate that from 2001 to 2009 obesity and obesity-related diseases were increasing in Appalachia, parallel to income growth. Employment growth, however, had a negative relationship with asthma, diabetes, and hypertension. This means that from 2001 to 2009 changing patterns in employment growth helped mitigate overall growth rates of diabetes, heart disease and hypertension in the region. Basically, these results imply that the healthcare sector of Appalachia did not have a sufficient health policy framework parallel to income and employment growth to improve health for people in the region. This implies there is a need for revitalizing prevailing healthcare policies or implementing new ones.

Logit analysis of each disease using individual-level data reveals that obesity significantly increases the risk of hypertension, arthritis, diabetes, cancer, asthma, and heart disease of adults in Appalachia. Results highlight that higher education, increasing income, and improving employment opportunities could decrease the probability of getting these diseases. This implies there is potential for controlling obesity through income, employment and education growth in Appalachia along with satisfactory infrastructure development. This is true within the prevailing socioeconomic context of Appalachia, which reports lower education levels, fewer employment opportunities and lower income compared to the rest of the United States (ARC, 
2010). Also, it is obvious that people care more about their health if they have more knowledge, and can do more about their health if they have more income.

The portion of healthcare costs of each disease due to obesity, calculated using the marginal effects from the logit functions and total healthcare cost of each disease, gives an impression of the burden associated with adult obesity in Appalachia. According to the calculations, these costs were $\$ 14.7$ billion in Appalachia in 2009. This is about 1.4 percent of GDP for all of Appalachia in 2009. Thus, the burden is substantial and demands efficient and effective healthcare policies. Calculations of economic gains that could occur with significant reductions of obesity rates argue for efficient policy targets. For instance, if obesity rates could be decreased to 21 percent, the obesity rate for Colorado, from the current Appalachian level of 31 percent, this could mean a $\$ 5$ billion gain to the Appalachian region. Also, this gain from reduced costs could be used to improve healthcare or the economy of Appalachia. Thus, understanding these potential targets and working on them with efficient policies is required to help Appalachia with obesity and weight gain control.

One potential way of controlling obesity is changing behaviors of individuals. This was examined using a system of simultaneous equations with the endogenous variables of BMI, the decision to reduce calorie intake and time spent in physical exercise. Results indicate a strong potential for engaging in physical exercise to achieve weight loss in Appalachia. Fewer calories have the same positive impact. Interestingly, obese people are more likely to decide to consume food with fewer calories than to engage in physical exercise. Access to recreation facilities and diet advice from healthcare professionals also appear to have positive effects on weight gain control in Appalachia.

5.2 Policy recommendations 
Based on the empirical results of the study and the policy discussion (objective 5) the policy recommendations to control obesity and improve healthcare management in Appalachia could be summarized as follows. However, it is important to recognize local areas within the region that have high obesity, high poverty and high unemployment rates and to prioritize those areas for policy implementation.

1. Investment in economic and infrastructure development with adequate investments in healthcare and recreational facilities, especially in poor areas of Appalachia.

2. Investment in the education sector in order to facilitate more educational opportunities with an emphasis on health, diet and food consumption and to improve living standards by creating more employment and income generating opportunities.

3. Investment in industrial and other job-creating sectors to increase employment and income earning opportunities which consequently improve affordability of healthcare, higher education, and a variety of other facilities with obesity reduction and related health improvement implications.

\subsection{Limitations of the study}

The Behavioral Risk Factor Surveillance Survey (BRFSS) is basically a cross-sectional telephone survey, which is conducted by state health departments with assistance provided by the CDC. Data is collected using a standardized questionnaire based on the responses given by adult individuals. Thus, all the data are based on the perceptions and understanding of the relevant individuals and it is assumed that they had the proper understanding of the questions before answering. Thus, wrong usage of their perceptions on health status, healthy days, and other view points, could lead to errors in the estimations. Also, the telephone-based survey limits the 
participation of people who do not have telephone facilities, especially for the very poor and in areas where the telephone reception is very poor.

Due to lack of sufficient information, it was assumed that change in cost is linearly related to obesity when estimating the costs for obesity-related diseases. In actuality some costs may be non-linearly related to obesity. Thus, estimated costs in the study should be interpreted carefully.

\subsection{Suggestions for future work}

Extensions of this study need to focus on expanding the variability in the data. The study mainly focused on cross-sectional data (though it also examined changes from 2001-2009) and there was limited available data. Data for distribution patterns of healthy people, other local differences like availability of natural amenities, landscape changes, migration patterns, weather patterns, investment in recreation and healthy food facilities, prevailing programs of obesity control, and other investment issues for employment and income changes, would enhance both county and individual level analyses. Analysis also can be expanded by taking a spatial approach to capture significant geographic patterns related to health and obesity.

Expanding this study could also be done by considering more recent data on healthcare costs. Also, looking at more indirect costs associated with obesity would make for a more complete cost calculation. Further, attempts to incorporate other factors, like genetic issues and disorders, would make the analysis more accurate. The study could be extended to a nationallevel analysis by increasing sample size. Increasing the scope of the study will yield insights on a broader perspective with more general applications of healthcare policies. 


\section{REFERENCES}

Akinbami, L. (2003). NCS Health E-Stat. Asthma Prevalence, Health Care Use and Mortality: United States. Retrieved from http://www.cdc.gov/nchs/data/hestat/asthma03-05/asthma03-05.htm

Akinbami, L. (2006). The State of Childhood Asthma, United Sates, 1985-2005. Advanced data from vital and health statistics (No.381). Hyattsville, MD: National Center for Health Statistics.

Alberini, A., Cropper, M., Fu, T.T., Krupnik, A., Liu, J.T., Shaw, D. and Harrington, W. (1997). Valuing health effects of air pollution in developing countries: The case of Taiwan, Journal of Environmental Economics and Management, 34(2), 107-126.

Amarasinghe, A., D’Souza, G., Brown, C., and Borisova, T. (2006). A spatial analysis of obesity in West Virginia. Research paper 13. Retrieved from www.rri.wvu.edu

Amarasinghe, A., D’Souza, G., Brown, C., Oh, H. and Borisova, T. (2009). The Influence of Socioeconomic and Environmental Determinants on Health and Obesity: A West Virginia Case Study. International Journal of Environmental Research and Public Health, 6, 2271-2287. doi: 10.3390/ijerph6082271

American Diabetes Association (ADA). Economic Costs of Diabetes in the U.S. in 2007. Retrieved from http://www.diabetes.org/assets/pdfs/cost-diabetes-executive-summary.pdf American Heart Association (AHA). (2012). Alcohol and Heart Disease. Retrieved from http://www.heart.org/HEARTORG/Conditions/More/MyHeartandStrokeNews/Alcoholand-Heart-Disease_UCM_305173_Article.jsp

Anderson, P.M. and Butcher, K.F. (2006a). Childhood obesity: Trends and potential causes. The Future of Children 16(1), 19-45. 
Anderson, P.M., Butcher, K.F. and Levine P. B. (2003). Economic perspectives on childhood obesity. Journal of Economic Perspectives (QIII). Retrieved from http://www.chicagofed.org/digital_assets/publications/economic_perspectives/2003/3qep part3.pdf

Apovian, C. M. (2004). Sugar-Sweetened soft drinks, obesity, and Type 2 diabetes. The Journal of the American Medical Association, 292(8), 978-79.

Appalachian Regional Commission [ARC] (2011). Economic Overview of Appalachia 2011. Retrieved from http://www.arc.gov/images/appregion/Sept2011/EconomicOverviewSept2011.pdf Appalachian Regional Commission [ARC]. (2010). Economic Assessment of Appalachia. An Appalachian Development Initiative Report. Retrieved from http://www.arc.gov/images/newsroom/publications/EconomicAssessmentofAppalachiaJu ne2010.pdf

Appalachian Regional Commission [ARC]. The Appalachian Region. Retrieved from http://www.arc.gov/appalachian_region/TheAppalachianRegion.asp

Aronne, L.J., and Segal, K.R. (2002). Adiposity and fat distribution outcome measures: Assessment and clinical implications. Obesity Research, 10, 14S-21S. doi:10.1038/oby.2002.184

Averett, S., and Korenman, S. (1996). The economic reality of the beauty myth. Journal of Man Resources, 31, 304-330.

Bartlett, S. (n.d.). Osteoarthritis weight management. Retrieved from http://www.hopkinsarthritis.org/patient-corner/disease-management/osteoandweight.html Becker, G. (1965). A Theory of the Allocation of Time. The Economic Journal, 75, 493-517. 
Becker, G.S. and Murphy, K.M. (1998). A Theory of Rational Addiction. Journal of Political Economy, 96(4), 675-700.

Boardman, J.D., Saint Onge, J.M., Rogers, R.C. and Denney, J.T. (2005). Race differential in obesity: The impact of place. Journal Health Social Behavior, 46(3), 229-243.

Brackbill, R.M., Siegel, P.Z. and Ackermann, S.P. (1995). Self-reported hypertension among unemployed people in the United States, British Medical Journal, 310: 568

Brooks, L. and Morley, M. (2011). RSNA Press Release. CT Angiography Improves Detection of Heart Disease in African Americans. Retrieved from http://www2.rsna.org/timssnet/media/pressreleases/pr_target.cfm?ID=547

Bureau of Economic Analysis [BEA] (2009). Regional Economic Accounts. Retrieved from http://www.bea.gov/regional/index.htm

Bureau of Economic Analysis [BEA] (2009). Regional Economic Accounts. Retrieved from http://www.bea.gov/regional/gdpmap/GDPMap.aspx

Burkhauser, R.V., and Cawley, J. (2005). Obesity, disability, and movement onto the disability insurance rolls. Research Brief. Retrieved from http://www.mrrc.isr.umich.edu/publications/briefs/pdf/rb073.pdf

Carlsson, S., Hammar, N. and Grill, V. (2005). Alcohol consumption and type 2 diabetes. Metaanalysis of epidemiological studies indicates a U-shaped relationship. Diabetologia 48, 1051-1054 DOI 10.1007/s00125-005-1768-5

Cawley, J. (1999). Rational addiction, the consumption of calories, and body weight (Doctoral dissertation). University of Chicago, Chicago, IL

Cawley, J., and Danziger, S. (2005). Morbid obesity and the transition from welfare to work. Journal of Policy Analysis and Management, 24(4), 727-743. 
Cawley, J., Meyerhoefer, C. and Newhouse, D. (2005). The impacts of state physical education requirements on youth physical activity and overweight. NBER Working Paper 11411.

Centers for Disease Control and Prevention [CDC]. (2001) Behavioral Risk Factor Surveillance System Survey Questionnaire. U.S. Department of Health and Human Services, Atlanta, Georgia.

Centers for Disease Control and Prevention [CDC]. (2009). Behavioral Risk Factor Surveillance System Survey Data. U.S. Department of Health and Human Services, Atlanta, Georgia. Centers for Disease Control and Prevention [CDC]. (2010). Overweight and obesity: U.S. obesity trends. Retrieve from http://www.cdc.gov/obesity/data/trends.html

Centers for Disease Control and Prevention [CDC]. (2011). Heart Disease. Heart Disease Facts and Statistics. Retrieved from http://www.cdc.gov/heartDisease/statistics.htm

Centers for Disease Control and Prevention [CDC] . (2011). Vital Signs. Retrieved from http://www.cdc.gov/VitalSigns/Asthma/

Centers for Disease Control and Prevention [CDC]. (2004). Trends in intake of energy and macro-nutrients- United States. Morbidity and Mortality Weekly Reports, 5, 80-82.

Centers for Disease Control and Prevention [CDC]. (2006). National Center for Chronic Disease Prevention and Health Promotion. http://www.cdc.gov/chronicdisease/index.htm .

Centers for Disease Control and Prevention [CDC]. (2009). Morbidity and Mortality Weekly Report, 58, 45. Retrieved from www.cdc.gov/mmwr

Centers for Disease Control and Prevention [CDC]. (2010). Arthritis related statistics. Retrieved from http://www.cdc.gov/arthritis/data_statistics/arthritis_related_stats.htm

Childhood Obesity Statistics. (2010). Childhood Obesity Facts. Retrieved from http://www.buzzle.com/articles/childhoodobesity-statistics.html 
Chopra, M., Galbraith, C. and Darnton-Hill, I. (2002). A global response to a global problem: The epidemic of overnutrition. Bull World Health Organization, 80, 952-958.

Chou, S., Grossman, M. and Saffer, H. (2004). An economic analysis of adult obesity: Results from the behavioral risk factor surveillance system. Journal of Health Economics, 23(3), $565-587$.

Classen, T. and Hokayem, C. (2005). Childhood influences on youth obesity. Economics and Human Biology, 3, 165-187.

Cohen, D.A., Finch, B.K., Bower, A. and Sastry, N. (2006). Collective efficacy and obesity: The potential influence of social factors on health. Social Science and Medicine, 62(3), 769778.

Colditz, G.A. (1992). Economic costs of obesity. American Journal of Clinical Nutrition, 55, 503s-507s.

Currie, J., Vigna, S.D., Moretti, E. and Pathania, V. (2010). The effect of fast food restaurants on obesity and weight gain, American Economic Journal, 2(3), 32-63.

Deller, S.C., Tsung-Hsiu, T., Marcouiller, D.W. and English, D.B.K. (2001). The role of amenities and quality of life in rural economic growth. American Journal of Agricultural Economics, 83(2), 352-365.

Dor, A., Ferguson, C., Langwith, C., and Tan, E. (2010). A heavy burden: The individual costs of being overweight and obese in the United States. Research Report. Department of Health Policy, School of Public Health and Health Services, The George Washington University.

Drewnowski, A. and Specter, S. (2004). Poverty and Obesity: The role of energy density and energy costs. American Journal of Clinical Nutrition, 79, 6-16. 
Eliasson, B. (2003). Cigarette smoking and diabetes. Progress in Cardiovascular diseases, 45, 5, 405-413.

Eustice, C. (2006). Smoking Puffs Up Risk Of Rheumatoid Arthritis. Study analyzes the effect of smoking on rheumatoid arthritis patients. Retrieved from http://arthritis.about.com/od/smoking/a/rheumatoidrisk.htm

Ewing, R., Schimd, T., Killingsworth, R., Zlot, A. and Raudenbush, S. (2003). Relationship between urban sprawl and physical activity, obesity and morbidity. American Journal of Health Promotion, 18, 47-57.

Finkelstein, E.A., Fiebelkorn, I.C. and Wang, G. (2004). State- level estimates of annual medical expenditures attributable to obesity. Obesity Research, 12, 18-24.

Finkelstein, E., Trogdon, J., Cohen, J.W. and Dietz, W. (2009). Annual medical spending attributable to obesity: Payer and service-specific estimates. Health Affairs, 28(5), 822831.

Finkelstein, E.A., Srrombotne, K.L. and Popkin, B.M. (2010). The costs of obesity and implications for policymakers, Choices-The Magazine of Food, Farm and Resource issues, $3^{\text {rd }}$ Quarter, 25, 3.

Fish, J.S., Ettner, S. and Brown, F. (2010). Association of perceived neighborhood safety on body mass index. American Journal of Public Health, 100(11), 2296-2303.

Flegal, K.M., Carroll, M.D., Ogden, C.L. and Johnson, C.L. (2002). Prevalence and trends in obesity among US adults, 1999-2000. Journal of American Medical Association, 288, $1723-1727$. 
Flegal, K.M., Caroll, M.D., Ogden, C.L. and Curtin, L.R. (2010). Prevalence and trends in obesity among US adults, 1999-2008. Journal of American Medical Association, 289(2), 187-193.

Fontaine, K.R., Redden, D.T., Wang, C., Westfall, A.O. and Allison, D.B. (2003). Years of life lost due to obesity. Journal of American Medical Association, 289(2), 187-193.

Frank, L.D., Andresen, M.A., and Schmid, T.L. (2004). Obesity relationships with community design, physical activity and time spent in cars. American Journal of Preventive Medicine, 27(2), 87-96.

Franklin, S.F., Larson, M.G., Khan, S.A., Wong, D., Leip, E.P., Kannel, W.B. and Levy, D. (2001). Does the Relation of Blood Pressure to Coronary Heart Disease Risk Change With Aging? Circulation, 103,1245-1249. doi: 10.1161/01.CIR.103.9.1245

French, S.A., Story, M., and Jeffery R.W. (2001). Environmental influences on eating and physical activity. Annual Review of Public Health, 22, 309-335.

Gangwisch, J.E., Malaspina, D., and Boden-Albala, B. (2005). Inadequate sleep as a risk factor for obesity: Analyses of the NHANES I. SLEEP, 28(10), 1289-1296.

Goodpaster, B.H., Delany, J.P., Otto, A.D., Kuller, L., Vockley, J., South-Paul, J.E., Thomas, S.B., Brown, J., McTique, K., Hames, K.C., Lang, W., and Jakicic, J.M. (2010). Effects of diet and physical activity interventions on weight loss and cardiometabolic risk factors in severely obese adults: A randomized trial. Journal of American Medical Association, 304(16), 1795-1802.

Gregg, E.W., Cheng, Y.J., Cadwell, B.L., Imperatore, G., Williams, D.E., Flegal, K.M., and Williamson, D. F. (2005). Secular trends in cardiovascular disease risk factors according 
to body mass index in US adults. Journal of American Medical Association, 293, 18681874.

Grossman, M. (1972). On the concept of health capital and the demand for health. The Journal of Political Economy, 80, 223-253.

Gujarati, D. N. (2003). Basic Econometrics. Fourth edition, McGraw-Hill Higher Education, London

Hagist, C. and Kotlikoff, L.J. (2009). Who's going broke? Comparing growth in public healthcare expenditures in ten OECD Countries, Hacienda Pública Española, IEF, 188(1), 55-72.

Hammond, R.A. and Levine, R. (2010). The economic impacts of obesity in the United States: Diabetes, Metabolic Syndrome and Obesity. Targets and Therapy, 3, 285-295. Health_Impacts_of_Air_Pollution_in_Mumbai.pdf

Hendrick, B. (2010). Arthritis on the Increase; Obesity Partly to Blame. Researchers Predict Arthritis Will Increase Significantly Over the Next 20 Years WebMD Health News. Retrieved from http://arthritis.webmd.com/news/20101007/arthritis-on-the-increaseobesity-partly-to-blame

Hendrick, B. (2011). Obesity Increases Risk of Deadly Heart Attacks, WebMD Health News. Retrieved from http://www.webmd.com/heart-disease/news/20110214/obesity-increasesrisk-of-deadly-heart-attacks

Henry, L. and Kaliner, M.A. (2006). Allergic Diseases Summaries. Allergic Asthma: Symptoms and Treatment. Retrieved from http://www.worldallergy.org/professional/allergic_diseases_center/allergic_asthma/ 
Hill, J.O., Wyatt, H.R., Reed, G.W., and Peters, J.C. (2003). Obesity and the environment: Where we should go from here? Science, 299(5608),853-855.

Inagmi, S., Cohen, D.A., Finch, B.K. and Asch, S.M. (2006). You are where you shop: Grocery store locations, weight and neighborhoods. American Journal of Preventive Medicine, 31(1), 10-17.

International Agency for Research on Cancer. Weight control and physical activity. Lyon, International Agency for Research on Cancer, 1-315

Johnson, E., McInnes, M.M. and Shinogle, J.A. (2006). What is the economic cost of overweight children? Eastern Economic Journal, 32(1), 17-187.

Kaiser State Health Facts. (2008). Percent of adults who smoke. Retrieved from www.statehealthfacts.org/comparemaptable.jsp?ind $=80 \& c a t=2$

Kannel, W.B. and Belanger, A.J. (1991). Epidemiology of heart failure. American Heart Journal, 121 (3):part 1. http://dx.doi.org/10.1016/0002-8703(91)90225-7

Kentucky Asthma Program. (2010). Connie Buckley, Respiratory Disease Program. Retrieved from http://chfs.ky.gov/dph/info/dpqi/cd/respiratorydisease.htm

Komlos, J., Smith, P.K. and Bogin, B. (2004). Obesity and the rate of time preference: Is there a connection? Journal of Biosocial Science, 36(2), 209-219.

Kotchen, T.A. (2008). Obesity- related hypertension? Weighing the evidence. Hypertension, 52, 801-802.

Kumanyika, S.K., Obarzanek, E., Stettler, N., Bell, R., Field, A.E., Formann, S.P., Franklin, B.A., Gillman, M.W., Lewis, C.E., Poston II, W.C., Stevens, J. and Hong, Y. (2008). Population based prevention of obesity: The need for comprehensive promotion of healthful eating, physical activity, and energy balance. Circulation, 118, 428-464. 
Lakdawalla, D. and Philipson, T. (2002). The growth of obesity and technological change: A theoretical and empirical examination. National Bureau of Economic Research Working Paper, No 8946.

Lancaster, K. (1966). A new approach to consumer theory. The Journal of Political Economy, $74,132-157$.

Lang, T. and Rayner, G. (2005). Obesity: A growing issue for European policy? Journal of European Social Policy, 15(4), 301-327.

Lee, D.S., Chiu, M., Manuel, D.G., Tu, K., Wang, X., Austin, P.C., Mattern, M.Y., Mitiku, T.F., Svenson, L.W., Putnam, W., Flanagan, W.M., and Tu, J.V. (2009). Trends in risk factors for cardiovascular disease in Canada: temporal, socio-demographic and geographic factors. Canadian Medical Association Journal, 4: 181(3-4):E55-66. Epub 2009 Jul 20.

Lloyd-Jones, D., Adams R.J., Brown T.M., Carnethon, M., Dai, S., De Simone, G., Ferguson, T.B., Ford, E., Furie, K., Gillespie, C., Go, A., Greenlund, K., Haase, N., et al. (2010). Heart Disease and Stroke Statistics-2010 Update. A Report from the American Heart Association Statistics Committee and Stroke Statistics Subcommittee. Circulation. 121, e1-e170

Loureiro, M. L. and Nayga, R. M. (2006). Obesity, weight loss and physician's advice. Medicine, $62,2458-2468$.

Lvovsky, K. (1998). Economic cost of air pollution with Special Reference to India, South Asia Environment Unit, World Bank, Washington, D.C.

Macleod, K. E. and Winkle, M.A. (2007). Socioeconomic and food related physical characteristics of the neighborhood environment are associated with body mass index. Journal of Epidemiology Community Health, 6(6), 491-498. 
MacMahon, S.W., Blacket, R.B., Macdonald, G.J., and Hall, W. (1984) Obesity, alcohol consumption and blood pressure in Australian men and women. The National Foundation of Australia Risk Factor Prevalence Study, Journal of Hypertension, 2, 85-91.

Malnick, S. D.H., and Knobler, H. (2006). The medical complications of obesity, QJM: An International Journal of Medicine, 99(9), 565-579. doi:10.1093/qjmed/hc1085

Mancino, L. (2003). American's food choices: The interaction of information, intentions, and convenience (Doctoral dissertation). Department of Applied Economics, University of Minnesota.

Mancino, L., Lin, B.H., and Ballinger, N. (2004). The role of economics in eating choices and weight outcomes. USDA Economic Research Service agriculture information bulletin, number 791. Retrieved from http://www.ers.usda.gov/publications/aib791/aib791.pdf

Manson, J.E., Colditz, G.A., Stampfer, M.J., Willett, W.C., Rosner, B., Monson, R.R., Speizer, F.E., and Hennekens, C.H. (1990). A Prospective Study of Obesity and Risk of Coronary Heart Disease in Women, New England Journal of Medicine, 322, 882-889.

Martins, D. and Norris, K. (2004). Hypertension treatment in African Americans: Physiology is less important than sociology. Cleveland Clinic Journal of Medicine, 7:735- 743

Mayo Clinic. (2011). Type two diabetes, Risk Factors. Retrieved from http://www.mayoclinic.com/health/type-2-diabetes/DS00585/DSECTION=risk-factors

Miljkovic, D., and Nganje, W. (2008). Regional Obesity determinants in the United States: A model of myopic addictive behavior in food consumption. Agricultural Economics, 38, 375-384. 
Milken Institute (2007). An Unhealthy America: Economic burden of chronic disease. Charting a new course to save lives and increase productivity and economic growth. Retrieved from http://www.chronicdiseaseimpact.com/ebcd.taf?cat=disease

Mokdad, A.H., Stroup, D.E. and Giles, W.H. (2003). Public health surveillance for behavioral risk factors in a changing environment: Recommendations from the Behavioral Risk Factor Surveillance Team. MMWR- Recommendations and Reports, 52 (RR-9), 1-12.

Morbidity and Mortality Weekly Report (MMWR) (2010). Prevalence of doctor-diagnosed arthritis and arthritis- attributable activity limitation, United States, 2007-2009. Retrieved from http://www.cdc.gov/mmwr/preview/mmwrhtml/mm5939a1.htm?s_cid=mm5939a1_w

Morimoto, L.M., White, E., Chen, Z., Chlebowwski, R.T., Hays, J., Kuller, L., Lopez, A.M., Manson, J., Margolis, K.L., Muti, P.C., Stefanick, M.L., and McTiernan, A. (2002). Obesity, body size and risk of postmenopausal breast cancer: The women's health initiative (United States). Cancer Causes Control, 13, 741-751.

Morland, K., Roux, A.V.D. and Wing, S. (2006). Supermarkets, other food stores, and obesity: The atherosclerosis risk in communities study. American Journal of Preventive Medicine, 30(4), 333-339.

Must, A., Spadano, J., Coakley, E.H., Field, A.E., Colditz, G., and Dietz, W.H. (1999). The disease burden associated with overweight and obesity. Journal of American Medical Association, 282(16), 1523-1529.

Muth, M.K. (2010). Themes overview: Addressing the obesity challenge, Choices. The Magazine of Food, Farm and Resource Issues, $3^{\text {rd }}$ Quarter 25, 3. 
National Cancer Institute (2008). Cancer Health Disparities. Retrieved from http://www.cancer.gov/cancertopics/factsheet/disparities/cancer-health-disparities National Institute of Health (NIH). Obesity. Retrieved from http://health.nih.gov/topic/Obesity Nayga, R.M. (2000). Schooling, health knowledge and obesity, Applied Economics 32, 815-822.

NHANES (2009). National health and nutritional examination survey. Retrieved from http://www.cdc.gov/nchs/nhanes/nhanes2009-2010/nhanes09_10.htm

Ogden, C.L., Flegal, K.M., Carroll, M.D. and Johnson, C. L. (2002). Prevalence and trends in overweight among US children and adolescents. Journal of American Medical Association, 288, 1728-1732.

Olstein, R. (2011). African Americans More Vulnerable to Heart Problems. Rush University Medical Center. Retrieved from http://rushinperson.rush.edu/2011/02/28/africanamericans-more-vulnerable-to-heart-problems/

Organization for Economic Co-operation and Development (OECD) (2011). How does the United States compare. Retrieved from http://www.oecd.org/dataoecd/46/2/38980580.pdf

Ostro, B. (1995). Fine particulate air pollution and mortality in two southern California counties, Environmental research, 70, 98-104.

Peters, A., Barendregt, J. J., Willekens, F., Mackenbach, J.P., Al Mamun, A., and Bonneux, L. (2003). Obesity in adulthood and its consequences for life expectancy: A life-table analysis. Annals of Internal Medicine, 7, 24-32.

Philipson, T. J. and Posner, R. A. (1999). The long run growth in obesity: An economic research agenda. Health Economics, 10, 1-7.

Philipson, T. J. and Posner, R.A. (2003). The long run growth in obesity as a function of technological change. Perspective in biology and medicine, 46, S87-S97. 
Quah, E., and Boon, T. L. (2002). The economic cost of particulate air pollution on health in Singapore, Journal of Asian Economics, 14, 73-90.

Raebel, M.A., Malone, D.C., Conner, D.A., Xu, S., Porter, J.A. and Lanty, F.A. (2004). Health services use and healthcare costs of obese and non-obese individuals. Archives of Internal Medicine, 164, 2135-2140.

Rashad, I., Grossman, M., and Chou, S.Y. (2006). The Super Size of America: An economic estimation of body mass index and obesity in adults. Eastern Economic Journal, 32(1), 133-148.

Richards, T.J., Patterson, P.M. and Tegene, A. (2004). Obesity and nutrient consumption: A rational addiction? Faculty working paper series MSABR 04-7, Arizona State University.

Rosen, B.D., Saad, M.F., Shea, S., Nasir, K., Edvardsen, T., Burke. G., Jerosch-Herold, M., Arnett, D.K., Lai, S., Bluemke, D.A., and Lima, J.A. (2006). Hypertension and smoking are associated with reduced regional left ventricular function in asymptomatic: individuals the Multi-Ethnic Study of Atherosclerosis. Journal of the American College of Cardiology, 47(6):1150

Rosenberger, R.S., Sneh, Y. and Gurvitch, R. (2005). A spatial analysis of linkages between healthcare expenditures, physical inactivity, obesity and recreational supply. Journal of Leisure Research, spring 2005.

Rosin, O. (2008). The economic causes of obesity: A survey. Journal of Economic Survey, 22 (4), 617-647.

Rossner, S. (2002). Obesity: The disease of the twenty-first century. International Journal of Obesity and Related Metabolic Disorders, 26(4), S2-S4. 
Ryan, D.H. and Kushner, R. (2010). The state of obesity and obesity research. Journal of American Medical Association, 304(16), 1835-1836.

Sabate, J. and Wien, M. (2010). Vegetarian diets and childhood obesity prevention. American Journal of Clinical Nutrition, 9(suppl), 1525s-1529s.

Sacerdote, B. (2007). How large are the effects from changes in family environment? A study of Korean American adoptees. Quarterly Journal of Economics 122 (1), 119-158.

Sasco, A.J., Secretan, M.B. and Straif, K. (2004). Tobacco smoking and cancer: a brief review of recent epidemiological evidence, Lung Cancer, 45, Supplement 2 , S3-S9,

Schmid, A., Schneider, H., Golay, A., and Keller, U. (2005). Economic burden of obesity and its co-morbidities in Switzerland, Social and Preventive Medicine, 50, 87-94.

Schulze, M.B., Manson, J.E., Ludwig, D.S., Colditz, G.A., Stampfer, M.J., Willett, W.C., and Hu, F.B. (2004). Sugar-sweetened beverages, weight gain, and incidence of type 2 diabetes in young and middle-aged women. Journal of American Medical Association, 292, 927-934.

Shahar, D., Shai, I., Vardi, H., Shahar, A. and Fraser, D. (2005). Diet and eating habits in high and low socioeconomic groups. Nutrition, 21, 559-566.

Shih, M., Hootman, J.M., Kruger, J. and Helmick, C.G. (2006). Physical activity in men and women with arthritis. American Journal of Preventive Medicine, 30(5), 385-393.

Smith, T.G. (2004). The McDonald's equilibrium. Social choice and welfare, 23(3), 383-413.

Smith, T.G., and Tasnadi, A. (2003). A theory of natural addiction. UCLA International Institute Global Fellows Working Paper, 18 December. 
Srivastava, A., and Kumar, R. (2001). Economic valuation of health impacts of air pollution in Mumbai. National Environmental Engineering Institute (NERER) Mumbai 400018, India. Retrieved from http://esl.fem.ipb.ac.id/uploads/media/Economic_Valuation_of_

STATA 9.0. Statistical/Data Analysis. StataCorp, 4905 Lakeway Drive, College Station, Texas, 77845 USA. Retrieved from http://www.stata.com

Stibich, M. (2007). Age and High Blood Pressure. Retrieved from http://longevity.about.com/od/whosatrisk/p/age.htm

Sturm, R. (2002). The effects of obesity, smoking, and drinking on medical problems and costs. Health Affairs, 21(2), 245-253.

Sturm, R., Ringel, J.S., and Andreyeve, T. (2004). Increasing obesity rates and disability trends, Health Affairs, 23(2), 199-205.

Trogdon, J.G., Finkelstein, E.A., Hylands, T., Dellea, P.S. and Kamal-Bahl, S.J. (2008). Indirect costs of obesity: A review of the current literature. Obesity Reviews, 9(5), 489-500.

Tsai, S.P., Ahmed, F.S., Wendt, J.K., Bhojani, F. and Donnelly. R.P. (2008). The impact of obesity on illness absence and productivity in industrial population of petrochemical workers. Annals of Epidemiology, 18(1), 8-14.

U.S. Census Bureau (2010). State and County QuickFacts. Retrieved from http://quickfacts.census.gov/qfd/states/54000.html

U.S. Census Bureau. (2000). Summary File 1 (SF 1) 100-Percent Data. Retrieved from http://www.census.gov/census2000/sumfile1.html

U.S. Census Bureau. (2010). Census Redistricting Data [P.L. 94-171]. Summary Files. Retrieved from http://www.census.gov/rdo/data/2010_census_redistricting_data_pl_94171_ 
U.S. Department of Health and Human Services. (2010). The Surgeon General call to action to prevent and decrease overweight and obesity. Rockville, MD: U.S. Department of Health and Human Services, Office of Surgeon General.

Wang, M C., Kim, S., Gonzalez, A.A., Macleod, K.E. and Winkleby, M.A. (2007).

Socioeconomic and food related physical characteristics of the neighborhood environment are associated with body mass index. Journal of Epidemiology Community Health, 6, 491- 498.

Wewers, M.R., Katz, M., Paskett, E.D. and Fickle, D. (2006). Risky behaviors among Ohio Appalachian adults. Preventive Chronic Disease, 3(4), A127.

Wingo, P.A., Tucker, T.C., Jamison, P.M., Martin, H., McLaughlin, C., Bayakly, R., BolickAldrich, S., Colsher, P., Indian, R., Kinght, K., Neloms, S., Wilson, R., and Richards, T.B. (2008). Cancer in Appalachia, 2001-2003. Cancer 1, 112(1), 181-192.

Wolin, K.Y., Carson, K. and Colditz, G.A. (2010). Obesity and Cancer. The Oncologist, 15, 556565.

World Health Organization. (2007). Ten statistical highlights in global public health. Retrieved from http://www.who.int/whosis/whostat2007_10highlights.pdf

World Health Organization. Risk factor projects. (2005). Overweight and obesity. Retrieved from http://www.who.int/mediacentre/news/releases/2005/pr44/en/index.html

Yancik, R. (1997). Cancer burden in the aged. Cancer, 80, 1273-1283. doi: 10.1002/(SICI)1097-0142(19971001)80:7<1273::AID-CNCR13>3.0.CO;2-4

Yelin, E., Cisternas, M., Foreman, A., Pasta, D., Murphy, L., and Helmick, C. (2007). National and state medical expenditures and lost earnings attributable to arthritis and other 
rheumatic conditions - United States, 2003. Morbidity and Mortality Weekly Report, $56(1), 4-7$.

Zagorsky, J.L. (2004). Is obesity as dangerous to your wealth as to your health? Research on Aging, 26(1), 130-152.

Zagorsky, J.L. (2005). Health and wealth: The late $20^{\text {th }}$ century obesity epidemic in the U.S. Economics and human biology, 3, 296-313.

Zellner, A. and Theil, H. (1962). Three-Stage Least Squares: Simultaneous estimation of simultaneous equations. Econometrica, 30 (1), 54-78.

Zhang, Z., Infante, A., Meit, M. and English, N. (2008). An analysis of mental health and substance abuse disparities and access to treatment services in the Appalachian Region, Appalachian Regional Commission. Retrieved from http://www.arc.gov/assets/research_ Zuidema, T., and Nentjes, A. (1997) Health damage of air pollution: An estimate of a doseresponse relationship for the Netherlands. Environmental and Resource Economics, 9, 291-308. 